Portland State University

PDXScholar

Summer 9-27-2018

\title{
Ozone-Surface Exchange and Transport and Transformation Near Ventilation Air Supply
}

Pradeep Ramasubramanian

Portland State University

Follow this and additional works at: https://pdxscholar.library.pdx.edu/open_access_etds

Part of the Mechanical Engineering Commons

Let us know how access to this document benefits you.

\section{Recommended Citation}

Ramasubramanian, Pradeep, "Ozone-Surface Exchange and Transport and Transformation Near Ventilation Air Supply" (2018). Dissertations and Theses. Paper 4552.

https://doi.org/10.15760/etd.6437

This Thesis is brought to you for free and open access. It has been accepted for inclusion in Dissertations and Theses by an authorized administrator of PDXScholar. Please contact us if we can make this document more accessible: pdxscholar@pdx.edu. 
Ozone-Surface Exchange and Transport and Transformation near Ventilation Air Supply

\title{
by
}

Pradeep Ramasubramanian

A thesis submitted in partial fulfillment of the requirements for the degree of

\author{
Master of Science \\ in \\ Mechanical Engineering \\ Thesis Committee: \\ Elliott Gall, Chair \\ Olyssa Starry \\ Raul Cal
}

Portland State University

2018 


\begin{abstract}
Ozone in indoor environments can pose a health risk to human occupants; around half of exposure to this pollutant occurs inside buildings. One approach to reducing indoor $\mathrm{O}_{3}$ levels is to mitigate $\mathrm{O}_{3}$ as it enters a building via outdoor air ventilation supply. Often, mechanical systems that introduce outdoor air into buildings are placed on building rooftops. At the urban scale, greenery has been shown to reduce levels of some harmful pollutants, including ozone and cities like Portland, OR, are mandating green roofs be built on large commercial buildings to increase urban green surfaces. We investigate if rooftop vegetation may act as a sink for $\mathrm{O}_{3}$ as transport occurs across a green roof. It is known that $\mathrm{O}_{3}$ can react with vegetated surfaces and the ground but there is scant empirical research on said pollutant dynamics on vegetated green roofs, and little data concerning pollutant interactions occurring on other rooftop designs. Essentially unstudied is the potential of rooftop designs to affect local concentrations of pollutants where building outdoor air supply may be co-located. In this study, we investigate $\mathrm{O}_{3}$ dry deposition using resistance uptake theory in an area that includes a green roof on a local big box retail store through a field study conducted during a two-week period in the Summer of 2017. Deposition velocities and subsequently surface resistances were measured. The $10^{\text {th }}, 50^{\text {th }}$, and $90^{\text {th }}$ percentiles for resistances were $54.8 \mathrm{~s} / \mathrm{m}, 195.3 \mathrm{~s} / \mathrm{m}$, and $3692.9 \mathrm{~s} / \mathrm{m}$ respectively. A 2-D advection-diffusion model of rooftop deposition is employed to describe transport across the green roof and sensitivity analysis was performed to compare the impact of different parameters. The sensitivity analysis demonstrated that the fetch length and the vegetation height had the biggest impact, followed by the meteorological parameters; the friction
\end{abstract}


velocity and heat flux. The surface resistance had the least impact on deposition. An ideal case was used to demonstrate that even when conditions are maximized for deposition, the impact on the concentration gradient is minimal at best. 


\section{Acknowledgements}

I would first and foremost like to thank my graduate advisor and mentor, Dr. Elliott Gall of the Mechanical Engineering department at Portland State University. The door to Dr. Gall's office was always open for help and support throughout my research and writing. Without his guidance and encouragement, the research and thesis would not be at the level and completion it is at. He has steered me in the right direction throughout my Master's degree and I attribute the quality of said degree to his help.

I would also like to thank Dr. Olyssa Starry, Dr. Todd Rosensteil and the Ecoroof team. Without their passionate participation and advice, this research could not have been successfully conducted.

I would like to recognize Dr. Raul Cal as well, for being part of my thesis committee and being a reader of this thesis. I am grateful and indebted for his valuable comments on my work.

Finally, I would like to express my profound gratitude towards my family. Without them providing me with unfailing support and encouragement throughout the years, I would not have been able to complete my study and write my thesis. This accomplishment could not have been completed without their backing. 


\section{Table Of Contents}



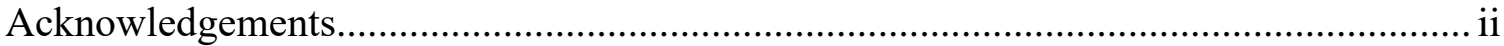

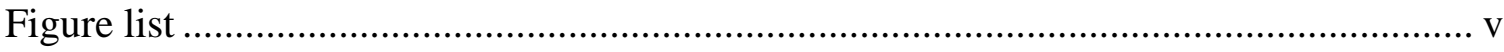

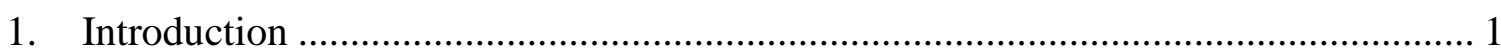

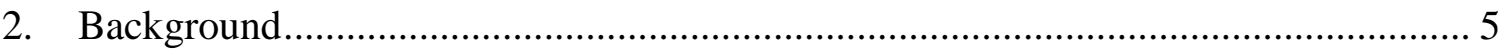



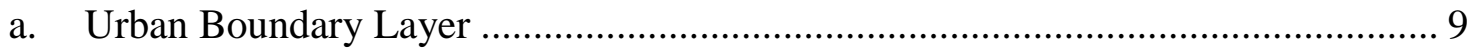

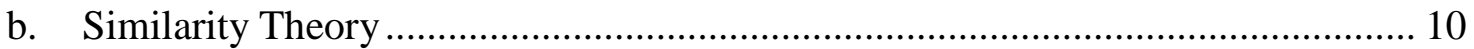

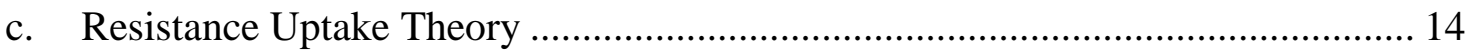

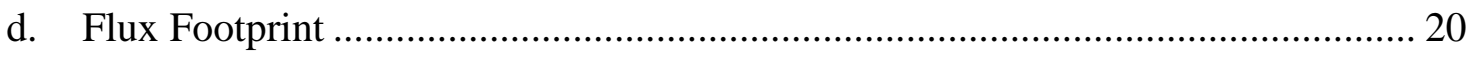

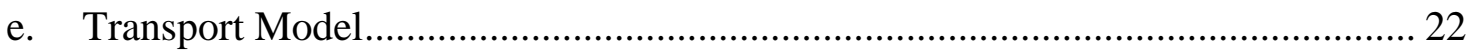

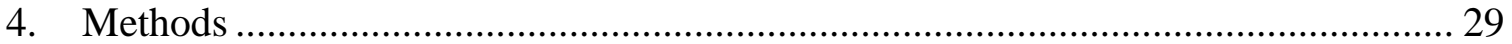

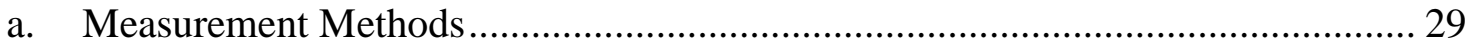

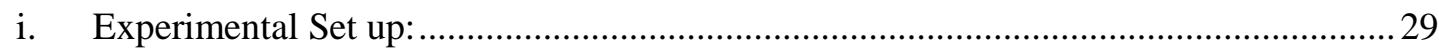

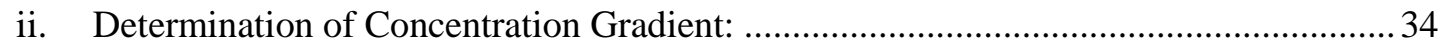

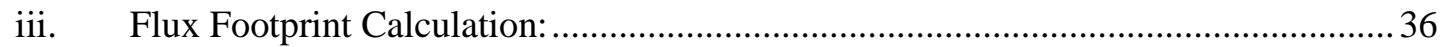

b. Rooftop advection-diffusion model development ............................................. 37







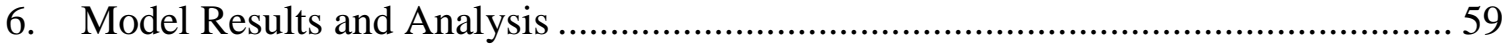

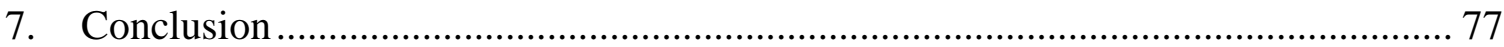

8. Limitations and Future Work ….......................................................................... 79





Appendix A: Supporting Figures for Field Measurements ......................................... 89

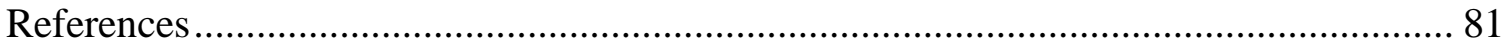

Appendix B: Model Results of Various Cases ......................................................... 89 


\section{Figure list}

Figure 1: Sketch of the Urban Boundary Layer (Rotach 2005) ...................................... 10

Figure 2: Resistance model for dry deposition reprinted from Atmospheric Chemistry and Physics: From Air Pollution to Climate Change (2nd ed. ed.). by J. Seinfeld and S.

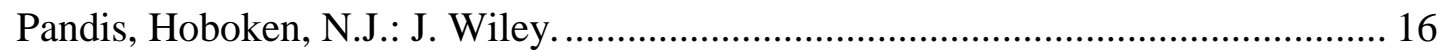

Figure 3: Extension of resistance model for vegetation reprinted from Atmospheric

Chemistry and Physics: From Air Pollution to Climate Change (2nd ed. ed.). by J.

Seinfeld and S. Pandis, Hoboken, N.J.: J. Wiley.................................................. 20

Figure 4: Example footprint estimate for a convective boundary layer (Kljun (2015)) ... 22

Figure 5: Model for ozone transport across a green roof.................................................. 23

Figure 6: Shell balance for ozone transport across a green roof....................................... 24

Figure 7: Representation of instantaneous and mean velocities over time ....................... 26

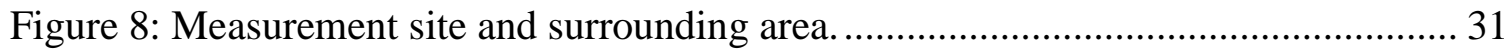

Figure 9: Location of Measurement equipment relative to rooftop .................................... 33

Figure 10: Measurement equipment description............................................................... 35

Figure 11: Model description with the assumed inlet column shown .............................. 41

Figure 12: Concentration profile at two heights .............................................................. 45

Figure 13: Friction velocity (red) and heat flux (blue) determined using the CSAT3 Sonic

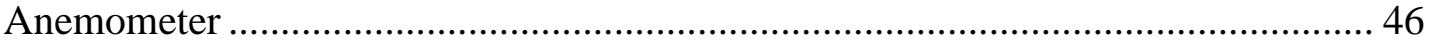

Figure 14: Wind rose of the data before selecting for predominantly vegetated surfaces

(top) and after selecting for vegetated surfaces (bottom)

Figure 15: Concentration and meteorological data after application of selection criteria 49

Figure 16: Flux Footprint of the concentration and meteorological data after applying selection criteria

Figure 17: Deposition velocities calculated using the AGM over the two-day

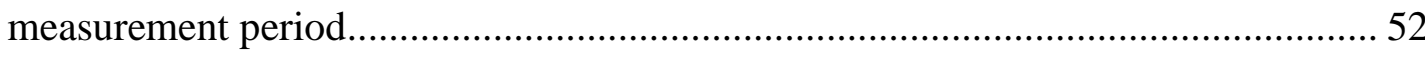

Figure 18: Total Resistances decoupled to their transport and surface resistances over the two-day measurement period. Intervals in which there was negative resistances were ignored.

Figure 19: Transport and Surface Resistances as a function of the overall resistance in percentage. 55 
Figure 20: Cumulative Density Function of the aerodynamic and boundary layer

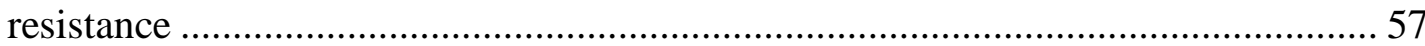

Figure 21: Cumulative Density Function of the surface resistance .............................. 58

Figure 22: The velocity (top), eddy diffusivity (middle) and Reynolds number (bottom) profiles as a function of height

Figure 23: Concentration profile as a function of height and distance. The color gradient

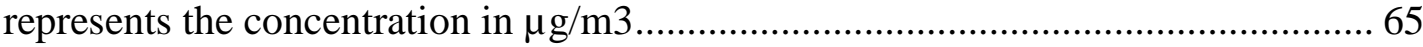

Figure 24: The base case concentration gradient in the column of air assumed to enter the RTU

Figure 25: The case in which the green roof fetch length was changed. The gradients represent the column of air assumed to enter the RTU

Figure 26: The case in which the green roof vegetation height was changed. The gradients represent the column of air assumed to enter the RTU.

Figure 27: The case in which the friction velocity was changed between the 10th, 50th and 90th percentile. The gradients represent the column of air assumed to enter the RTU

Figure 28: The case in which the heat flux was changed between the 10th, 50th and 90th percentile. The gradients represent the column of air assumed to enter the RTU.... 73

Figure 29: The case in which the surface resistance was changed between the 10th, 50th and 90th percentile. The gradients represent the column of air assumed to enter the RTU

Figure 30:- Sensitivity analysis of the different parameters at the inlet RTU height of 0.75 meters. The $\mathrm{x}$-axis represents the elasticity, a measure of how impactful the parameter is

Figure 31: The ideal case in which the parameters were set to produce the lowest concentration at the RTU inlet height ( 0.75 meters) in the column of air assumed to enter the RTU 


\section{Introduction}

As the economies around the world grow, so does urbanization to sustain this growth. This increase in urban concentrations and in gross domestic product (GDP) per capita (in logs) has a strong correlation coefficient, approximately 0.85 (Henderson (2003)) and is shown to lead to greater air pollution in the urban environment (Cole and Neumayer (2004)). One study conducted in 45 US Metropolitan areas found that urban concentrations was significantly associated with both ozone precursor emissions and ozone exceedances over a 13-year study (Stone Jr. (2008)). Although urban air pollution emissions exist mainly outdoors, the effect to human health is predominantly experienced indoors because humans spend more than 85 percent of their time in indoor settings (Jenkins et al. (1992)). These adverse health effects could be due to both indoor and outdoor pollutants and are dependent on the ventilation rate of the indoor environment. The U.S. Environmental Protection Agency (EPA) states that the pathways to indoor pollutant exposure are dependent on the flow of air from one space to another, whether the pollutant is emitted indoors or existent outdoors. Increased rates of ventilation have shown improved health and productivity, but this is dependent on the quality of air brought indoors. This study will focus on pathways of outdoor pollutants entering indoors, specifically ozone entering the indoor environment through roof top ventilation units (RTU).

Ozone is a criteria pollutant regulated by the EPA, it is colorless unstable toxic compound composed of three oxygen molecules and can be naturally occurring in the stratosphere where it performs as a shield from the sun's ultraviolet rays. But ozone in the troposphere, the surface atmosphere, can be harmful. This ozone is created through 
chemical reactions between nitrogen oxides (NOx) and volatile organic compounds (VOCs) (Hanst et al. (1956)) and is a respiratory hazard. The homogeneous gas-phase interaction of ozone with hydrocarbons in the indoor environment has the potential to produce harmful compounds, such as formaldehyde (Salthammer et al. (2010)).

A simple mass balance can show the impact of outdoor ozone to the indoor environment and understand the sources and sinks of ozone. A common parameter used to compare the indoor concentration to the outdoor concentration is the indoor concentration divided by the outdoor concentration (I/O ratio). Weschler (2000) found that the I/O ratio of ozone is dependent on the air exchange rate (the air flow rate over the volume of the indoor space), indoor sources of ozone, the indoor surface removal rate and the chemicals in the air. The air exchange rate however, plays the most consequential role on the I/O ratio of ozone, in that same study. Therefore, we want to remove ozone from the air prior to entering the indoor environment using mitigation techniques, one of which may be increasing of urban vegetation for ozone uptake.

Urban forestry and subsequently urban surface vegetation such as green roofs, have been modeled to be ozone sinks in the urban environment and may potentially provide the same benefits for the indoor environment. The Urban Forestry Effects Model (U.F.O.R.E.) found that although pollutant removal varied from city to city, the overall removal estimated approximately 711,000 metric tons, an approximate $\$ 3.8$ billion value (Nowak et al. (2006)). Increasing surface vegetation, such as implementing green roofs, has also been linked to reductions of urban air pollution. Speak et al. (2012) showed that green roofs have the ability to reduce urban particle pollution near road ways in the UK. Another team 
conducted a study in Toronto where they found that green roofs play a similar role to urban forestry in reducing urban air pollution (Currie and Bass (2008)). Green roofs though, present a challenge as the cost of installing a green roof outweighs the air pollution benefits, and to improve urban air quality, it may be cheaper to install trees and other vegetation at the street level (Yang et al. (2008)). Regarding indoor removal of ozone, Abbass et al. (2017) looked at 5 common species of indoor plants and found that the plants themselves have a modest ozone removal effectiveness of approximately $0.9-9 \%$ and depends on the type of plant as well as the light available. The practice of increasing indoor vegetation may also not be the most effective method for ozone removal. What has not fully been studied yet is the effect of vegetation, such as green roofs, on improving indoor air quality when co-located in the air flow path ways for roof top ventilation units (RTU).

Recently developed cities are mandating green roofs to increase surface vegetation in the urban environment. Cities such as Stuttgart, Copenhagen, Toronto and Portland have all mandated green roofs be implemented for large commercial buildings (Stutz, Yale 360). These large commercial buildings tend to provide outdoor air supply through RTUs and if a green roof is installed directly in front of an RTU, indoor air may be impacted by the vegetated roof. Abbass et al. (2018) tested two HVAC filters, one from an RTU on a white membrane roof and one from a green roof and found that the green roof filters provided better ozone removal efficiency, indicating a potential impact of green roof surfaces on ozone removal across filters. The impact of green roofs may also be exhibited in the outdoor air entering the RTU unit. As air moves across the green roof, the vegetation is allowed to interact with the air and may serve as 'cleaning' of the air similar to urban 
forestry's impact on urban air flow (Escobedo et al. (2010)). The height of RTUs may also influence the quality of air brought in doors. ASHRAE, a professional society dedicated to building science that a vast number of cities base their building code from, specifies a distance between the rooftop and the ventilation air supply of $0.3 \mathrm{~m}$, implying that, whether beneficial or detrimental, pollutant dynamics on rooftops may occur in proximity to ventilation air supply (Table 5.1 ASHRAE 62.1 (2007)).

Currently there is scant empirical research on air pollutant dynamics on vegetated green roofs, and little data concerning pollutant interactions occurring on other rooftop designs. Essentially unstudied is the role of the rooftop design to affect local concentrations of pollutants where building outdoor air supply may be co-located. This study will set out to characterize ozone deposition at the local scale in an urban environment around a green roof. To our knowledge there are no such field measurements of ozone fluxes to urban greenery available in the literature. It will also investigate key interactions that occur among air pollutants near green roofs and illuminate how green roofs or other rooftop surfaces alter air pollutants entering a building. The results may then be used to design and construct green roofs and other rooftops to mitigate pollutants prior to entering the indoor environment. 


\section{Background}

The classic effort of AC Chamberlin (1953) forms the fundamental basis of this study. His effort was to classify the gaseous deposition of atmosphere pollutants as a dry deposition process in which the flux of a pollutant is proportional to the concentration at a measurement height. This characterization is universally accepted as the method of modelling atmospheric dry deposition. Wesely and Hicks (1977) built on this work to develop a model to characterize deposition of sulfur dioxide and other gases using a 'big leaf' theory where the deposition velocity is broken into three resistances which will be later described in detail. They were also one of the first to introduce the aerodynamic and boundary layer formulations into the resistance uptake theory. McRae et al. (1982) applied the dry deposition model on urban air pollution, developing relationships between deposition, turbulent diffusion and surface removal processes.

Hicks et al. (1987) developed a preliminary model for characterizing the subresistances below the vegetated canopy using a multiple resistance model for $\mathrm{SO}_{2}, \mathrm{O}_{3}$, $\mathrm{HNO}_{3}$ and submicron particles. This effort was a trial effort to simplify the complicated overall atmosphere/surface exchange process between the plant canopies and the lower atmosphere. Baldocchi (1987) pushed this work into a realistic, multi-layer 'big leaf' model that would pose as the fundamental bases for analysis of sub-resistances underneath the canopy. His work demonstrated that the canopy resistance, which had been treated as a bulk term, can be decoupled further into parallel sub-resistances which can be measured. A comparison study was performed on $\mathrm{SO}_{2}$ and ozone fluxes to a deciduous forest by Meyers and Baldocchi (1988) between simple single-layer 'big leaf' model, a more 
complex multi-layer 'big leaf' model, and direct eddy correlation measurements. The multi-layer model prediction of deposition rates improved by approximately $40-50 \%$. Further improvements are made to the multi-layer model to incorporate 'K-theory' by Baldocchi (1988) where the treatment of the flux towards the surface involves the eddy exchange coefficient of pollutants. This study adopted realistic physiological concepts that allowed for the measurement of deposition velocities to be more sensitive variations in surface resistance parameters. This formulation was the basis for various models estimating deposition to surfaces. The Regional Acid Deposition Model (RADM) and Acid Deposition and Oxidant Model (ADOM) incorporated this formulation in their dry deposition modules (Walcek et al. (1986), Chang et al. (1987), Padro and Edwards (1991), Padro (1996)). This inferential approach (the 'big leaf' model without the multi-layer aspect) has been used for continuous estimates of dry deposition velocity at the EPA's Clean Air Status and Trends Network (CASTNet), where they made local measurements of pollutant concentrations, meteorological conditions and surface conditions (Clarke et al (1997)). Later, the relatively more sophisticated multilayer model was applied to CASTNet (Pratt et al. (1996)) and further improvements have been made to the multi-layer 'K-theory' model. This model was slightly revised by Zhang et al. (2003) where measurements of $\mathrm{SO}_{2}$ and ozone fluxes to 5 different vegetation types using a 'two-big leaf' mode. The improvements from these measurements showed a more accurate depiction of deposition velocities for both pollutants in dry and wet canopies.

These same models have been applied on the urban scale to understand dispersion and deposition of gases and particles to urban vegetation. Most urban dispersion and 
deposition studies have been conducted with eddy covariance measurements to provide direct flux measurements under heterogeneous conditions. Direct measurements of $\mathrm{CO}_{2}$ as well as VOC fluxes have been used in many recent studies (Grimmond et al. (2002), Velasco et al. 2005a), Langford et al. (2009), Karl et al. (2009)). In cases where direct measurements were not possible, one-dimensional multi-layer models are used to identify the downward flux of a particle or pollutant. Because of the complicated nature of urban environments, these methods are applied only to describe deposition to vegetated surfaces by defining a situation of an airstream moving across a single leaf or vegetated surface (Janhall (2015)). In this case the particle or pollutant is inhibited by the same three resistances used in the 'big leaf' model; aerodynamic, boundary layer and surface resistance. Nowak and Crane (1998b) developed a module known as the Urban Forests Effects (UFORE) that incorporated dry deposition onto vegetation using the 'big leaf' model developed by Baldocchi (1988) where, hourly resistances to ozone uptake were continuously calculated. A modelling study was performed using this module to understand the impact of urban trees on ozone deposition (Nowak et al. (2000)). Using estimates of ground and tree coverage, the model predicted a net positive effect in reducing ozone in urban areas and also found that the physical effects of vegetation changes have a greater effect on the ozone concentration than the impact of atmospheric biogenic VOC interactions. Taha (1995) modelled the impacts of increasing vegetation on ozone in the south coast air basin and found that the increase in urban vegetation had a net positive effect in reducing ozone if the vegetation were low emitters of hydrocarbons. 
Yang et al (2008) found similar results in the removal of ozone in the urban environment through the use of green roofs but found that the cost associated with the green roofs outweighed the air pollution control benefits. But the impact the impact of urban vegetation to the indoor environment needs to be further investigated. A large amount of commercial building bring fresh outdoor air to the indoor environment through roof top units (RTU) and with green roofs placed close to these RTUs, there may be an effect to the quality of air brought indoors. A two-dimensional advection-diffusion equation that considers dry deposition similar to Lin and Hildemann (1995) and Tirabassi et al (2008) using a 'K-theory big leaf' model may be developed to understand the transport and dispersion of ozone on to green roofs prior to entering the indoor environment. 


\section{Theory}

a. Urban Boundary Layer

Transport of pollutants onto rooftops is determined through a turbulent dispersion process governed by the structure of the atmospheric boundary layer (Figure 1). The atmospheric boundary layer, also known as the planetary boundary layer, is the lowest part of the atmosphere where the behavior is strongly influenced by surface conditions. In an urban environment, the complex construction of the landscape influences the atmospheric flow and turbulent structures in the boundary layer. The urban structures reduce the motion of the air over the city and increases the mechanically generated turbulence. Anthropogenic sources of heat also impact the energy balance as well and alter the boundary layer. At a local scale, the treatment of the urban morphology can be synthesized to one parameter, zo $(\mathrm{m})$, the roughness sublayer layer.

Atmospheric flows are turbulent and governed by the fundamental laws of conservation, and these turbulent flows are random in nature which make a deterministic approach to a solution difficult. Statistical methods can be used to decompose the governing momentum equation to its mean and fluctuating parts. By applying Reynolds' averaging and applying the reasonable assumptions for the atmospheric boundary layer, the transport equation can be simplified. But unfortunately, still more unknowns than equations appear, and a closure assumption must be made. One such approach is to use a similarity theory. 


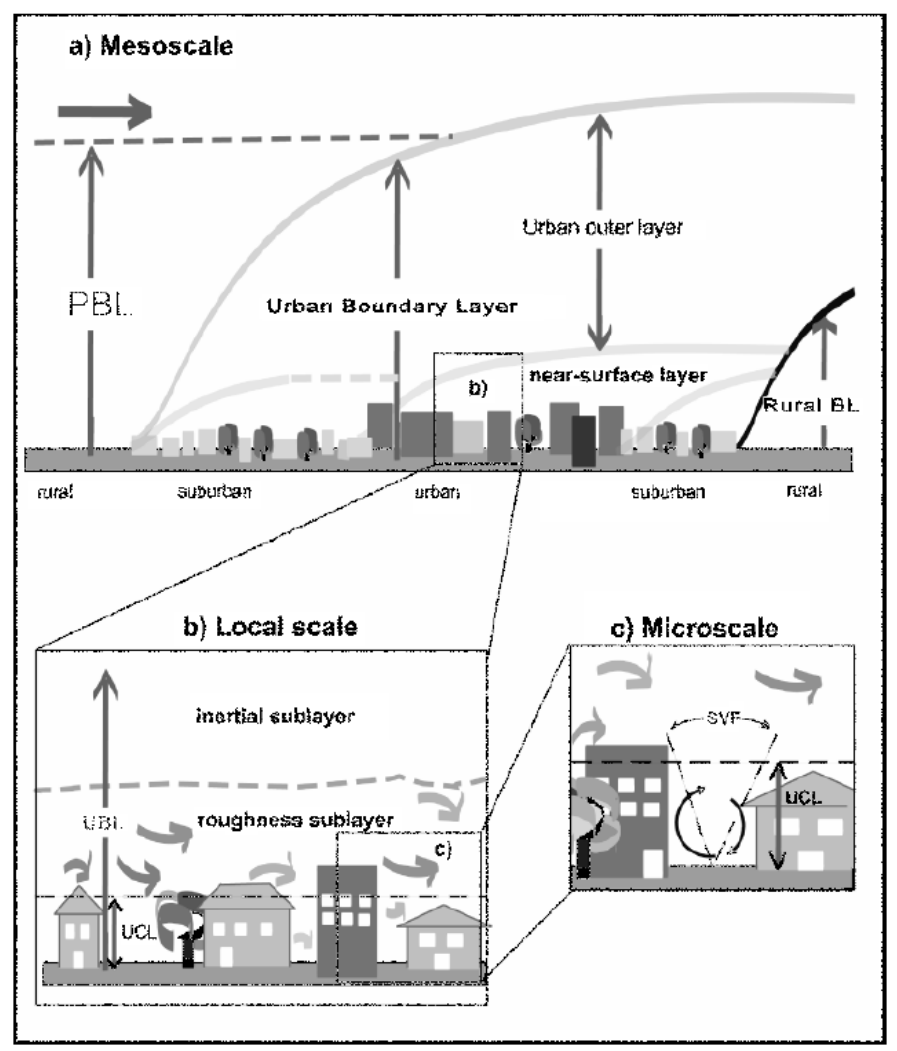

Figure 1: Sketch of the Urban Boundary Layer (Rotach 2005)

\section{b. Similarity Theory}

A similarity theory provides an empirical relationship of the vertical behavior of the mean flow and turbulent of the flow above a surface. By using the appropriate scales, the boundary layer can be divided into various sublayers described by some form of similarity solutions. If we consider the neutral surface layer over a flat surface, typically the lower $10 \%$ of the boundary layer, we can make a case that the momentum flux is constant with height and the Reynolds shear stress is correlated to the wall-shear stress, $\tau_{\mathrm{O}}$ $\left(\mathrm{N} / \mathrm{m}^{2}\right)$. This implies that the mean velocity gradient and turbulent properties rely only on height and shear stress at the surface. Surface roughness, geostrophic wind and the 
boundary layer height are considered through changes in $\tau_{\mathrm{O}}$. A reasonable similarity approximation for the velocity gradient is (Gabero (2008)):

$$
\frac{\partial \bar{u}}{\partial z}=f\left(z, \tau_{o} / \rho\right)
$$

Where $\bar{u}$ is the wind speed in units of $(\mathrm{m} / \mathrm{s}), z$ is the height above the ground (m).

Using dimensional analysis:

$$
\frac{z}{u_{*}} \frac{\partial \bar{u}}{\partial z}=\frac{1}{k}
$$

Where $k$ is the dimensionless Von Karman constant derived empirically to be approximately 0.40 (Shepphard (1947)). $u_{*}(\mathrm{~m} / \mathrm{s})$ is the friction velocity described as:

$$
u_{*}=\sqrt{\frac{\tau_{O}}{\rho}}=\left(\left(\overline{w^{\prime} u^{\prime}}\right)^{2}+\left(\overline{w^{\prime} v^{\prime}}\right)^{2}\right)^{1 / 4}
$$

Where $\overline{u^{\prime} w^{\prime}}$ is the Reynolds shear stress $\left((\mathrm{m} / \mathrm{s})^{2}\right)$. Eq. 2 equation can be integrated to generate the logarithmic velocity profile, known as the log-law:

$$
\bar{u}=\frac{u_{*}}{k} \ln \left(\frac{z}{z_{o}}\right)
$$

This log-law is valid when the flow is homogenous in the horizontal planes and when the fluctuating velocity field has only one velocity scale, the friction velocity $u_{*}$. An inclusion of the roughness elements is required to describe the flow immediately above the urban canopy. The flow in this region is dynamically influenced by the urban structures, making the flow field non-homogeneous. The logarithmic profile is shifted upwards by a displacement height, d (m), to account for the presence of obstacles (Molder (1999)). The new logarithmic velocity profile becomes: 


$$
\bar{u}=\frac{u_{*}}{k} \ln \left(\frac{z-d}{z_{o}}\right)
$$

A first order closure approximation can be made that assumes that the turbulent fluxes are related to the mean velocity gradient by an eddy-diffusivity coefficient (Nieuwstadt and van Dop (2012)). The behavior turbulent transport in this closure approximation is similar to molecular diffusivity in Fick's law:

$$
\overline{u^{\prime} w^{\prime}}=-K \frac{\partial \bar{u}}{\partial z}
$$

Where $K$ is the eddy diffusivity term $\left(\mathrm{m}^{2} / \mathrm{s}\right)$. This formulation can be solved by substituting Eq. 2 and Eq. 3 into Eq. 6:

$$
\overline{u^{\prime} w^{\prime}}=u_{*}^{2}=-K \frac{u_{*}}{k * z}
$$

Restructuring and including the zero-plane displacement height, d, gives us:

$$
K=-\left(u_{*} \times k \times(z-d)\right)
$$

In addition to shear stresses, turbulent atmospheric transport is also strongly influenced by thermal fluxes from the earth's surface. These fluxes can substantially vary the boundary layer height throughout periods during the day. To account for thermal fluxes, Monin and Obukhov introduced an extension to the similarity theory, the MoninObukhov Length, $L(\mathrm{~m})$ (Monin and Obukhov (1954)). This new length scale is defined as the distance from a wall where thermal and mechanical production of turbulent kinetic energy are equal. Using this new length scale a dimensionless parameter can be derived, the stability parameter is defined as: 


$$
\delta=\frac{z-d}{L}
$$

Where $\mathrm{L}$ is the Monin-Obukhov length given by:

$$
L=-\frac{u_{*}^{3}}{k\left(\frac{g}{T}\right)\left(\frac{H}{\rho c_{p}}\right)}
$$

Where $g$ is gravity $\left(\mathrm{m} / \mathrm{s}^{2}\right), T$ is temperature $(\mathrm{K}), H$ is heat flux $\left(\mathrm{W} / \mathrm{m}^{2}\right), c_{p}$ is specific heat $(\mathrm{J} /(\mathrm{Kg} * \mathrm{~K}))$ and $\rho$ is the density $\left(\mathrm{kg} / \mathrm{m}^{3}\right)$.

Mechanical turbulence dominates when $z<|L|$ and when $z>|L|$ buoyancy effects are more dominant. To note, if $-10^{5}<L<0$, the atmosphere is unstable, $0<L<10^{5}$, the atmosphere is stable, and $L<-10^{5}$ or $L>10^{5}$, the atmosphere is considered neutral (Hogstrom (1988) place citation). This incorporation of thermal fluxes changes the vertical mean velocity profile and the eddy diffusivity coefficient, and a universal function needs to be used to describe the stability of the atmosphere in the differentiated mean velocity gradient:

$$
\frac{\partial \bar{u}}{\partial z}=\frac{1}{k} \frac{z-d}{u_{*}} \times \varphi(\delta)
$$

Where all terms are as defined previously.

An empirical relationship is made for the non-dimensional stability parameter $\varphi(\delta)$ (Hogstrom (1988)) and is the most common method of parameterization today.

$$
\begin{aligned}
& \varphi(\delta)=1+6(\delta) \text { for } \delta>0 \text { (Stable atmosphere }) \\
& \varphi(\delta)=1 \text { for } \delta=0 \text { (Neutral atmosphere) }
\end{aligned}
$$




$$
\varphi(\delta)=(1+19.3(\delta))^{-1 / 4} \text { for } \delta<0 \text { (Unstable atmosphere) }
$$

Integrating and solving for the mean velocity gives:

$$
\left.\bar{u}=\frac{u_{*}}{k} \ln \left(\frac{z-d}{z_{o}}\right)-\psi(\delta)\right)
$$

Where:

$$
\begin{gathered}
\psi(\delta)=-6(\delta) \text { for } \delta>0 \text { (Stable atm. ) } \\
\psi(\delta)=\ln \left[\left(\frac{1+x^{2}}{2}\right)\left(\frac{1+x}{2}\right)^{2}\right]-2 \tan ^{-1} x+\frac{\pi}{2} \text { for } \delta<0 \text { (Unstable atm. ) Eq. } 17 \\
x=(1-19.3(\delta))^{1 / 4}
\end{gathered}
$$

Similarly, the eddy diffusivity is modified for the stability parameters:

$$
K_{m}=\frac{\left(u_{*}\right)(k)(z-d)}{\varphi(\delta)}
$$

\section{c. Resistance Uptake Theory}

Dry deposition is an important pathway in which ozone is removed from the troposphere as it serves as a cleaning process for atmospheric ozone. It is unrealistic to describe in explicit detail the microphysical pathway by which ozone travels from the bulk atmosphere to the surface elements. The transport of a pollutant to the surface is continuous and can be extremely convoluted; and involves the level of atmospheric turbulence, the chemical properties of the species and the nature of the surface (Seinfeld and Pandis (1998)). The time scales that can be associated with the process of uptake can span anywhere from seconds to hours, days or years depending on the atmospheric and 
physiological conditions. Instead, the process may be simplified with the assumption that the dry deposition of ozone is linearly correlated to the local concentration of ozone and the vertical dry deposition flux can be described as:

$$
F_{O}=v_{d} \times C_{\mathrm{o}}
$$

Where $v_{d}$ is a constant of proportionality known as the deposition velocity $(\mathrm{cm} / \mathrm{s})$ and $C_{\mathrm{o}}$ is the concentration $\left(\mu \mathrm{g} / \mathrm{m}^{3}\right)$ at a measurement height.

The advantage of this approach is that the complexity of the flux is reduced to one term, but the disadvantage is that it may difficult to characterize all of the physical and chemical transport processes. To further characterize the mechanism of dry deposition, the process can be characterized into three steps occurring in series: aerodynamic transport, molecular or boundary layer transport, and reaction at the surface. These three phenomena are modeled as resistances according to equation 20 (Baldocchi (1987)):

$$
\mathrm{v}_{\mathrm{d}}=\frac{1}{r_{t}}=\frac{1}{r_{a}+r_{b}+r_{c}}
$$

Where $r_{a}$ is the aerodynamic resistance, $r_{b}$ is the aerodynamic resistance, and $r_{c}$ is the canopy or surface resistance.

Resistances determined based on Figure 2 is as follows:

$$
F=\frac{C_{3}}{r_{t}}=\frac{C_{3}-C_{2}}{r_{a}}=\frac{C_{2}-C_{1}}{r_{b}}=\frac{C_{1}-C_{0}}{r_{c}}=\frac{C_{3}-C_{0}}{r_{a}+r_{b}+r_{c}}=\frac{C_{3}}{r_{a}+r_{b}+r_{c}}
$$




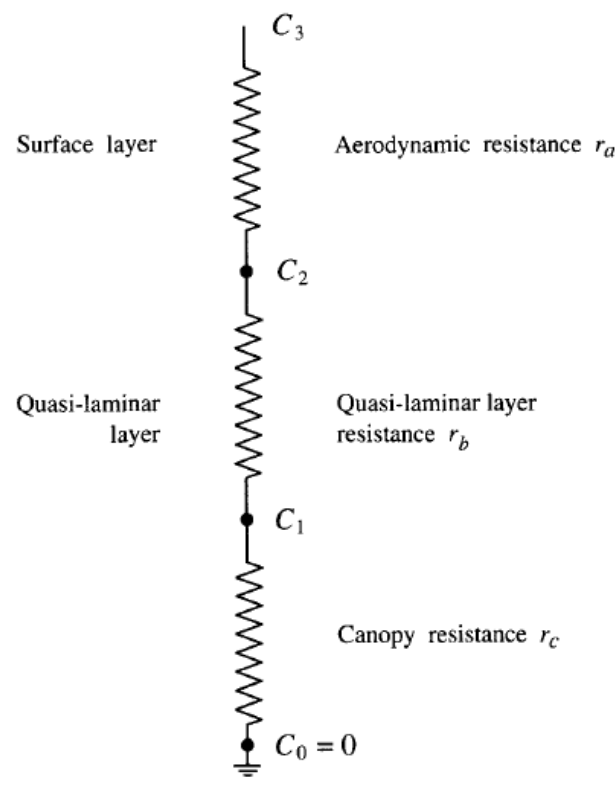

Figure 2: Resistance model for dry deposition reprinted from Atmospheric Chemistry and Physics: From Air Pollution to Climate Change (2nd ed. ed.). by J. Seinfeld and S. Pandis, Hoboken, N.J.: J. Wiley.

The Aerodynamic resistance is governed by the turbulent transport that brings material from the bulk atmosphere down to the canopy. This transport is based off of gradient transport theory and the momentum transfer similarity hypothesis. The surface layer in which this transport occurs is assumed to be a constant flux layer, which allows the vertical turbulence mass transfer to be expressed as an eddy diffusivity coefficient multiplied by a concentration gradient:

$$
F_{a}=K \frac{\partial \overline{\mathrm{C}}}{\partial z}
$$

Where $K$ is the eddy diffusivity $\left(\frac{\partial \overline{\mathrm{C}}}{\partial z}\right)$ and $F_{a}$ is the aerodynamic concentration flux, assumed to be constant across the surface layer. 
With respect to figure 2, we can rewrite the aerodynamic concentration flux as:

$$
\left.F_{a}=\left(\int_{z_{2}}^{z_{3}} \frac{\varphi(\delta)}{(z-d)}\right)\right) *\left(C_{3}-C_{2}\right)
$$

Where $\varphi(\delta)$ is the universal function used to describe the atmospheric stability discussed previously.

From Eq. 23, we can determine the aerodynamic resistance:

for $\delta>0$ (Stable atmosphere)

$$
r_{a}=\frac{1}{k * u_{*}}\left[\ln \left(\frac{z-d}{z_{o}}\right)+6\left(\delta-\delta_{0}\right)\right]
$$

for $\delta=0$ (Neutral atmosphere)

$$
r_{a}=\frac{1}{k * u_{*}}\left[\ln \left(\frac{z-d}{z_{o}}\right)\right]
$$

for $\delta<0$ (Unstable atmosphere)

$$
r_{a}=\frac{1}{k * u_{*}}\left[\ln \left(\frac{z-d}{z_{o}}\right)+\ln \left[\left(\frac{1+x^{2}}{2}\right)\left(\frac{1+x}{2}\right)^{2}\right]-2 \tan ^{-1} x+\frac{\pi}{2}\right]
$$

Where $x=\left(1-19.3\left(\delta-\delta_{O}\right)\right)^{1 / 4}$

Boundary layer resistance, $r_{b}$, in the resistance-uptake model of dry deposition assumes that directly adjacent to the surface, a quasi-laminar boundary layer exists. Across this layer, the only mode of transport is molecular diffusion. This mode of transport serves as an impediment to the depositing species regardless of orientation of the surface. The layer itself is a direct consequence of the many viscous layers adjacent to the obstacles and 
may only exist intermittently on surfaces that move such as leaves, and foliage. The height of the layer depends on the smoothness and the shape of the elements as well as the variability of the near-surface turbulence. Essentially, we assert that the area and time we averaged is a large enough that the quasi-laminar boundary layer is very small at any location and at any point in time, but nevertheless included to model large swaths of surfaces even if it is not completely realistic at all locations at all times. The flux of concentration across the quasi-laminar boundary layer can be expressed as such:

$$
F_{b}=B \times u_{*} \times\left(C_{2}-C_{1}\right)
$$

Where $\mathrm{B}$ is the dimensionless mass transfer coefficient and is dimensionalized by $u_{*}($ Seinfeld and Pandis (1998)).

The boundary layer resistance is then given by:

$$
r_{b}=\frac{1}{B \times u_{*}}
$$

The resistance, $r_{b}$, is dependent on the molecular and thermal diffusivity of the gas, in this case ozone, and for gases, the mass transfer coefficient is derived empirically using the Schmidt number and Prandtl number (Yang et al. (2005)).

$$
r_{b}=\frac{2 \times S c^{2 / 3} \times P r^{-2 / 3}}{u_{*}}
$$

Where the $S c=\frac{v}{D}$, which is the relationship between kinematic viscosity and molecular diffusivity and $\operatorname{Pr}=\frac{v}{\alpha}$, which is the relationship between kinematic viscosity and thermal diffusivity. 
The boundary layer resistance has been shown to be insensitive to the roughness length, therefore it is not included in its formulation (Seinfeld and Pandis 1998).

Surface resistance for gases depends on the nature and structure of the surface. The surface resistance can be broken down into many sub-resistances, each describing a different pathway for deposition. For example, in the case of canopy resistance, the subresistances are stomata pore resistance, cuticular resistance and mesophilic resistance. These resistances can be divided even further depending on moisture availability, type of plant, amount of available sunlight and other criteria that define the surface composition of vegetation. These complicated sub-resistances are shown in Figure 3. The resistance model displayed in figure 3 does incorporate the resistance to particles, which is not in this study, but shows that the particle deposition may also be modeled similarly, with slight changes to the resistance pathways. 


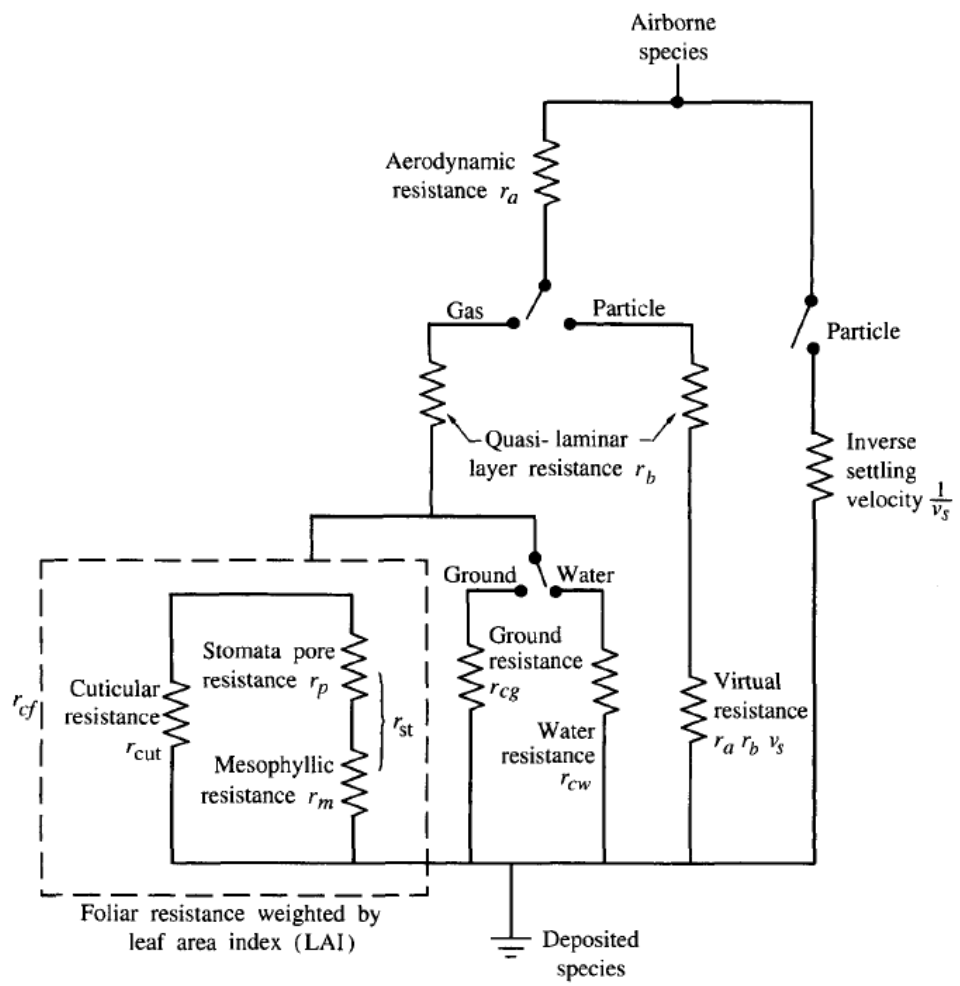

Figure 3: Extension of resistance model for vegetation reprinted from Atmospheric Chemistry and Physics: From Air Pollution to Climate Change (2nd ed. ed.). by J. Seinfeld and S. Pandis, Hoboken, N.J.: J. Wiley.

We take an initial treatment of the surface resistance for canopies using the 'big leaf' approach (Baldocchi 1987) where a bulk $r_{\mathrm{c}}$ term is used to first understand the magnitude of the field canopy resistances. Further experiments treating the canopy resistance using multi-layer submodel can be performed to evaluate the different factors that impact the surface resistance.

\section{d. Flux Footprint}

Any measurement of the turbulent concentration flux at elevated points must consider the effective footprint, otherwise known as the upwind area, sensed by the instrument. The prerequisites for flux measurements are stationarity and the existence of 
homogeneity. In case of complex structures, is required that the measurements be taken in the constant flux region of the boundary layer. The vertical turbulent flux, $F\left(0,0, z_{m}\right)$, can be defined as:

$$
F\left(0,0, z_{m}\right)=\int_{-\infty}^{\infty} \int_{0}^{\infty} F(x, y, 0) \times f\left(x, y, z_{m}\right) d x d y
$$

Where is the $F(x, y, 0)$ is the surface flux upwind of the measurement equipment and $f\left(x, y, z_{m}\right)$ is the footprint function defining that flux (Kormann and Meixner (2000)).

For simplicity, we can neglect the vertical reference height for the footprint function because the footprint is always specific to the given measurement height. The footprint function is proportional to the increment arising from a single unit point $\operatorname{sink} Q_{u}$ :

$$
f(x, y)=\frac{F(x, y, 0)}{Q_{u}(x, y)}
$$

$F$ is the flux density (per unit area) and $Q_{u}$ is the sink integrated over a unit area (Kljun (2015)).

The footprint function has units of $\mathrm{m}^{-2}$. The crosswind turbulent dispersion is treated independently from the vertical or streamwise transport. The crosswind-integrated footprint, $\overline{f^{y}}(x)$, and the crosswind function, $D_{y}$, can be used to find the footprint function:

$$
f(x, y)=\overline{f^{y}}(x) \times D_{y}
$$

A scaled parameterization of the upwind and cross-wind shapes of the footprint is then used to determine the maximum footprint. Figure 4 is an example of a footprint associated with a flux in a convective boundary layer: 

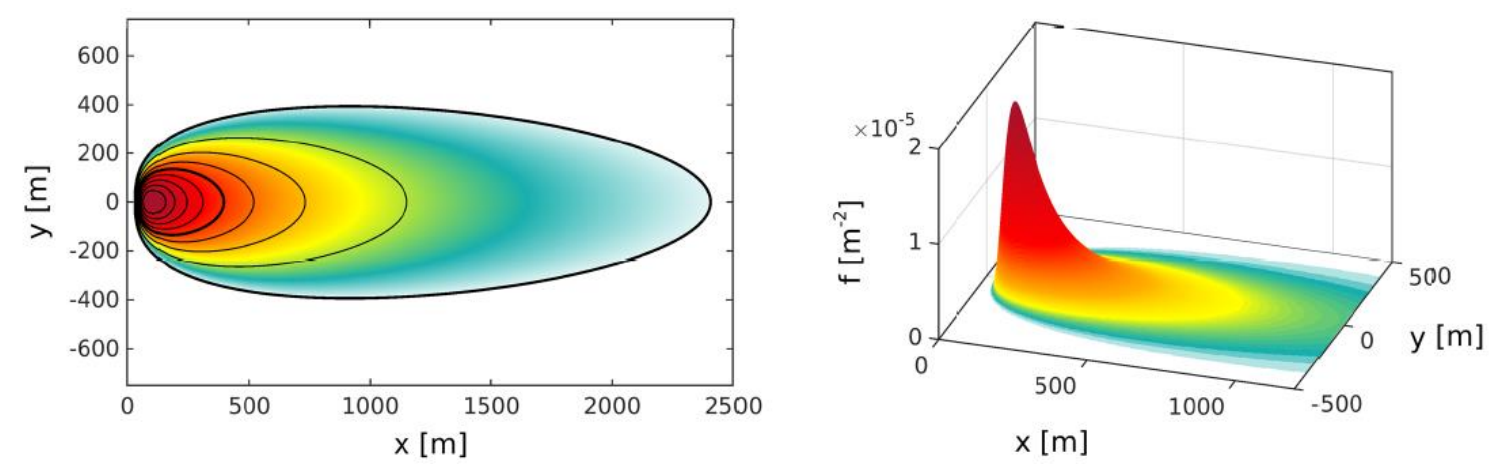

Figure 4: Example footprint estimate for a convective boundary layer (Kljun (2015))

This footprint parameterization is generally accepted as a predictor and applied in a software package provided by N. Kljun at the Institute for Atmospheric and Climate Science ETH in Zurich, Switzerland.

\section{e. Transport Model}

Green roofs are comprised of multiple layers: the vegetation layer, the growing medium (soil), the drainage layer, and the waterproof membrane (Berndtsson (2009)). For the pollutant model, the focus will be specifically on the interaction between ozone transported across the green roof, the vegetation and the green roof substrate. Figure 5 shows how ambient ozone has the potential to interact with green roofs prior to entering the roof top unit (RTU). Essentially, local meteorology drives ozone downward towards the surface where it interacts with vegetation and a reactive process transforms and removes ozone from the atmosphere. This process may act as a cleaning prior to entering the RTU. 


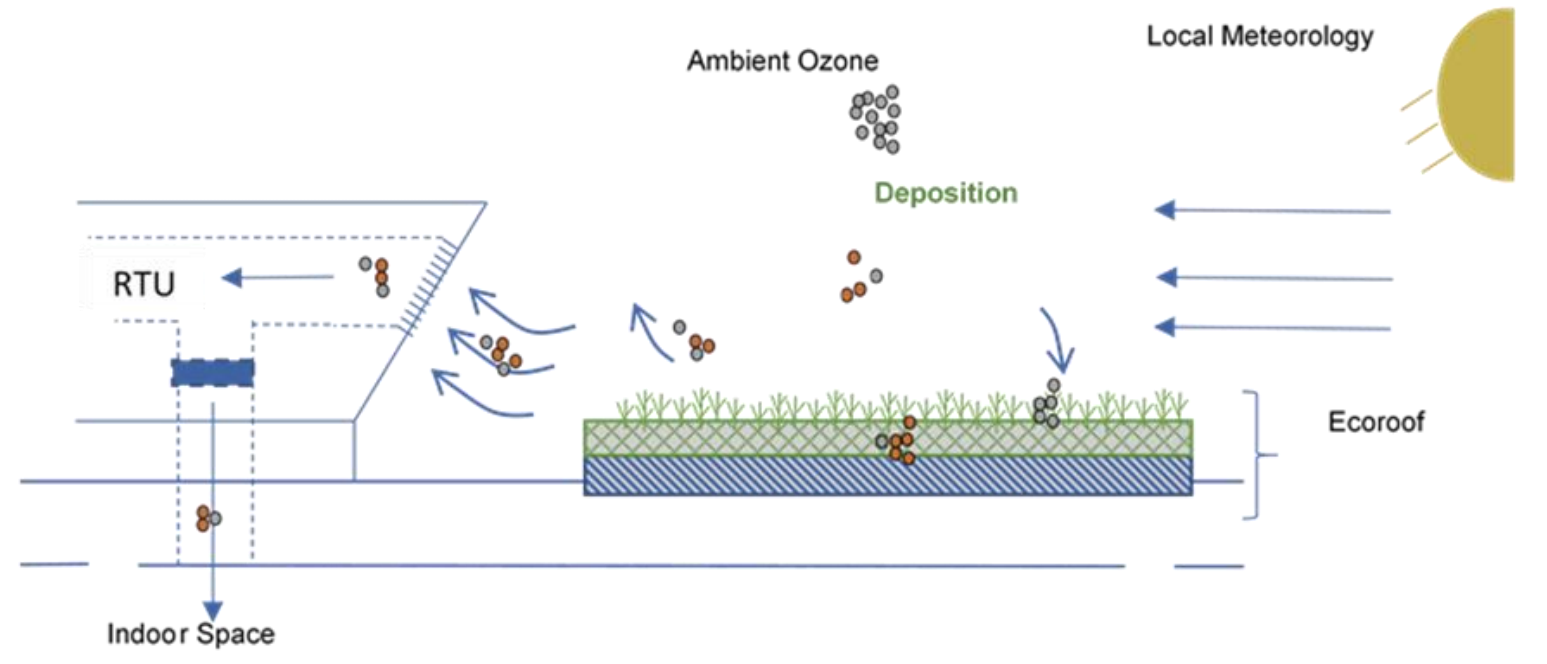

Figure 5: Model for ozone transport across a green roof

Transport across the green roof is modeled in the same way as the urban atmospheric advection-diffusion models (Rotach (1999), Taggeson (2012), Baik and Kim (1998)); the vegetation is treated as roughness elements and thermal stratification describes the size and shape of the boundary layer. The use of two-dimensional shell balance allows for the evalution of the species transport mechanisms over the green roof, shown in Figure 6. 




Figure 6: Shell balance for ozone transport across a green roof

We make a two-dimensional assumption similar to a plug flow assumption which allows us to neglect the y-direction. We do this because we are concerned with understanding the essential elements deposition due to transport across and towards the rooftop. This allows us to conceptualize the source and sinks as well as identify the gaps in knowledge that will provide the basis for more detailed quantitative models. The source of ozone is assumed to only be from external sources and inside the control volume, there are no emitting sources for ozone on the surface. The only removal mechanism of ozone in the control volume is heterogeneous interaction between ozone and the surface elements (Yang et al. (2008)). The homogeneous interactions for ozone and other volatile organic compounds (VOCs) happen at a slower rate than the expected residence time on the rooftop, a few hours to react (Weschler (2000)) versus a few seconds to transport across the model space, and they require prior knowledge of the VOCs released by the green roof, the rate at which they are emitted and the rate of reaction of the specific compound to 
ozone. For this reason, the gas-phase interactions are ignored. A shell balance method can now be applied to the control volume:

$$
\begin{gathered}
\frac{\partial C_{o}}{\partial t} \times V=\left(\left.N_{o x}\right|_{x} \times A_{x-\text { Surface }}-\left.N_{o x}\right|_{x+d x} \times A_{(x+d x)-\text { Surface }}\right)+\left(\left.N_{o z}\right|_{z} \times\right. \\
\left.A_{z-\text { Surface }}-\left.N_{o z}\right|_{z+d z} \times A_{(z+d z) \text {-Surface }}\right)-L
\end{gathered}
$$

Where $L$ is the loss to the surface.

In this work, heterogeneous dry deposition process is the only internal sink term considered in the shell balance. Specifically, it is the flux ozone depositing multiplied by the area of the surface elements (Ma and Daggupaty (2000)).

$$
L=F_{\mathrm{O}} \times A_{\mathrm{i}}
$$

Where $F_{O}$ is the flux of ozone to the surface and $A_{i}$ is the area of deposition surface

The flux to the surface can be correlated to the flux of a species due to turbulent dispersion in the roughness layer presented previously in equation $19, F_{O}=v_{d} \times C_{o}$. The molar flux terms can be decoupled into diffusive and bulk transport terms which can then be added:

$$
\begin{aligned}
& \frac{N_{o x}}{C_{o}}=\frac{J_{o z}}{C_{o}}+x_{o} N \\
& \frac{\partial C_{o}}{\partial t}=-\frac{\partial}{\partial x}\left(D_{o} \frac{\partial\left(C_{o}\right)}{\partial x}+C_{o} u\right)-\frac{\partial}{\partial z}\left(D_{o} \frac{\partial\left(C_{o}\right)}{\partial z}+C_{o} w\right)-\left[\sum_{i=1}^{n} \frac{v_{d i} * A_{i}}{V}\right] * C_{o}
\end{aligned}
$$


Here, $u$ and $w$ are the instantaneous velocity in the $\mathrm{x}$ and z-direction, respectively. Using Reynolds decomposition, the instantaneous velocity can be reduced to a mean and fluctuating velocity, as seen in Figure 7 and given in equation 37.



Time, $t$

Figure 7: Representation of instantaneous and mean velocities over time

$$
u=\bar{u}+u^{\prime}
$$

The fluctuations in concentration also need to be accounted for in our control volume:

$$
\begin{aligned}
& \frac{\partial}{\partial t}\left(\overline{C_{0}}+C_{o}^{\prime}\right)=-\frac{\partial}{\partial x}\left[D_{o} \frac{\partial}{\partial x}\left(\overline{C_{0}}+C_{o}^{\prime}\right)+\left(\overline{C_{0}}+C_{o}^{\prime}\right)\left(\bar{u}+u^{\prime}\right)\right]-\frac{\partial}{\partial z}\left[D_{o} \frac{\partial}{\partial z}\left(\overline{C_{0}}+C_{o}^{\prime}\right)+\right. \\
& \left.\left(\overline{C_{0}}+C_{o}^{\prime}\right)\left(\bar{w}+w^{\prime}\right)\right]-\left[\sum_{i=1}^{n} \frac{v_{d i^{*} A_{i}}}{V}\right] * C_{o}
\end{aligned}
$$

After time-averaging and applying continuity:

$$
\frac{\partial \overline{C_{0}}}{\partial t}=D_{o}\left[\frac{\partial^{2} \overline{C_{0}}}{\partial x^{2}}+\frac{\partial^{2} \overline{C_{0}}}{\partial z^{2}}\right]-\bar{u} \frac{\partial \overline{C_{0}}}{\partial x}-\bar{v} \frac{\partial \overline{C_{0}}}{\partial z}-\frac{\partial}{\partial x}\left(\overline{C^{\prime}{ }_{o} u^{\prime}}\right)-\frac{\partial}{\partial z}\left(\overline{C^{\prime}{ }_{o} w^{\prime}}\right)-\left[\sum_{i=1}^{n} \frac{v_{d i} * A_{i}}{V}\right] * \overline{C_{0}}
$$

Eq. 39

Similar to the constant flux assumption for the local scale urban transport model, a flux-gradient relationship can be made for the turbulent mass transport term. 


$$
\overline{C^{\prime}{ }_{o} W^{\prime}}=K_{m} \frac{\partial \overline{C_{0}}}{\partial z}
$$

The turbulent transport in the $\mathrm{x}$ direction can be neglected as the turbulent fluctuating terms relatively small compared to the mean advective transport terms in the $\mathrm{x}$ direction:

$$
\overline{C_{o} u} \gg \overline{C^{\prime}{ }_{o} u^{\prime}}
$$

In the same manner, molecular diffusion can be ignored as it is a negligible process when compared to advective transport in the $\mathrm{x}$-direction and turbulent transport in the $\mathrm{z}$ direction. The governing transport equation for flow over the green roof becomes:

$$
\frac{\partial \overline{C_{0}}}{\partial t}=-\bar{u} \frac{\partial \overline{C_{0}}}{\partial x}-\frac{\partial}{\partial z} K_{m} \frac{\partial \overline{C_{0}}}{\partial z}-\left[\sum_{i=1}^{n} \frac{v_{d i} * A_{i}}{V}\right] * \overline{C_{0}}
$$

Where $\overline{C_{0}}$ is the mean ozone concentration, $\bar{u}$ is the mean velocity, $K_{m}$ is the eddy diffusivity coefficient for mass, $v_{d i}$ is the deposition velocity, $A_{i}$ is the area of the deposition surface, $V$ is the control volume.

The treatment of flow over the rooftop is similar to the atmospheric flow over an urban area. In the case of the rooftop, the plants and vegetation play the role of the complex structures that buildings play in urban atmospheric models. The turbulent diffusivity for mass transport is usually taken as 0.80 of the momentum turbulent diffusivity (Taggeson (2012)). The mean velocity and momentum turbulent diffusivity are given as:

$$
\begin{aligned}
& \left.\bar{u}=\frac{u_{*}}{k} \ln \left(\frac{z-d}{z_{o}}\right)-\psi(\delta)\right) \\
& K_{\text {mass }}(z)=(0.80) \times \frac{\left(u_{*}\right)(k)(z-d)}{\varphi(\delta)}
\end{aligned}
$$


Here $d$ is the zero-plane displacement height, given as approximately two-thirds the height of the roughness element (Mölder et al. (1999)). The stability of the atmosphere $(\delta)$ is given by Eq. 9 and the universal function $\varphi(\delta)$ and subsequently $\psi(\delta)$ is given by Eq. $12-14$ for $\varphi(\delta)$ for Eq. 16 and Eq. 17 for $\psi(\delta)$. 


\section{Methods}

a. Measurement Methods

We conducted a field-based measurement campaign to enable calculation of ozone deposition fluxes in an urban area characterized by vegetation typical of an urban environment. The field campaign took place from 8/26/2017 to 9/7/2917 during a period characterized by high temperatures including periods of a major regional wildfire from 9/2/2017 to 9/7/2017 which reduced the dataset substantially. This wildfire persisted for nearly two months after the data collection period. The field campaign was designed considering the limitations of the surrounding site, instrumentation, and access to rooftop where sampling occurred. Importantly, site meteorology was considered, and determined the footprint over which fluxes were calculated. In this study, we measured ozone fluxes through the use of the atmospheric gradient method (AGM) (Edwards et al. (2005)) due to the limitations of commercially available ozone monitors that are not of high frequency. The AGM involves the measurement of ozone concentration at two heights, as well as the three orthogonal velocity fluctuations and the temperature fluctuations at the higher height. In the atmospheric gradient method, these data enable the calculation of time-averaged surface fluxes, typically averaged over a period of on the order of tens of minutes. From August $26^{\text {th }}$ to September $4^{\text {th }}$ instruments were deployed at a field site in Portland, OR. A sonic anemometer (Cambell Sci., CSAT3) and a UV absorption ozone monitor (2BTech, Model 106L) were used to measure fluxes.

i. Experimental Set up: 
The measurement site is a rooftop of a big-box retail store in north Portland, OR. The building includes a 37,000 sqft. rooftop that is split between green roof and white membrane, shown in figure 8 , with rooftop units (RTUs) operating at periodically. The green roof portion of the rooftop is split into three zones, extensive, where the substrate depth, the thickness of the soil that the vegetation is planted in, is less than 6 inches, semiintensive, where the depth is 6 to 12 inches and intensive where the depth is variable and undulating. The predominant species of plants on the rooftops were sedums, a type of succulent found generally in the northern hemisphere, but some of the sedums themselves were dead due to a dry summer season. The site is surrounded by streets, parking lots, vehicles, urban structures and urban vegetation. A major interstate highway (I-5) is present on the western side of the building, with traffic running to the northwest-southeast. This interstate highway is located approximately $1000 \mathrm{~m}$ away from the measurement location and its impact on air quality will be relatively minimal as pollutant levels are likely to reach urban background concentrations within approximately 500 meters (Karner et al. (2010)).

Immediately surrounding the rooftop there exists an area of urban vegetation and urban structures, which allows for studies of air flow over unalike surfaces. Importantly, urban surfaces are stratified by the direction to the rooftop: to the north and the west, there exists predominately urban greenery including large field north west of the rooftop location. To the south and the east, there exists large urban structures including parking lots where traffic related urban pollution may stem from. This stratification of urban surfaces enables surface fluxes to be apportioned more specifically into categories of urban surfaces, if the site meteorology is measured in conjunction with the parameter of interest. 
As will be discussed shortly, we select for periods where sustained winds were northwesterly, allowing for the surface flux measurements to a fetch of urban surfaces that predominantly consist of urban greenery.

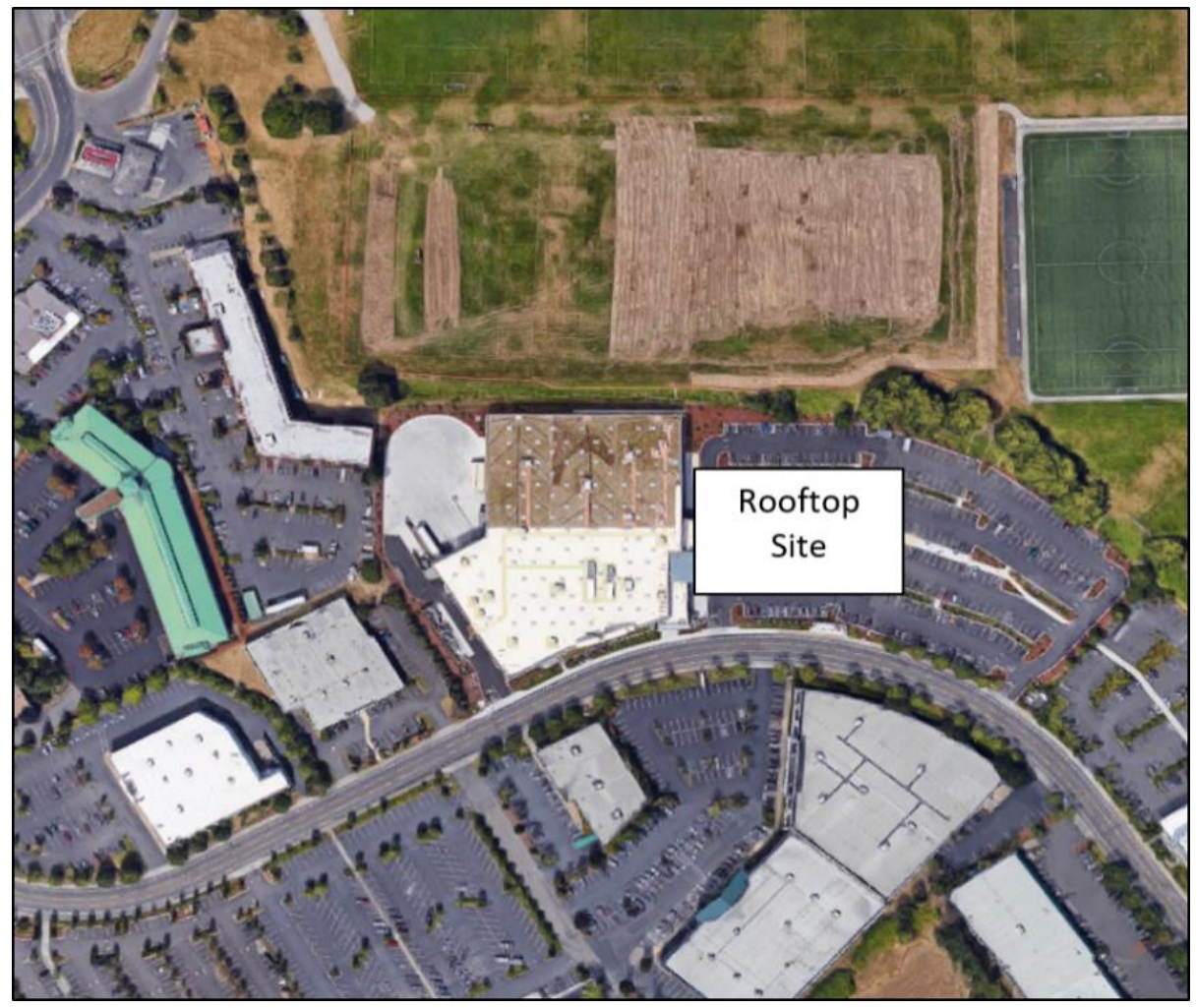

Figure 8: Measurement site and surrounding area.

Shown in Figure 9 is a schematic of the location of the experimental set-up relative to the rooftop used to determine the site fluid mechanics. A three-dimensional sonic anemometer (Cambell Sci., CSAT3) measured velocity fluctuations in the $\mathrm{x}, \mathrm{y}$ and $\mathrm{z}$ directions and temperature fluctuations at a measurement rate of $10 \mathrm{~Hz}$. The sonic anemometer is placed 7 meters above ground on top of the rooftop where the centre of axis in the $\mathrm{z}$ direction is 8 meters above ground. The instrument is oriented parallel to the edge of the rooftop where the y-direction is perpendicular to the back wall of the rooftop. The 
orientation is then aligned with compass direction, where the y-direction is associated with $303^{\circ}$ wind direction. A single $\mathrm{O}_{3}$ monitor (2B Tech, 106L) measured ozone concentration at two heights, $8.1 \mathrm{~m}$ and $7 \mathrm{~m}$ each minute. The monitor measured the ozone level every 10 seconds and recoded concentrations every minute. An automated Swagelok switching valve (SS-43ZF2-41DCZ) controlled by a Sestos timer and controller (B3S-2R-24) alternated between the heights at 10 min interval. The switching valve is a mechanical valve that took approximately 5 seconds to alternate between the two measurement heights. We installed a solenoid relief valve to reduce strain on the ozone monitor due to vacuum caused during the switching. A particle filter is used to remove the dust and water from the lines prior to entering the ozone monitor. All monitoring equipment and the switching valve were enclosed in a custom fabricated acrylic enclosure to protect the instruments from wind, rain, and heat. The enclosure is ventilated with a continuously operating computer fan. A heating mat is wrapped around the inlet lines to try to reduce the condensation in the lines but the morning periods still showed uncertainty induced by condensation. This method of measurement is known to have issues, similar studies have been performed where gradients in the morning were determined to be quite uncertain relative to other techniques (Keronen et al. (2003)). The concentration and meteorological data is averaged over a 30 -minute period, a common averaging period to relate the concentration data to the meteorological data, take at a higher frequency similar to work done by (Keronen et al. (2003)). 




Figure 9: Location of Measurement equipment relative to rooftop 


\section{ii. Determination of Concentration Gradient:}

Velocity fluctuations in the $\mathrm{x}, \mathrm{y}$ and $\mathrm{z}$ direction are used to determine the friction velocity similar to the approach employed by Bryan et al. 2012 whereby the shear stresses measured by a sonic anemometer is used to determine the wall shear stress and subsequently the friction velocity. Temperature fluctuations in combination with a velocity fluctuation in the $\mathrm{z}$ direction are used to determine heat flux over the rooftop. The friction velocity and heat flux are key components for the aerodynamic resistance used in the AGM. The flux associated with the AGM will be to a large area, that includes both urban greenery and urban structures. Therefore, we separated the data so that the flux can be attributed predominantly to the urban vegetation by selecting for winds between $273^{\circ}$ to $333^{\circ}$ which is prescribed to be areas in which the wind is over urban vegetation. Even though this data is selected for surface vegetation, the flux cannot be attributed fully to urban vegetation as that would only be met in ideal conditions, such as an infinite vegetated fetch. Therefore, the flux is determined in non-ideal conditions where it cannot be associated completely to the urban vegetation. The footprint associated with the flux is calculated using a software provided by Institute for Atmospheric and Climate Science ETH in Zurich, Switzerland and will be discussed in further detail in a later section.

The time-series ozone concentrations at the two heights were measured consecutively (i.e., alternating between the upper and lower measurement height shown in figure 10). As a result, the ozone concentrations data at the two heights required processing to align the time-series data to a common measurement time for each 30 -minute period. A linear interpolation where a midpoint prediction is taken from two time-steps for the 
concentration at the lower height is used to relate to the concentration at upper height. This linear interpolation is similar to the approach presented by Stutz et al. (2002). Another approach from the same study, gradients due by fast temporal fluctuations were ignored. Measurements of gradients greater than $35 \%$ from measurement to measurements as such fast changes in concentrations lead to concentration spikes that unrealistic fluxes of ozone.

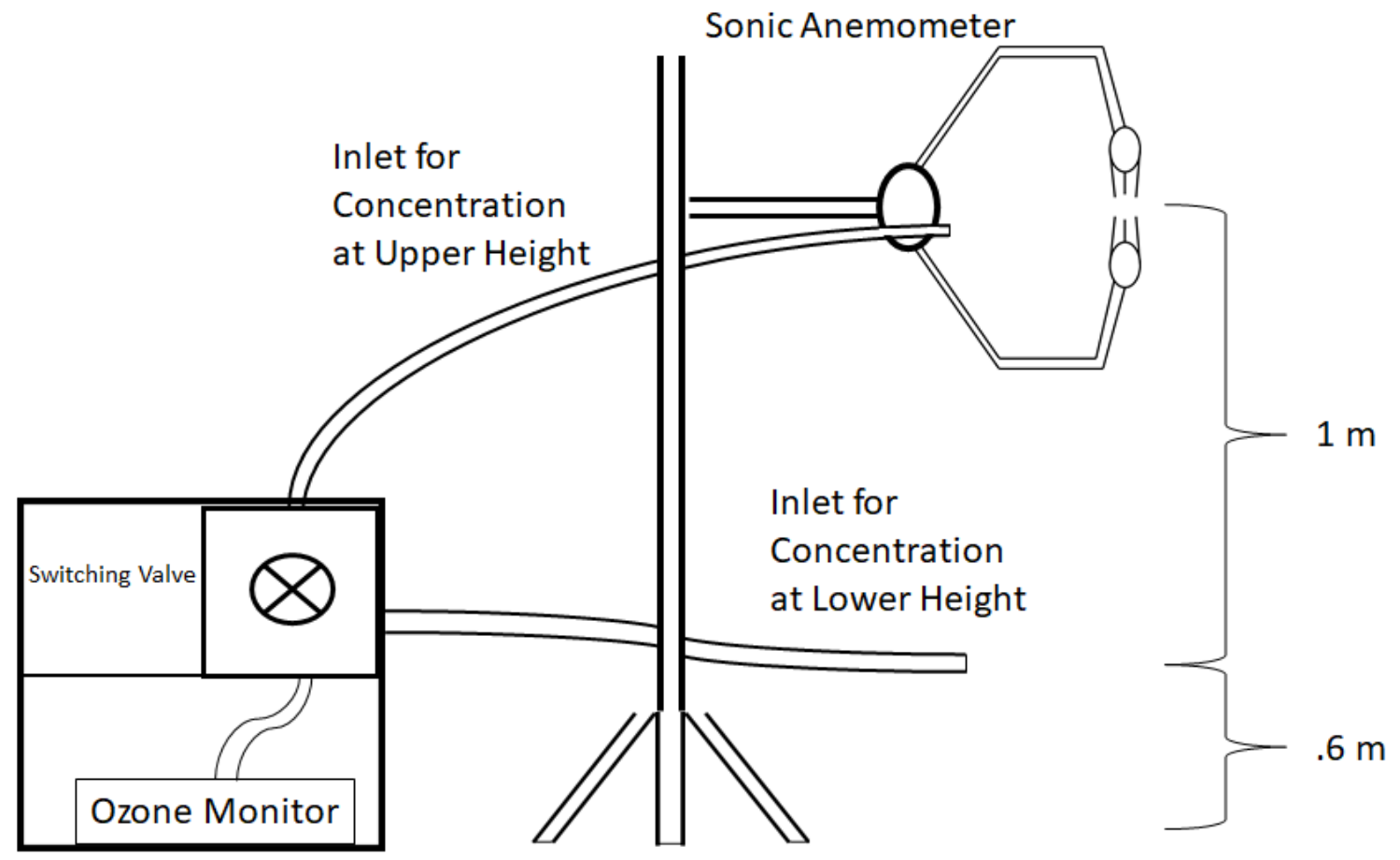

Figure 10: Measurement equipment description

Stationarity for momentum is evaluated using the same process as outlined by Velasco et al. (2009). The criterion used for stationarity is to determine if there is a difference between the average of fluxes of 6 continuous 5 -minute periods and a 30 -minute average during the same period. If the difference is less than $30 \%$ the data is considered 
high quality (Aubinet et al. (2000)). In our case, all data is under $30 \%$ and therefore is considered high quality.

\section{iii. Flux Footprint Calculation:}

In a practical sense, a flux measured by an instrument is not directly associated to the location of the instrument but instead a region upwind of the instrument. This flux footprint is a function of a few parameters, including the atmospheric boundary layer height, the measurement height of the instrument, and local meteorological conditions. The instrument height and meteorological conditions are all measured from the field. The atmospheric boundary layer height is derived using an empirical relation developed by Nieuwstadt (1981). The boundary layer height is dependent on the thermal stratification of the atmosphere, for neutral and stable boundary layers, the height is not time dependent, but for unstable boundary layers, the height of the boundary layer is dependent on the height of the boundary layer during the previous averaging period. A diagnostic equation, that is an equation dependent on atmospheric scaling parameters, for the height of the stable boundary layer can be shown as (Seibert et al. 2000):

$$
h_{a b l}=\frac{L_{*}}{3.8}\left(-1+\sqrt{1+2.28 \frac{u_{*}}{f * L_{*}}}\right)
$$

Where $L_{*}$ is the Obukhov length $(\mathrm{m}), u_{*}$ is the friction velocity $(\mathrm{m} / \mathrm{s})$ and $f$ is the Coriolis force taken at the latitude of the measurement location.

A slightly different diagnostic formulation is a given for the height of the unstable boundary layer (Seibert et al. (2000)): 


$$
\frac{\partial h_{a b l}}{\partial t}=\frac{(1+2 A) * w_{*}{ }^{3}+2 B * u_{*}}{\gamma_{\theta} \beta h_{a b l}{ }^{2}}
$$

Where A and B are derived empirically by Driedonks (1981,1982b) as 0.4 and 5 respectively. $w_{*}$ is the surface heat flux, given as $w_{*}=\frac{g}{T} *\left(\overline{w^{\prime} T^{\prime}}\right) * h_{a b l}, \gamma_{\theta}$ is the dry adiabatic lapse rate taken as $9.8 \frac{K}{\mathrm{~km}}$, and $\beta$ is the buoyancy parameter, taken as $\frac{\mathrm{g}}{\mathrm{T}}$.

The flux footprint is computed through a model developed by N. Kljun at the Institute for Atmospheric and Climate Science ETH in Zurich, Switzerland, where the input parameters are field measurements as well as the atmospheric boundary layer height and the output is the flux footprint, both 2D and 3D versions.

\section{b. Rooftop advection-diffusion model development}

The measured parameters from the field can now be applied to an advectiondiffusion model to better understand the impacts of different variables to rooftop ozone deposition. A parametric study is performed using these values independently of each other and a sensitivity analysis is used to understand the impacts and the direction of the impacts. To understand the model, we will look at the governing equation again:

$$
\frac{\partial \overline{C_{0}}}{\partial t}=-\bar{u} \frac{\partial \overline{C_{0}}}{\partial x}-\frac{\partial}{\partial z} K_{m} \frac{\partial \overline{C_{0}}}{\partial z}-\left[\sum_{i=1}^{n} \frac{v_{d i} * A_{i}}{V}\right] * \overline{C_{0}}
$$

Where the terms have been defined earlier in equation 39.

This governing equation of the transport model is a second order non-linear partial differential equation that does not have a specific analytical solution. A numerical approach, specifically, explicit finite difference methods were instead used to solve for the 
concentrations as a function of time and space. This equation has both first and second order spatial terms as well as a first order temporal term. For time discretization, a backwards difference method to calculate the concentration at the current time-step based on the previous time-step is used:

$$
\frac{\partial \overline{C_{0}}}{\partial t}=\frac{{\overline{C_{0 x, z}}}_{t}^{t}-{\overline{C_{0 x, z}}}_{-\Delta t}^{\Delta t}}{\Delta t}
$$

Since this is a first order differential term, this difference method has a first order error. The error can be found by expanding the original partial differential term through Taylor expansion. After rearranging the expanded terms:

$$
\frac{\partial \overline{C_{0}}}{\partial t}=\frac{{\overline{C_{0}, z}}^{t}-{\overline{C_{0}}}_{x, z}^{t-\Delta t}}{\Delta t}+\left(\frac{1}{2 !}\right) \frac{\partial^{2} \overline{C_{0}}}{\partial t^{2}}(\Delta t)+\left(\frac{1}{3 !}\right) \frac{\partial^{3} \overline{C_{0}}}{\partial t^{3}}\left(\Delta t^{2}\right)+\cdots
$$

As $\Delta t$ decreases, the higher order terms are negligible in comparison to the first order term. The truncation error, which defines the accuracy of the scheme, is of the order of $\Delta t$ shown as $O(\Delta t)$.

$$
\frac{\partial \overline{C_{0}}}{\partial t}=\frac{{\overline{C_{0}, z}}^{t}-{\overline{C_{0 x, z}}}^{t-\Delta t}}{\Delta t}+O(\Delta t)
$$

Similarly, a backwards difference method is used to describe the advective term:

$$
\frac{\partial \overline{C_{0}}}{\partial x}=\frac{{\overline{C_{0 x, z}}}_{t-\Delta t}-{\overline{C_{0}}}_{x-\Delta x, z}^{t-\Delta t}}{\Delta x}+O(\Delta x)
$$

For the diffusive terms, a three-point central scheme is applied for second order partial derivatives. After Taylor expansion of the second order differential term, the truncation error for this term is of the order of $\Delta z^{2}$ : 
$\frac{\partial^{2}{\overline{C_{0}}}^{2}}{\partial z^{2}}=\frac{\left.\left.{\overline{\left(C_{0}, z+\Delta z\right.}}_{t-\Delta t}-{\overline{C_{0}}}_{x, z}^{t-\Delta t}\right)-{\overline{\left(C_{0}\right.}}_{x, z}^{t-\Delta t}-{\overline{C_{0}}}_{x, z-\Delta z}^{t-\Delta t}\right)}{\Delta z^{2}}+O\left(\Delta z^{2}\right)=\frac{\left.{\overline{\left(C_{0}\right.}}_{x, Z+\Delta z}^{t-\Delta t}-2{\overline{C_{0}}}_{x, z}^{t-\Delta t}+{\overline{C_{0}}}_{x, Z-\Delta z}^{t-\Delta t}\right)}{\Delta z^{2}}+O\left(\Delta z^{2}\right)$

Eq. 52

Substituting these terms into Eq. 18, combing like terms and rearranging:


${\overline{C_{0}}}^{t-\Delta t}$

Eq. 53

Finally, a non-uniform grid spacing is used for appropriately apply the model. The grid is discretized non-uniformly so that the treatment of the roughness sublayer (RS) occurs in one layer while the inertial surface layer is split into multiple layers The RS is a layer in which the constant flux term does not hold, instead a proportionality term, $v_{d i}$, must be used characterize the downward flux (Wu et al. 2015). Therefore, a single layer is taken to describe transport in the RS. The height of the RS is assumed to be somewhere between 2 to 5 times the height of the roughness elements, for this model, we have taken it to be 3 times the height of the roughness elements (Rotach (1999)) To simplify the discretization further, the area for deposition is assumed to be the entire surface area of the control volume, which allows for the reduction of the bulk deposition term.

$$
\frac{v_{d i} * A_{i}}{V}=\frac{v_{d i}}{h}
$$

Where $h$ is the height of the control volume.

The model is run until steady state, which is taken as $\frac{2}{10} \frac{p p b}{\min }$ (Coleman et al. (2008)) and varied from run to run depending on the input parameters. A grid sensitivity 
study is performed so that we can define an effective grid size to minimize the errors associated with a grid while still being efficient enough to save computational time. The grid chosen is $125 \times 125$ nodes.

\section{i. Parametric Study:}

A parametric sensitivity study is performed using measured parameters from the field; green roof fetch length, green roof element height, friction velocity, heat flux and surface resistance. The fetch lengths varied from 1, 3, and 5 meters while the element height varied from $0.065,0.13$ and 0.20 meters. Friction velocity, heat flux is taken from the $10^{\text {th }}$, $50^{\text {th }}$ and $90^{\text {th }}$ percentiles of measured values as shown in Table 1 . Friction velocity, and heat flux in combination with the roughness sublayer height is used to calculate the aerodynamic and boundary layer resistance. The surface resistance is taken from the value calculated from the data collected at the field site in the Summer of 2017 at the $10^{\text {th }}, 50^{\text {th }}$ and $90^{\text {th }}$ percentiles. Summing of the resistance terms gives the inverse of the deposition velocity used in the model in the roughness sublayer. The model is run to steady-state and a sensitivity analysis is used to assess the model response to changes in measured parameters. A base case is set as either the middle value or the $50^{\text {th }}$ percentile of the measured values, high and low cases were changed independently from the measured base case.

\begin{tabular}{|c|c|c|c|c|}
\hline $\begin{array}{c}\text { Fetch } \\
\text { Length }\end{array}$ & $\begin{array}{c}\text { Element } \\
\text { Height }\end{array}$ & $\begin{array}{c}\text { Friction } \\
\text { Velocity }\end{array}$ & $\begin{array}{c}\text { Heat } \\
\text { Flux }\end{array}$ & $\begin{array}{c}\text { Surface } \\
\text { Resistance }\end{array}$ \\
\hline 1.00 & 0.13 & 10th & 10th & 10th \\
\hline 3.00 & 0.07 & 50th & 50th & 50th \\
\hline 5.00 & 0.20 & 90th & 90th & 90th \\
\hline
\end{tabular}

Table 1: The variation in different variables for parametric study 
The column of concentration at the edge of the control volume is assumed to be the concentration gradient entering the roof top unit. The concentration at a height of 0.75 meters, the height at which the RTU inlet is located, in the column concentration is used as the value that will be compared when performing the sensitivity analysis. Sensitivity indices, $S I_{C_{0.75}}$, and subsequently the elasticity indices, $E I_{C_{0.75}}$, were performed as follows (Jain and Singh):

$$
\begin{aligned}
& S I_{x-C_{0.75}}=\frac{C_{0.75, \text { S.S. }}\left(x_{0}+\Delta x\right)-C_{0.75, \text { S.S. }}\left(x_{0}-\Delta x\right)}{2 \Delta x} \\
& E I_{x-C_{0.75}}=\frac{x_{0}}{C_{0.75, \text { S.S. }}\left(x_{0}\right)} S I_{x-C_{0.75}}
\end{aligned}
$$

Where $x$ is the input parameter, $x_{0}$ is the base case parameter and $\Delta x$ is the change in the input parameter. The elasticity index, $E I_{C_{0.75}}$, shows how a single parameter affects the $C_{0.75 \text {,S.S. }}$ meter, i.e. if the $E I_{C_{0.75}}$ is positive, the relationship between the variable and the concentration is

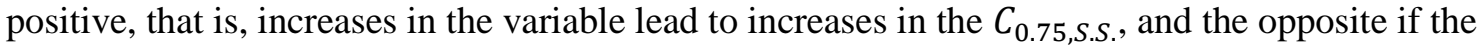
$E I_{C_{0.75}}$ is negative; increases in the variable lead to decreases in the $C_{0.75, \text { S.S. }}$.

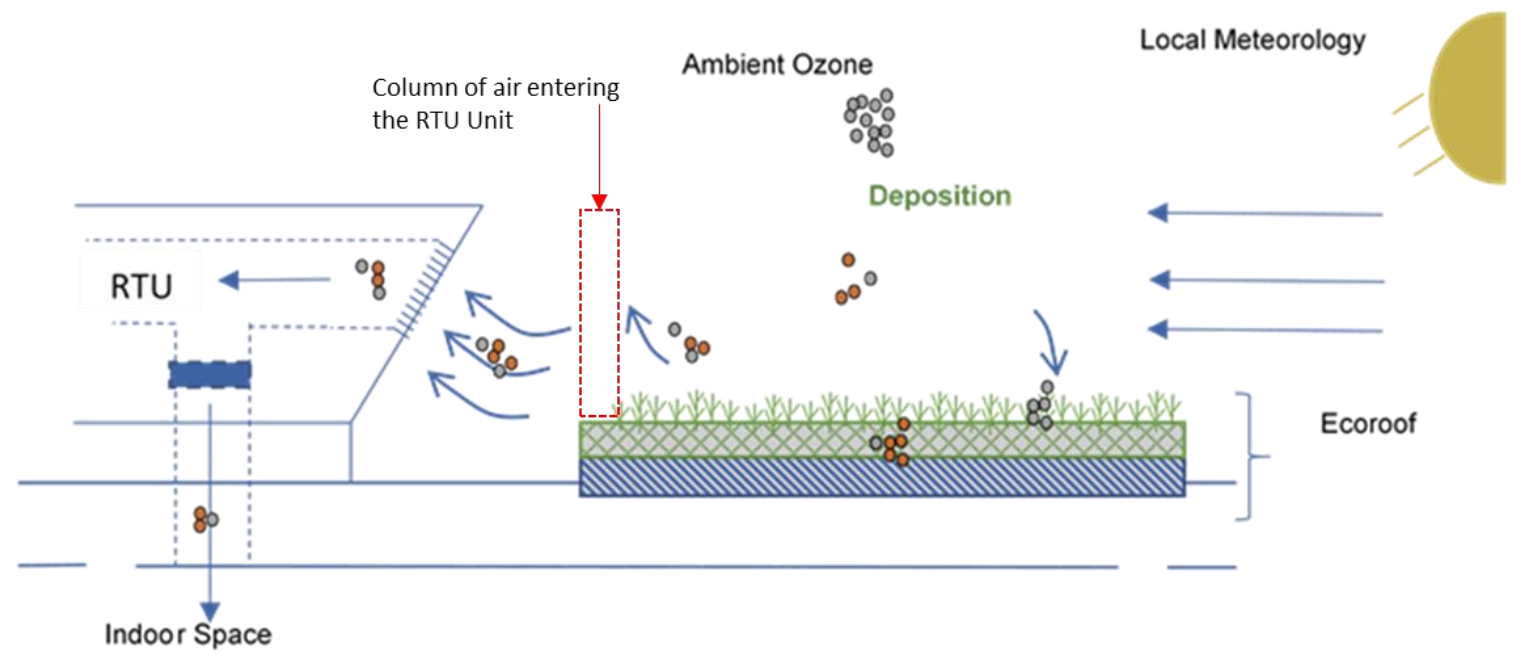

Figure 11: Model description with the assumed inlet column shown 


\section{Field Study Results and Analysis}

In this section, the data collected during the field campaign is analyzed. The atmospheric gradient method is used to calculate the fluxes from the concentrations at two heights above the rooftop, this data is then used to calculate the deposition velocity.

Shown in Figure 12 and 13 is the concentration and meteorological data from the ozone monitor (2BTech, Model 106L) and the sonic anemometer (Cambell Sci., CSAT3). These data are also compared with ozone concentration data collected at the local department of environmental quality (DEQ). The concentration profile during the two-day period reported by the DEQ matched well with the field data, with an r-squared value of .93. The DEQ data had periods in which the concentration is not reported most likely due to quality or maintenance issues at the DEQ data collection site. Nevertheless, this comparison serves as a screening-level comparison to assure that the data collected at the field site is of similar magnitude and experience similar trends as those reported by DEQ and the Federal Reference Method ozone monitoring employed at that site.

The ozone profile develops in a diurnal pattern, with higher concentrations in the daytime and lower concentrations at night which is generally the behavior of ozone. This is due to the interaction of oxides of nitrogen, hydrocarbons and sunlight, and as there is higher sunlight during the day, the concentration of ozone is higher during the daytime. Another thing to note is the difference in the concentration at the higher and lower locations. During the first day, there does not appear to be a substantial difference between the upper and lower concentrations, but during the second day, there is an extended period in which there is a large concentration difference. This difference can be a sign of a flux 
that occurs because ideal conditions have been met for ozone deposition to vegetated surfaces. During morning periods, the reported concentrations at the upper and lower sampling heights are highly variable in magnitude, which is most likely due to the monitor itself. We speculate that the 2Btech Ozone monitor could have been affected by high relative humidity or possible condensation in the lines during the morning periods which may be the cause for the variability. We attempted to heat the sampling inlets to remedy this but were not able to resolve the high variability in those periods.

Figure 13 shows the micrometeorological data during the same period of collection. The friction velocity is a measure of the shear above the rooftop and the heat flux is a descriptor of the buoyancy of the atmosphere. These two forces also follow a diurnal profile above the rooftop. As the sun heats surfaces, meteorological forces increase and subsequently wind and buoyancy forces increase. This trend is observed in measurements of both the friction velocity and heat flux, with maximum values of each occurring in the early to mid-afternoon of each day.

The friction velocity and heat flux are input parameters to the Obukhov length, a key variable in determining the behavior of the atmosphere. During the afternoon period on both days, the atmosphere is unstable, but during late evenings, nights and early mornings, the atmosphere is stable or neutral. This is most due to the direction of heat flux, as a parcel of air rises, if the heat flux is negative, that parcel of air is cooler than its surroundings, allowing it to sink. If it is unstable, the parcel of air will keep increasing as it is warmer than its surrounding environment. The friction velocity is also a key parameter in determining the aerodynamic and boundary layer resistance. As the friction velocity 
increases, the respective resistances decrease, meaning that the shear is allowing for more mixing. 


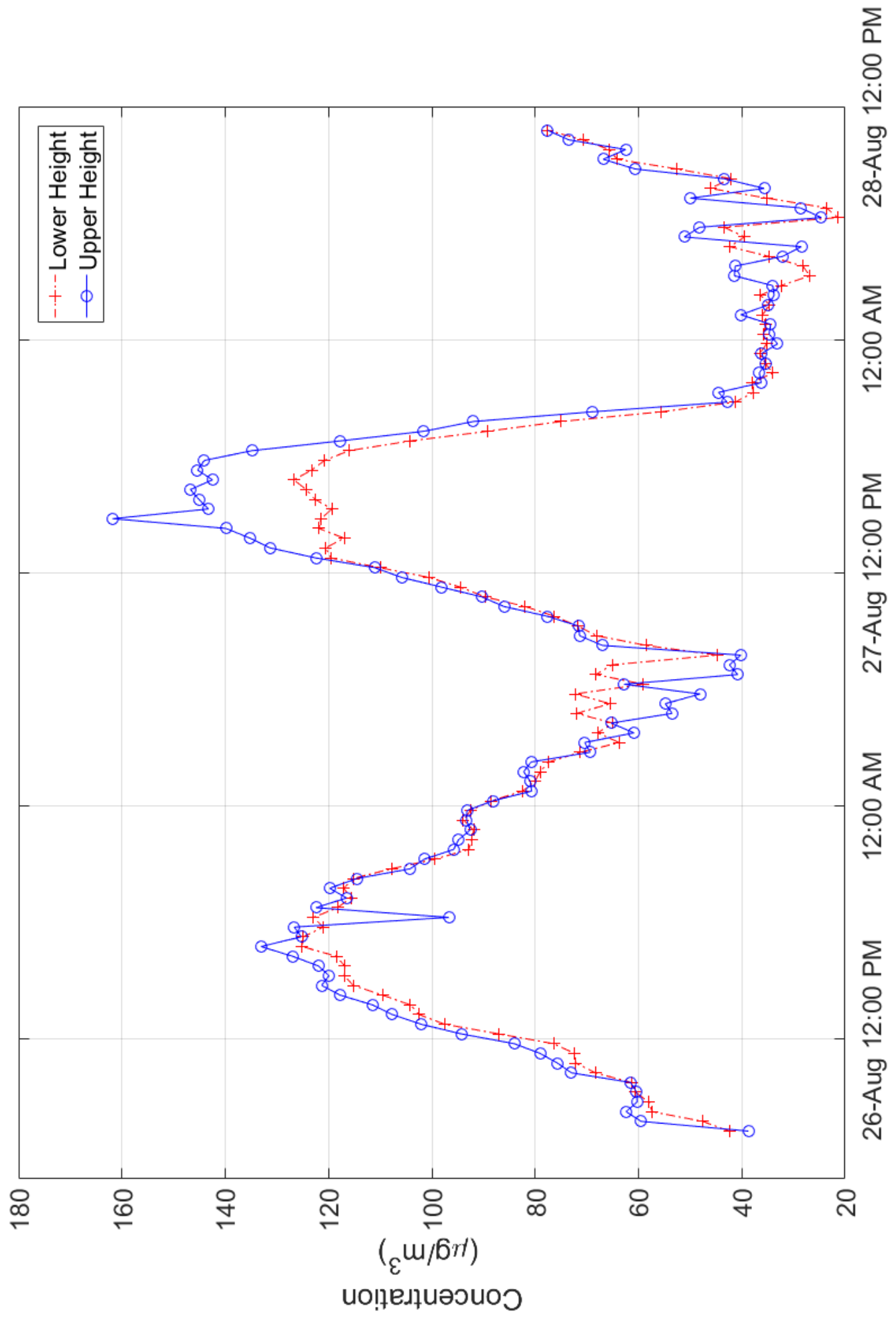

Figure 12: Concentration profile at two heights 


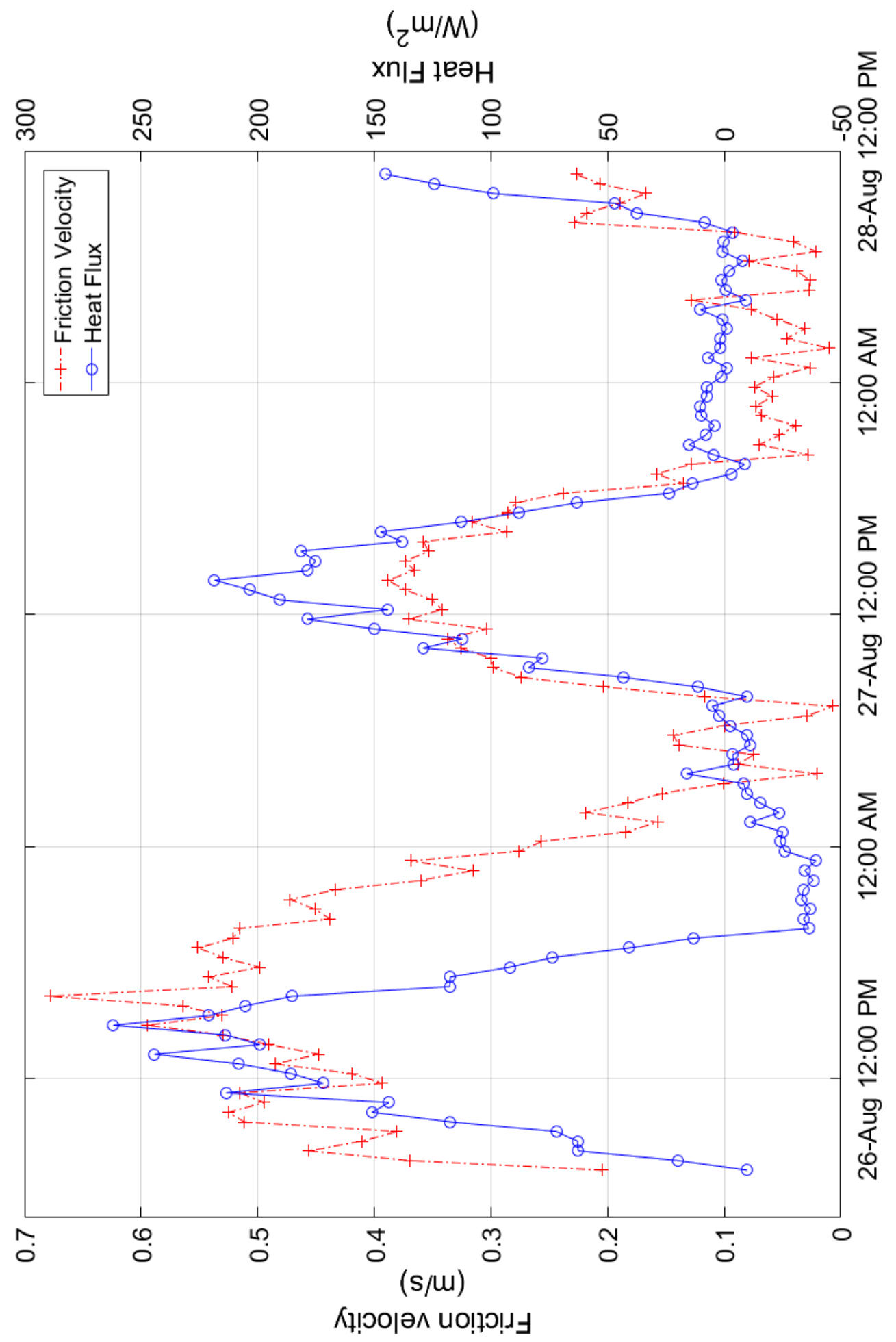

Figure 13: Friction velocity (red) and heat flux (blue) determined using the CSAT3 Sonic Anemometer 
Figure 14 (top) shows the wind direction and relative frequency of the meteorological field data. The directions were measured using the sonic anemometer. The data showed that although most of the measured period is over the vegetated area, there are still periods in which the data cannot be predominantly contributed to flow over vegetated surfaces. Therefore, the data is selected so that the flux can be attributed to vegetated surfaces, from $276^{\circ}$ to $336^{\circ}$ in compass wind direction. The resulting wind rose is shown in Figure 14 (bottom). Data is also selected so that any changes in concentration gradient greater than thirty-five percent is ignored as gradients greater than that from measurement to measurement can lead to unrealistic flux measurements (Stutz et al. 2002).


Figure 14: Wind rose of the data before selecting for predominantly vegetated surfaces (top) and after selecting for vegetated surfaces (bottom) 
The application of the selection criteria maintains approximately 47 percent concentration and meteorological profile shown in figure 15, but the periods of high ozone concentration during day times is maintained. From this data, a flux can be calculated which will represent the flux to the predominantly vegetated surfaces present to the northwest of the building rooftop. Also noteworthy, is that there were some periods in which the concentration at the lower height is higher than the concentration at the higher height. We speculate that these issues can be attributed to moisture issues with the instrument in early morning periods. Water vapor absorbs weakly in the same range as ozone that the monitors are tuned to detect $(254 \mathrm{~nm})$ (Wilson 1997). As the lower monitoring height is in closer proximity to the surface, it is possible that this sampling height experienced greater water vapor concentrations in the early morning, leading to higher levels than those at the upper monitoring height. This data is included for completion, with the understanding that the flux will be negative during these periods, which is not physically representative of the possible fluxes at the site.

Figure 16 shows cross-wind integrated flux footprint using the software provided by Kljun at the Institute of Atmospheric and Climate Science in Zurich, Switzerland. The estimated footprint is over-layed over an image taken from google maps, showing the $80^{\text {th }}$ percentile of the flux can be attributed to vegetated surfaces only. 

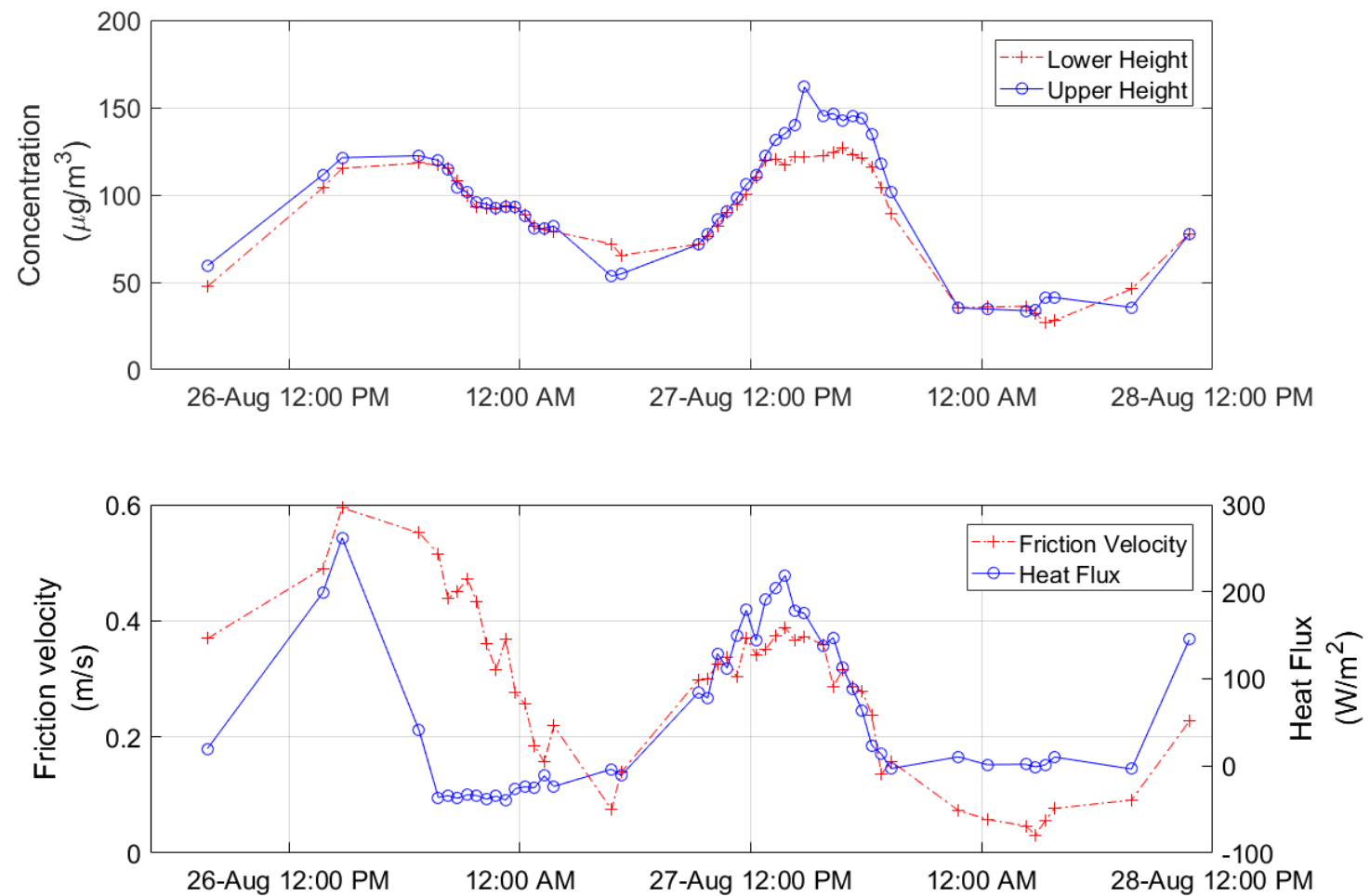

Figure 15: Concentration and meteorological data after application of selection criteria

\begin{tabular}{|r|}
\hline 10th percentile \\
-20 th percentile \\
-30 th percentile \\
-40 th percentile \\
-50 th percentile \\
60th percentile \\
-- 70th percentile \\
-80 th percentile
\end{tabular}



Figure 16: Flux Footprint of the concentration and meteorological data after applying selection criteria 


\section{a. Calculation of ozone deposition velocities}

The concentration flux can be calculated using the atmospheric gradient method given in equation 19, from the two heights above the rooftop. From this flux, a deposition velocity can be calculated for the upper height above the rooftop.

Figure 17 shows the deposition velocity over the two-day period of measurement. During the first day, the distinction between the upper and lower concentrations is small, and that is seen in low deposition velocity values. On the second day, where the concentration at the higher measurement location is much higher than the lower measurement location, there is a very high flux and therefore a very high deposition velocity. In the early morning periods, the deposition velocity is negative, which is improbable but expected most likely due to issues with instrumentation and moisture. The mean deposition velocity is $0.7 \mathrm{~cm} / \mathrm{s}$ which is approximately the range is expected for deposition over land. Hauglustaine et al. (1998) estimated deposition over oceans, land and snow as $0.07,0.50$, and $0.07 \mathrm{~cm} / \mathrm{s}$ respectively. The $10^{\text {th }}, 50^{\text {th }}$ and $90^{\text {th }}$ percentile of deposition velocity is $.002 \mathrm{~cm} / \mathrm{s}, .48 \mathrm{~cm} / \mathrm{s}$ and $1.5 \mathrm{~cm} / \mathrm{s}$ respectively. The $90^{\text {th }}$ percentile is very high in comparison to what's given in prior work. This could be due to some phenomena occurring with the plants themselves or it could be due to the AGM applied, which is known to overestimate deposition in the roughness sublayer by approximately a factor of 2 (Wu et al. 2015). Although the $90^{\text {th }}$ percentile may be abnormally high, there exists precedence where the deposition velocities of foliage have been measured to be in the range of the $90^{\text {th }}$ percentile (Fowler et al. (2001)) 
From the deposition velocity, the surface resistance can be parsed out using the resistance uptake theory. The aerodynamic and boundary layer resistance can be calculated using the meteorological field measurements and what remains is simply the surface resistance. Figure 18 shows the total resistance throughout the two-day period broken down into the two transport and surface resistance. Negative surface resistances occurred because the aerodynamic and boundary layer resistances calculated from the meteorological measurements were greater than the deposition velocity. These periods and periods of negative concentration flux, which also leads to negative resistances, were neglected as they are indicative of moisture issues with the instrument. 


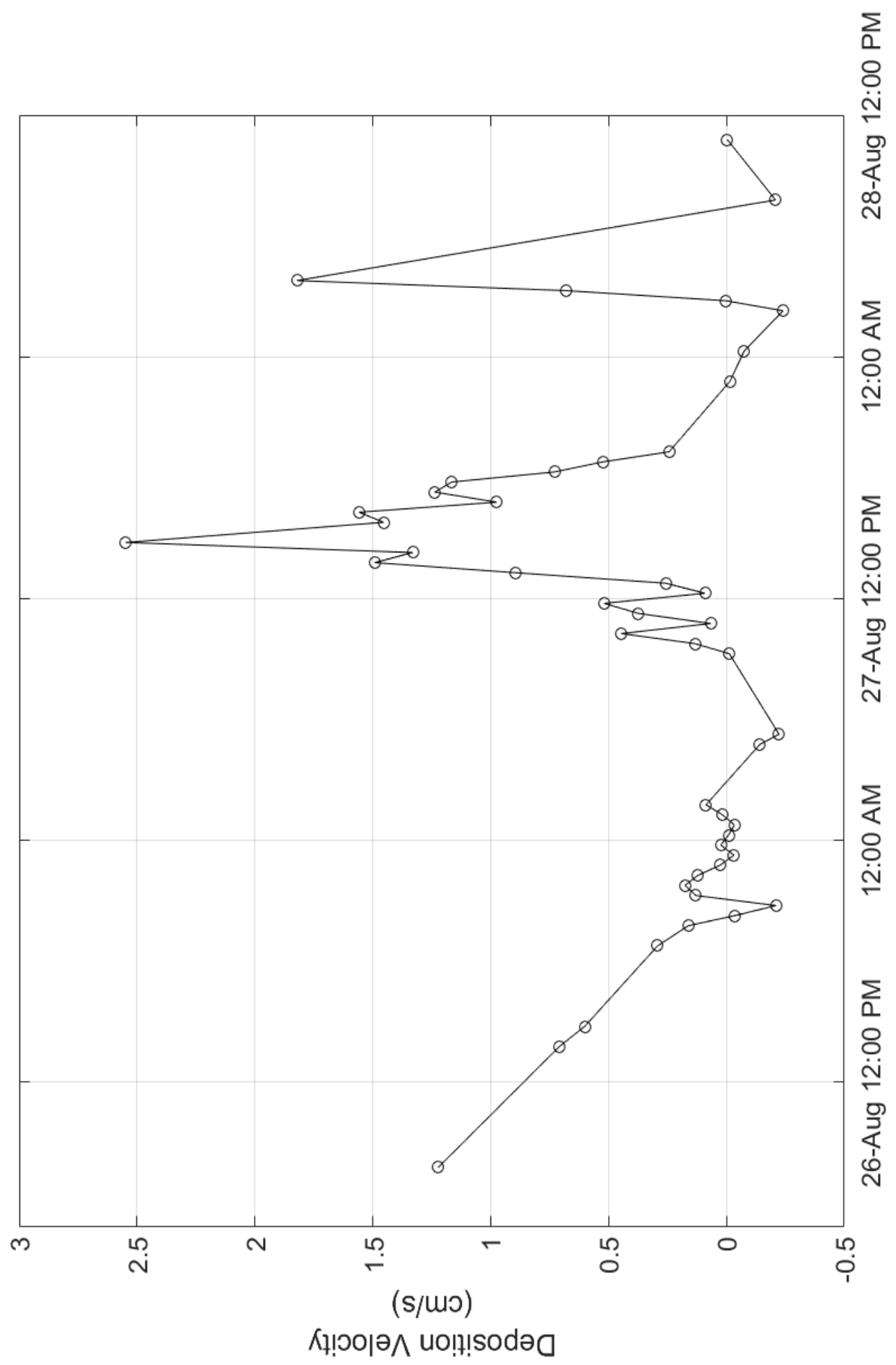

Figure 17: Deposition velocities calculated using the AGM over the two-day measurement period 


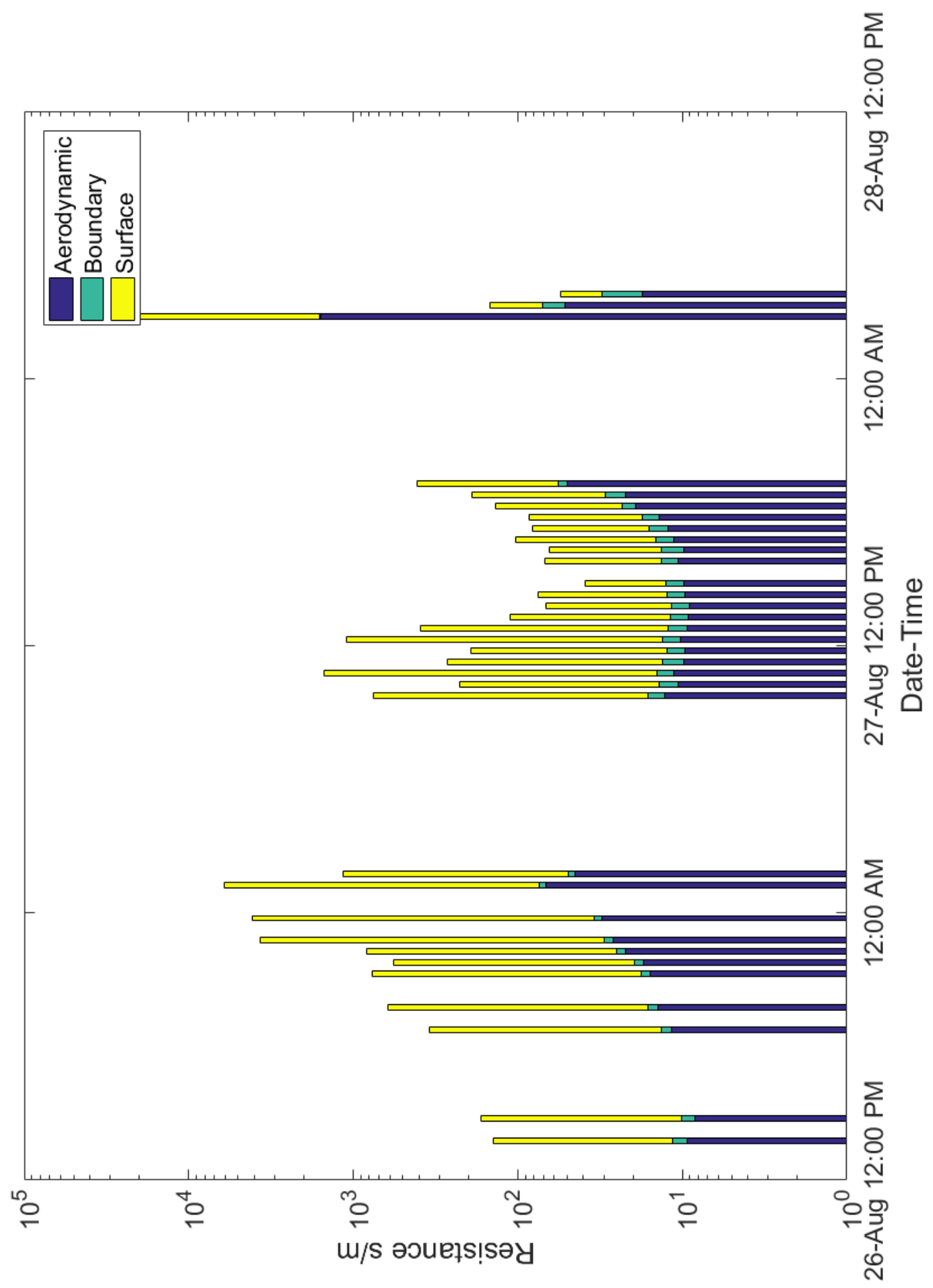

Figure 18: Total Resistances decoupled to their transport and surface resistances over the twoday measurement period. Intervals in which there was negative resistances were ignored. 
Figure 19 shows the relative contribution of all resistances. Surface resistance is on average an order of magnitude greater than aerodynamic and boundary layer resistance, meaning it is the dominant resistance, but in periods of low surface resistance, high deposition occurs. On the second day, where high deposition velocity is seen, the aerodynamic resistance and surface resistance are the lowest relative to the prior days. Figure 19, it can be noted that the surface resistance is the rate limiting step in the deposition process as it represents the largest portion of the total resistance. It should be noted that any error associated with the calculation of the aerodynamic and boundary layer resistance is apportioned to the surface resistance, so if for any reason the aerodynamic and boundary layer resistance are underestimated, it will simply get accounted for at the surface. 




Figure 19: Transport and Surface Resistances as a function of the overall resistance in percentage.

A cumulative distribution function (CDF) allows for the understanding of the relationship between the observed magnitudes of the resistances and the probabilities that a given magnitude or less is observed. Shown in Figure 20, the boundary layer and aerodynamic resistance are between $2.1 \mathrm{~s} / \mathrm{m}$ to $13.7 \mathrm{~s} / \mathrm{m}$ and $9.3 \mathrm{~s} / \mathrm{m}$ to $67.25 \mathrm{~s} / \mathrm{m}$ for the $10^{\text {th }}$ and $90^{\text {th }}$ percentile respectively.

A surface resistance CDF (Figure 21), shows the impact of the vegetated surface and the probability of the resistance to occur. The $10^{\text {th }}$ and $90^{\text {th }}$ percentile of the resistances are approximately $54.8 \mathrm{~s} / \mathrm{m}$ and $3692.9 \mathrm{~s} / \mathrm{m}$ respectively with a median value of $195.3 \mathrm{~s} / \mathrm{m}$. The $10^{\text {th }}$ and $50^{\text {th }}$ percentile of the resistance is of similar scales to prior work presented by 
Weseley et al. (1988) for midsummer with lush vegetation in various land types including urban, agricultural and various forests. The $90^{\text {th }}$ percentile is of the same scale as water, salt and fresh and non-forested wetland. It noteworthy that the conditions of the plants on the rooftop and surrounding area may have been drier than reported by Weseley but the comparison can be still made because the temperature and land conditions were the same. The variation in the magnitude resistance is most likely due to biological processes brought on by the period of day, soil moisture conditions or the local meteorological conditions. Ideally, ozone deposition to vegetated surfaces requires various processes that allow for uptake, which is not always met. In some periods, such as the time periods in which $90^{\text {th }}$ percentile and above of surface resistance occur, there is no uptake to the surface, which is most likely due to biological conditions not allowing the vegetated surface to uptake ozone. Conditions that allow for uptake have been investigated by Weiser et. al. (2002) and showed that the uptake of ozone depended on the plant stomatal conditions, the interaction with the mesophyll inside the plant as well as the outer surface and soil resistances. There is also a seasonal dependence on vegetation, as plants are more conducive to uptake of ozone in different periods of the year, presumably because of seasonal dependence of the biological mechanisms described previously. Further exploration of the contributors to surface resistances for a common class of plants used on green roofs, sedums and succulents, will be further investigated using chamber set-ups. 

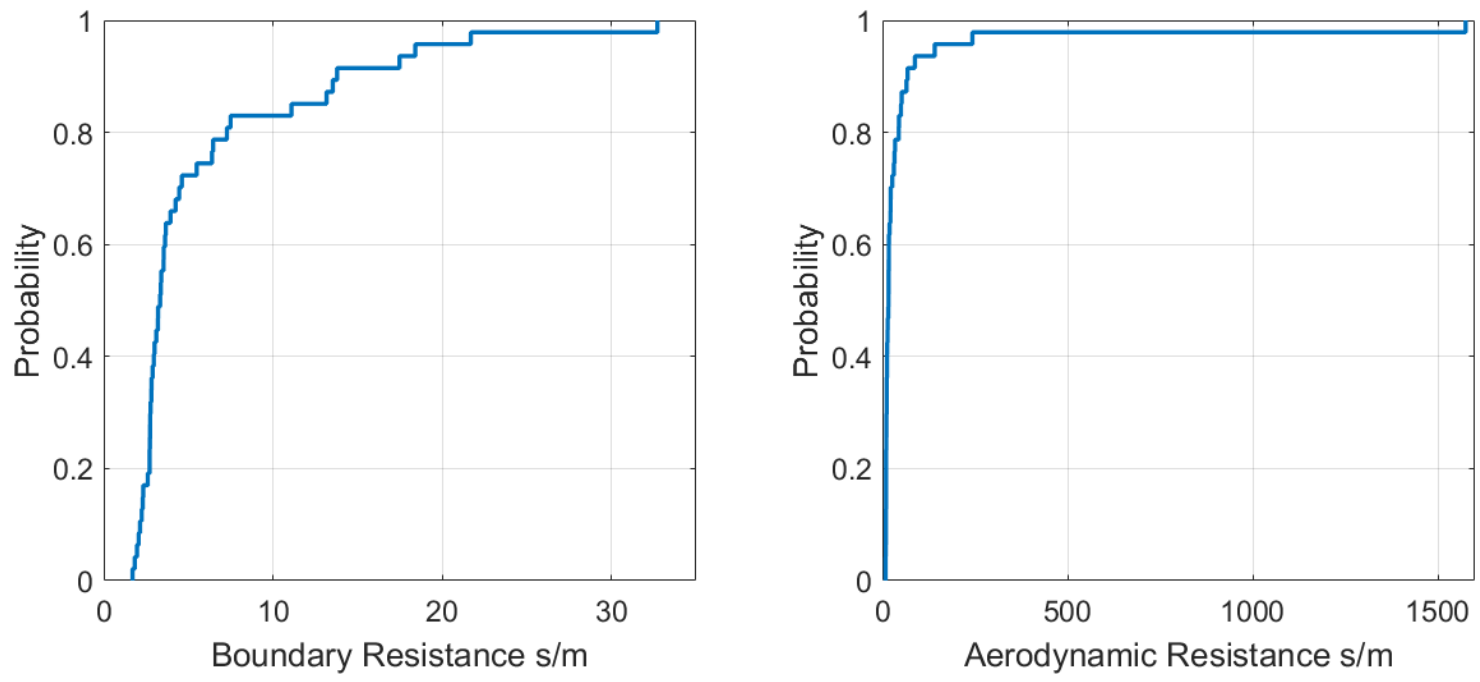

Figure 20: Cumulative Density Function of the aerodynamic and boundary layer resistance 


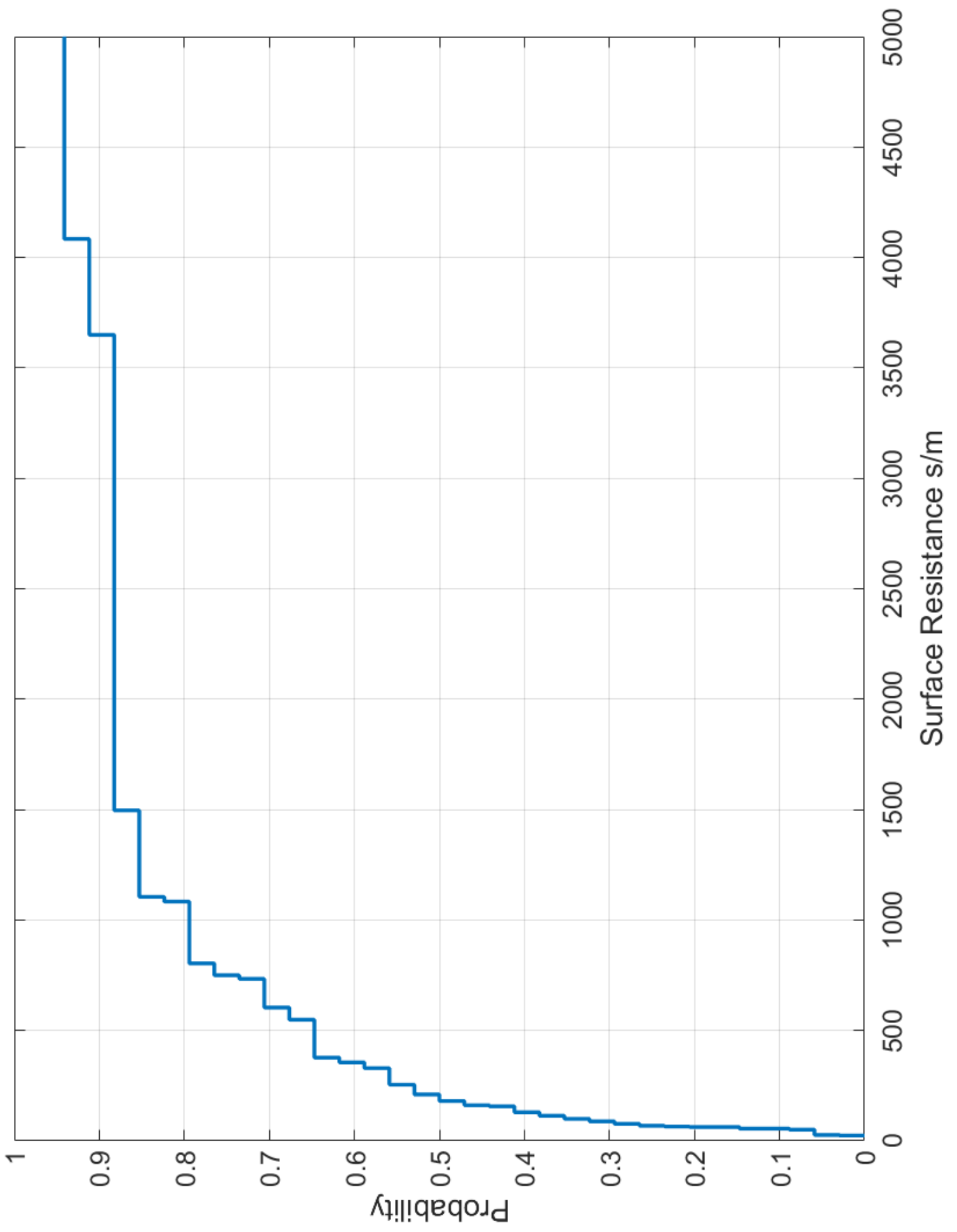

Figure 21: Cumulative Density Function of the surface resistance 


\section{Model Results and Analysis}

Part of the aim of this study is to understand the impact of the measured values in the field at the rooftop scale. As mentioned earlier, the parameters measured represent a footprint that includes the green roof as well as the surrounding vegetation. Now we apply those parameters to understand the effect on ozone deposition at just the rooftop scale. A parametric study of pollutant transport across the green roof is performed on the transport equation. If we recall the model and look at the transport equation:

$$
\frac{\partial \overline{C_{0}}}{\partial t}=-\bar{u} \frac{\partial \overline{C_{0}}}{\partial x}-\frac{\partial}{\partial z} K_{m} \frac{\partial \overline{C_{0}}}{\partial z}-\left[\sum_{i=1}^{n} \frac{v_{d i} * A_{i}}{V}\right] * \overline{C_{0}}
$$

Where $\overline{C_{0}}$ is the mean ozone concentration, $\bar{u}$ is the mean velocity, $K_{m}$ is the eddy diffusivity coefficient for mass, $v_{d i}$ is the deposition velocity, $A_{i}$ is the area of the deposition surface, $V$ is the control volume.

And the discretized version of it is:

$$
\begin{aligned}
& \quad \bar{C}_{0, z}^{t}=\left[-\bar{u} \frac{{\overline{C_{0, z}}}_{x-\Delta t}^{t-}-{\overline{C_{0}}}_{x-\Delta x, z}^{t-\Delta t}}{\Delta x}-K_{m} \frac{\left.{\overline{\left(C_{0, Z+\Delta z}\right.}}_{x-\Delta t}^{t-2 \bar{C}_{0, z}^{t}+\Delta t}+{\overline{C_{0}}}_{x, z-\Delta z}^{t}\right)}{\Delta z^{2}}-\left[\sum_{i=1}^{n} \frac{v_{d i} * A_{i}}{V}\right] * \bar{C}_{0 x, z}^{t-\Delta t}\right](\Delta t)+ \\
& {\overline{C_{0}}}_{x, z}^{t-\Delta t}
\end{aligned}
$$

Where the mean velocity and eddy diffusivity profiles were generated from Monin-

Obukhov Similarity Theory:

$$
\left.\bar{u}=\frac{u_{*}}{k} \ln \left(\frac{z-d}{z_{o}}\right)-\psi(\delta)\right)
$$

Where:

$$
\psi(\delta)=-6(\delta) \text { for } \delta>0(\text { Stable atm. })
$$




$$
\begin{aligned}
& \psi(\delta)=\ln \left[\left(\frac{1+x^{2}}{2}\right)\left(\frac{1+x}{2}\right)^{2}\right]-2 \tan ^{-1} x+\frac{\pi}{2} \text { for } \delta<0(\text { Unstable atm. }) \quad \text { Eq. } 61 \\
& x=(1-19.3(\delta))^{1 / 4}
\end{aligned}
$$

and

$$
K_{\text {mass }}(z)=(0.80) * \frac{\left(u_{*}\right)(k)(z-d)}{\varphi(\delta)}
$$

Where:

$$
\begin{array}{lr}
\varphi(\delta)=1+6(\delta) \text { for } \delta>0 \text { (Stable atmosphere }) & \text { Eq. } 63 \\
\varphi(\delta)=1 \text { for } \delta=0 \text { (Neutral atmosphere) } & \text { Eq. } 64 \\
\varphi(\delta)=(1+19.3(\delta))^{-1 / 4} \text { for } \delta<0 \text { (Unstable atmosphere) } & \text { Eq. } 65
\end{array}
$$

The parameters that varied between low, median and high cases to understand the impact of each variable. A sensitivity analysis is performed and an elasticity index is developed to understand the magnitude and direction of each variable.

\begin{tabular}{|c|c|c|c|c|c|c|}
\hline Case & $\begin{array}{c}\text { Fetch } \\
\text { Length }\end{array}$ & $\begin{array}{c}\text { Element } \\
\text { Height }\end{array}$ & $\begin{array}{c}\text { Friction } \\
\text { Velocity }\end{array}$ & Heat Flux & $\begin{array}{c}\text { Surface } \\
\text { Resistance }\end{array}$ & Nodes \\
\hline Base Case & 1.00 & 0.13 & 0.31 & 112.57 & 57.50 & 125.00 \\
\hline 2 & 3.00 & 0.13 & 0.31 & 112.57 & 57.50 & 125.00 \\
\hline 3 & 5.00 & 0.13 & 0.31 & 112.57 & 57.50 & 150.00 \\
\hline 4 & 1.00 & 0.07 & 0.31 & 112.57 & 57.50 & 125.00 \\
\hline 5 & 1.00 & 0.20 & 0.31 & 112.57 & 57.50 & 125.00 \\
\hline 6 & 1.00 & 0.13 & 0.07 & 112.57 & 57.50 & 125.00 \\
\hline 7 & 1.00 & 0.13 & 0.44 & 112.57 & 57.50 & 125.00 \\
\hline 8 & 1.00 & 0.13 & 0.31 & 6.62 & 57.50 & 125.00 \\
\hline 9 & 1.00 & 0.13 & 0.31 & 208.08 & 57.50 & 125.00 \\
\hline 10 & 1.00 & 0.13 & 0.31 & 112.57 & 10.40 & 125.00 \\
\hline 11 & 1.00 & 0.13 & 0.31 & 112.57 & 3579.10 & 125.00 \\
\hline Ideal Case & 5.00 & 0.20 & 0.44 & 6.62 & 10.40 & 125.00 \\
\hline
\end{tabular}


Table 2: Cases for parametric study. Measured values (friction velocity and heat flux) and calculated values (surface resistance) varied between the 10th, 50th and 90th percentile.

Length varied between 1, 3, 5 meters and height varied between $0.07,0.13,0.20$

The base case assumes a green roof length of 1 meter, which is what is expected on green roofs. Although green roofs can be fair large, it is difficult to find uninterrupted green roof fetch in front of RTUs of greater than a few meters whereby the changes between the different fetch length is only at a maximum 5 meters. The height of the plant elements for the base case is 0.13 meters, which is based measurements of the dominant species of sedum, most common to the rooftop we measured the deposition. A parallel effort was conducted where the plant species, plant height and plant cover were recorded over a year. The variations include measurements of species found on the rooftop site that ranged from short species at $0.07 \mathrm{~m}$ and tall species 0.20 meter.

The friction velocity and heat flux is chosen based on the median values measured from the field for the base case. The $50^{\text {th }}$ percentile friction velocity is approximately .31 $\mathrm{m} / \mathrm{s}$ and the $50^{\text {th }}$ percentile heat flux is $112.57 \mathrm{~W} / \mathrm{m}^{2}$. The friction velocity will be varied between $0.07 \mathrm{~m} / \mathrm{s}$ and $.44 \mathrm{~m} / \mathrm{s}$, the $10^{\text {th }}$ and $90^{\text {th }}$ percentile, outside of the base case. The heat flux will vary between $6.62 \mathrm{~W} / \mathrm{m}^{2}$ and $208.08 \mathrm{~W} / \mathrm{m}^{2}$, again the $10^{\text {th }}$ and $90^{\text {th }}$ percentile of the measured heat flux value. Finally, the surface resistance is also pulled from measured values in the field. The median value is used for the base case, $195.3 \mathrm{~s} / \mathrm{m}$, and varied between the $10^{\text {th }}$ percentile, $54.8 \mathrm{~s} / \mathrm{m}$ and the $90^{\text {th }}$ percentile, $3692.9 \mathrm{~s} / \mathrm{m}$. The aerodynamic and boundary layer resistance is calculated from the friction velocity and heat flux. The 
initial concentration is taken to be $70 \mathrm{ppb}$ or approximately $142 \mathrm{ug} / \mathrm{m}^{\wedge} 3$. This magnitude of concentration can be expected in urban areas of high traffic and is the point at which the EPA would look to perform regulatory measures to reduce the concentration. Finally, an ideal case is also chosen based on trying to maximize deposition to the green roof, although most likely not a realistic case.

The base case velocity and eddy diffusivity profile is shown in Figure 22 (top and middle). The velocity profile follows an expected logarithmic profile, where the velocity is zero at the roughness height and increases logarithmically. The eddy diffusivity increases nearly constantly, which is expected as the assumption used for this transport model is that the deposition is occurring in the constant flux layer. The Reynolds number $(\mathrm{Re})$ shown in Figure 21 (bottom), shows that the transport is in the turbulent regime, greater than a few $1000 \mathrm{Re}$, throughout the height of our control volume. 

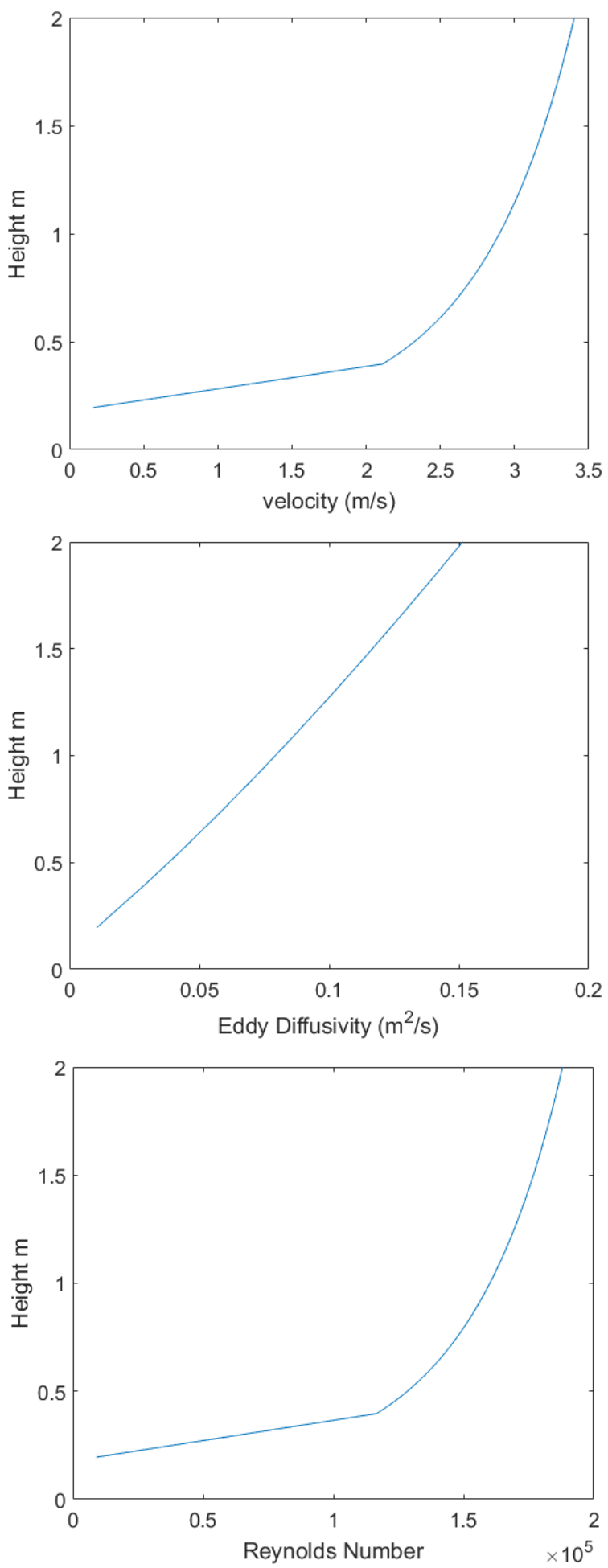

Figure 22: The velocity (top), eddy diffusivity (middle) and Reynolds number (bottom) profiles as a function of height 


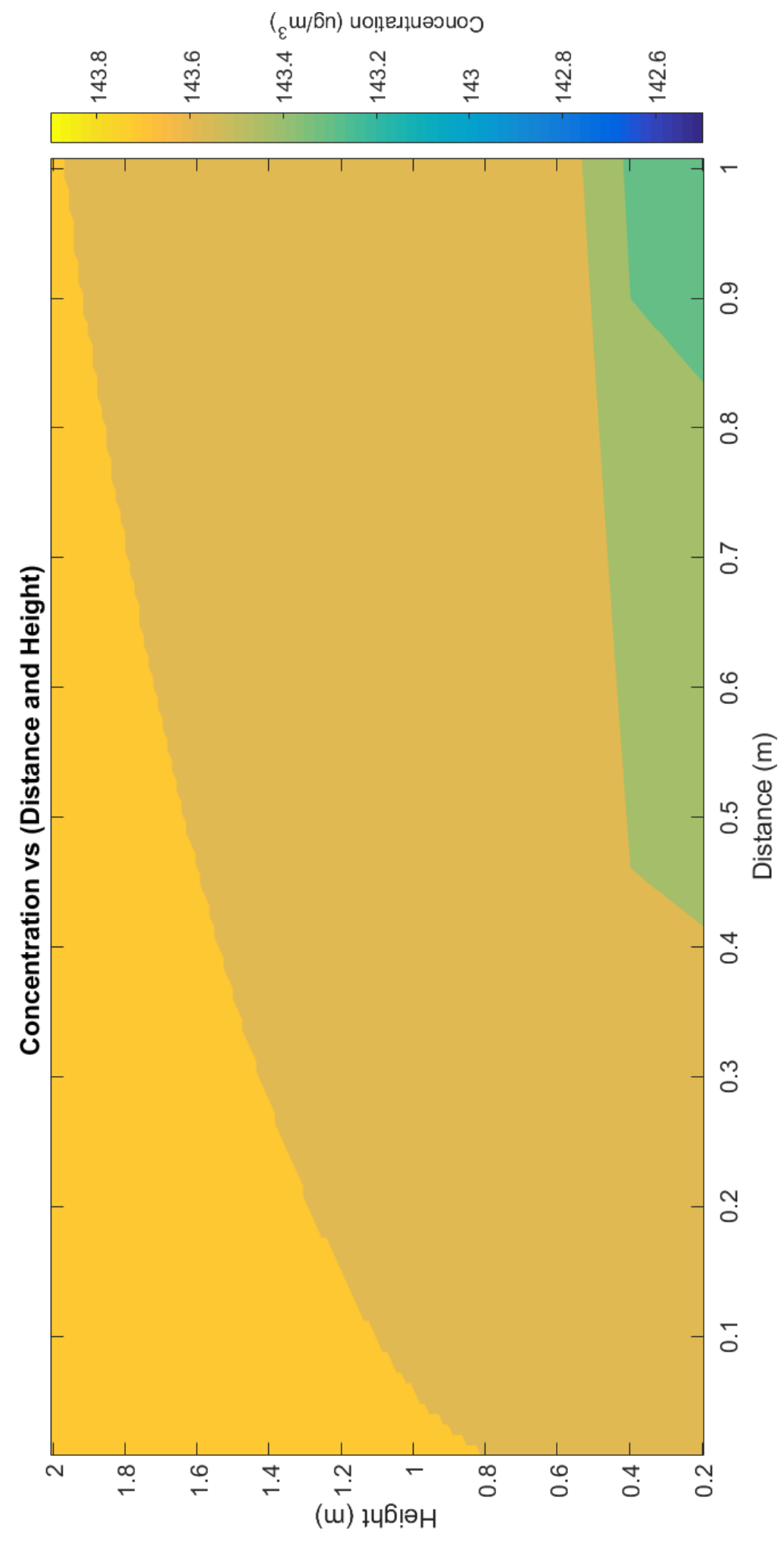

Figure 23: Concentration profile as a function of height and distance. The color gradient represents the concentration in $\mu \mathrm{g} / \mathrm{m} 3$ 
The concentration profile is shown in Figure 23, where the rooftop is on the lefthand side of the plot and the ventilation unit is on the right-hand side of the contour plot. As the pollutant moves across the rooftop, the interaction with the surfaces creates a concentration boundary layer. The color gradient represents a concentration gradient. The deposition velocity for this base case is $.34 \mathrm{~cm} / \mathrm{s}$, which leads to a small deposition at the surface which is why there isn't a large concentration gradient. The concentration of ozone prior to entering the RTU unit, therefore, it is important to look at the column of air entering the RTU unit as this is most representative of the impacts of the green roof prior to entering the RTU. This column is assumed to be the final column of the control volume in the model space and no further ozone deposition is assumed, which may not always be the case, as there is still interaction between ozone and the RTU material as well as the filtration, but for the sake of understanding the impact of green roofs, we will use this column as what will enter the indoor environment. To perform the sensitivity analysis, we compare the concentration at a specific height of $0.75 \mathrm{~m}$, the height at which RTU is sited on the big box retail store for different model scenarios.

The column of base case scenario is given in Figure 23 and shows the concentration gradient with respect to height. The concentration gradient stops at a height of approximately $0.39 \mathrm{~m}$. This is because at that height ( 3 times the height of the plant elements) and below exists the roughness sublayer, and in this layer, we cannot use a constant flux assumption. In this layer, we use the bulk deposition term, $v_{d}$. The base case shows some deposition but is modest, which is indicative of the low deposition velocity. 




Figure 24: The base case concentration gradient in the column of air assumed to enter the RTU

The first variation is varying the fetch length, from 1,3 , and 5 meter, shown in Figure 25. The largest fetch length has the greatest concentration gradient which should occur as the greater the fetch length, the more interaction time the pollutant has with the rooftop surface, therefore depositing onto the rooftop. It should be noted that the lowest concentration at a height of $0.75 \mathrm{~m}$ is also with a $5 \mathrm{~m}$ fetch. Finally, although the gradient is much greater than the base case for a large fetch, the reduction in concentration at the lowest height is a little over $1.5 \mathrm{ug} / \mathrm{m}^{\wedge} 3$ more for the large fetch case. 


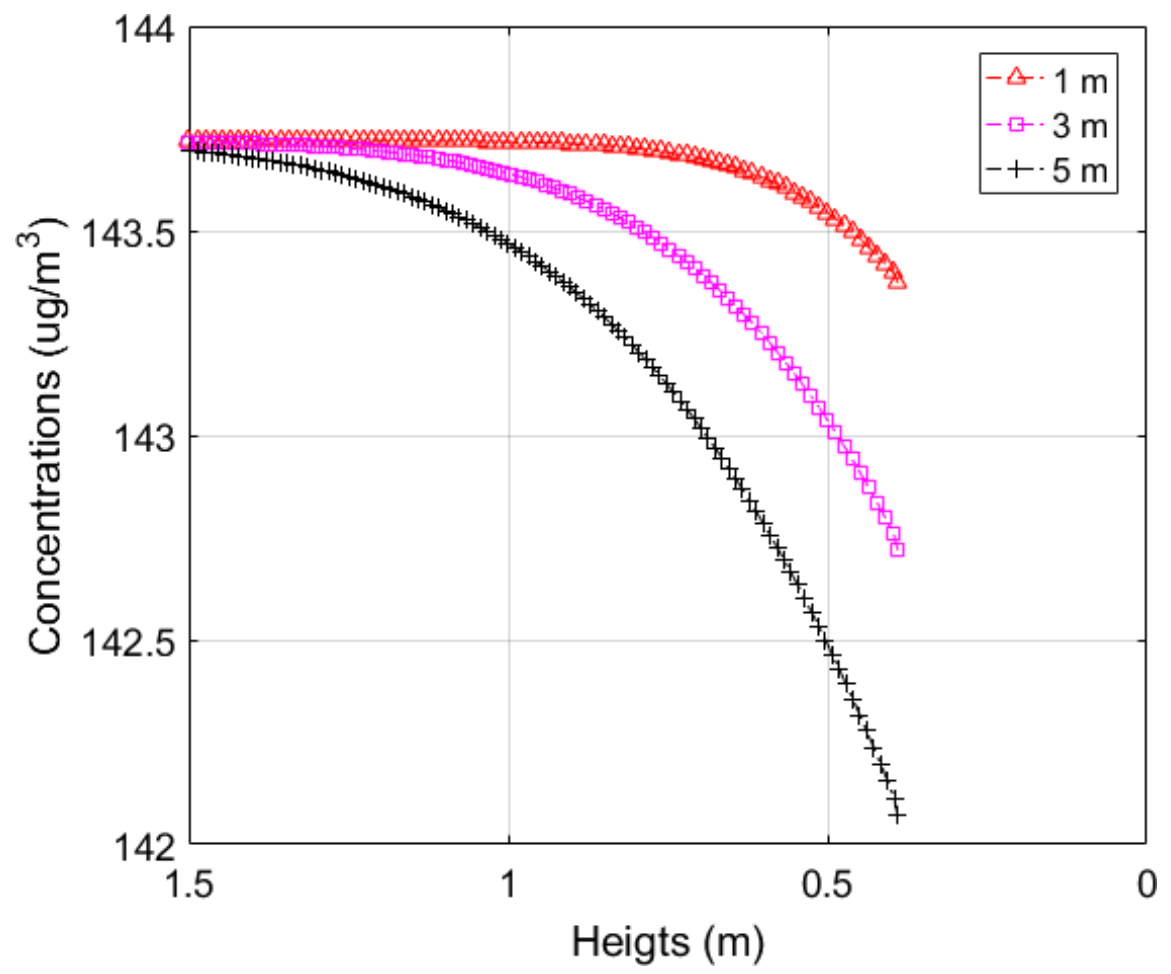

Figure 25: The case in which the green roof fetch length was changed. The gradients represent the column of air assumed to enter the RTU

The next variation tested are the changes in element height, shown in Figure 26. This case shows that the largest element has the greatest concentration gradient in the column entering the RTU unit. The impact of the height also changes the location of the lowest concentration calculated, because the higher the element height, the higher the roughness sublayer, and we do not model the turbulent transport in the sublayer outside of the deposition term. In this model, the height also effects the velocity and eddy diffusivity profiles by effectively shifting them upwards by increasing the height of the zero-plane displacement. This shifting of the profile allows for lower advection at lower heights, meaning more of the pollutant can interact with the surface, leading to a lower concentration at a higher height. The height would also increase the surface area for interaction with ozone, but in this model, it is not parameterized as such. Essentially, by 
increasing the height, the leaf area index (LAI), which is the amount of leaf area per given surface area, must also increase. But in the case of this model, we are using a bulk roughness sublayer and the LAI is necessarily needed. It is important to note that the higher element height leads to a lower concentration at a height of 0.75 meters.

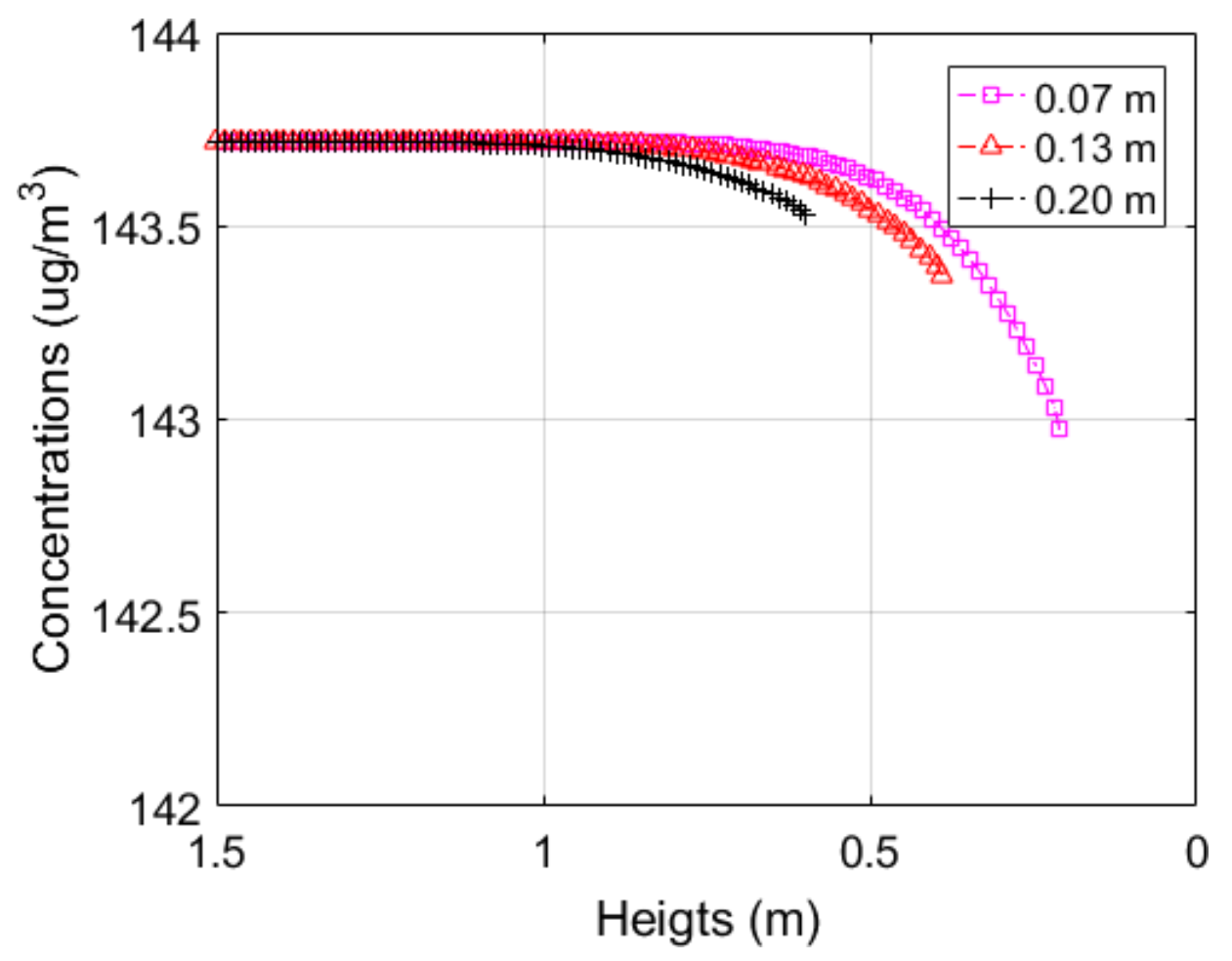

Figure 26: The case in which the green roof vegetation height was changed. The gradients represent the column of air assumed to enter the RTU

Varying friction velocity, shown in Figure 27, also has an impact the concentration gradient. The friction velocity is an important parameter in many aspects of the model. The friction velocity above the roughness sublayer and in the constant flux layer affects the advective and turbulent diffusive properties. The lower the friction velocity, the lower the advection allowing more time for a parcel air to interact with the surface. At the same time, the lower the friction velocity, the lower the turbulent diffusivity, leading to lower vertical transport to the surface. In the roughness sublayer, the friction velocity affects the 
aerodynamic and boundary layer resistances. Increases in friction velocity leads to lower aerodynamic and boundary layer resistance as there is more shear allowing for more vertical transport in the roughness sublayer. According to Figure 27, the effect of the aerodynamic resistance in the sublayer play a more dominant role than the effect of the transport profiles in the constant flux layer, because a higher friction velocity leads to a greater concentration gradient and a lower concentration at a height of the RTU inlet.

Heat flux is an important parameter that effects the stratification of the atmosphere above the rooftop. In this parametric study though, only unstable cases were chosen. The data taken from the field is taken at the $10^{\text {th }}, 50^{\text {th }}$ and $90^{\text {th }}$ percentiles which were all positive heat flux values. The direction of heat flux determines the thermal stratification and in the case of positive heat flux, the atmosphere above the rooftop is always unstable. As shown in figure 28 , the magnitude of the heat flux still influences the concentration gradient. A lower heat flux, a slightly greater concentration gradient and a lower concentration at a height of $0.75 \mathrm{~m}$ can be seen because there is less buoyancy in the air and therefore more of the air parcel can interact with the surface. 


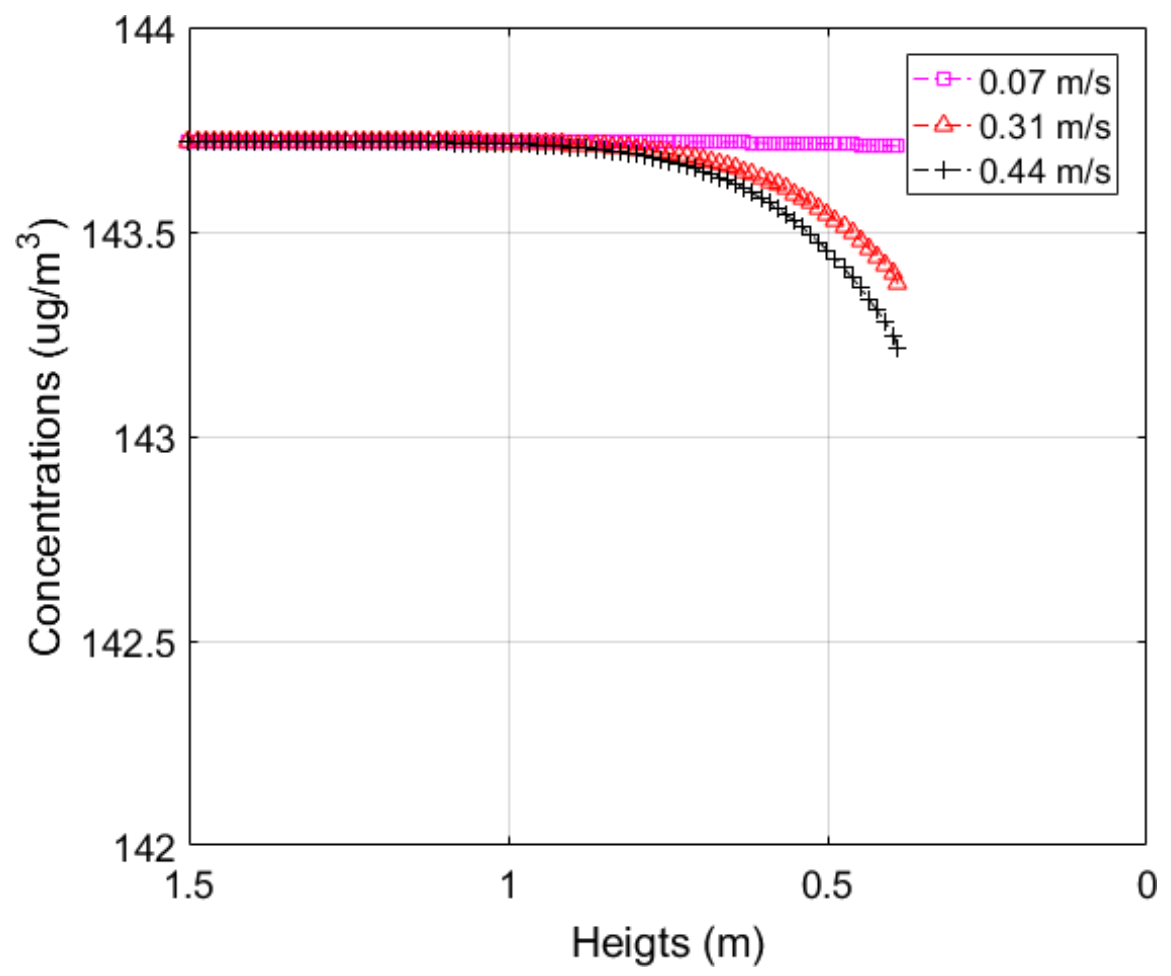

Figure 27: The case in which the friction velocity was changed between the 10th, 50th and 90th percentile. The gradients represent the column of air assumed to enter the RTU

Finally changes in surface resistance were modeled. Varying these cases is intuitive, as surface resistance increases, the deposition decreases, and this is evident in the Figure 29. The $10^{\text {th }}$ percentile case, $54.8 \mathrm{~s} / \mathrm{m}$, has the greatest concentration and the lowest concentration at a height of $0.75 \mathrm{~m}$. Although this magnitude of resistance may possibly be reached in ideal biological conditions, the deposition velocity most likely would not be reached. From the field measured values, we recognized that even when the surface resistance is at the $10^{\text {th }}$ percentile, it still dominated the total resistance, but in the model, keeping all other variables the same, the surface resistance would not dominate the total resistance when using the $10^{\text {th }}$ or $50^{\text {th }}$ percentile. In this case, aerodynamic resistance $(236.50 \mathrm{~s} / \mathrm{m})$, taken from the $50^{\text {th }}$ percentile of friction velocity and heat flux, is the rate 
limiting step, which may not be feasible. But nonetheless, these cases are considered when performing the sensitivity analysis.

A sensitivity analysis is performed on the different cases to show the impact of various parameters on the concentration at $0.75 \mathrm{~m}$ and is shown in Figure 30. The fetch length has the biggest impact at a height of 0.75 meters, with height, friction velocity, heat flux and surface resistance impactful in that order. This is interesting but should be taken with a grain of salt. The impact of the length and height are telling in that the physiology of plants plays a greater role than the ability for uptake and the meteorological conditions. And in future versions of the model, the LAI index will be incorporated, which should further amplify the impacts of the green roof geometry. The impact of the friction velocity and heat flux are also telling. The impact of friction velocity is negative, meaning greater friction velocity leads to a lower concentration at a height of 0.75 meters and the impact of heat flux is the exact opposite, lower heat flux leads to a lower concentration at that height. It is also important to note that the magnitudes are approximately the same, meaning they have about equal impact. 


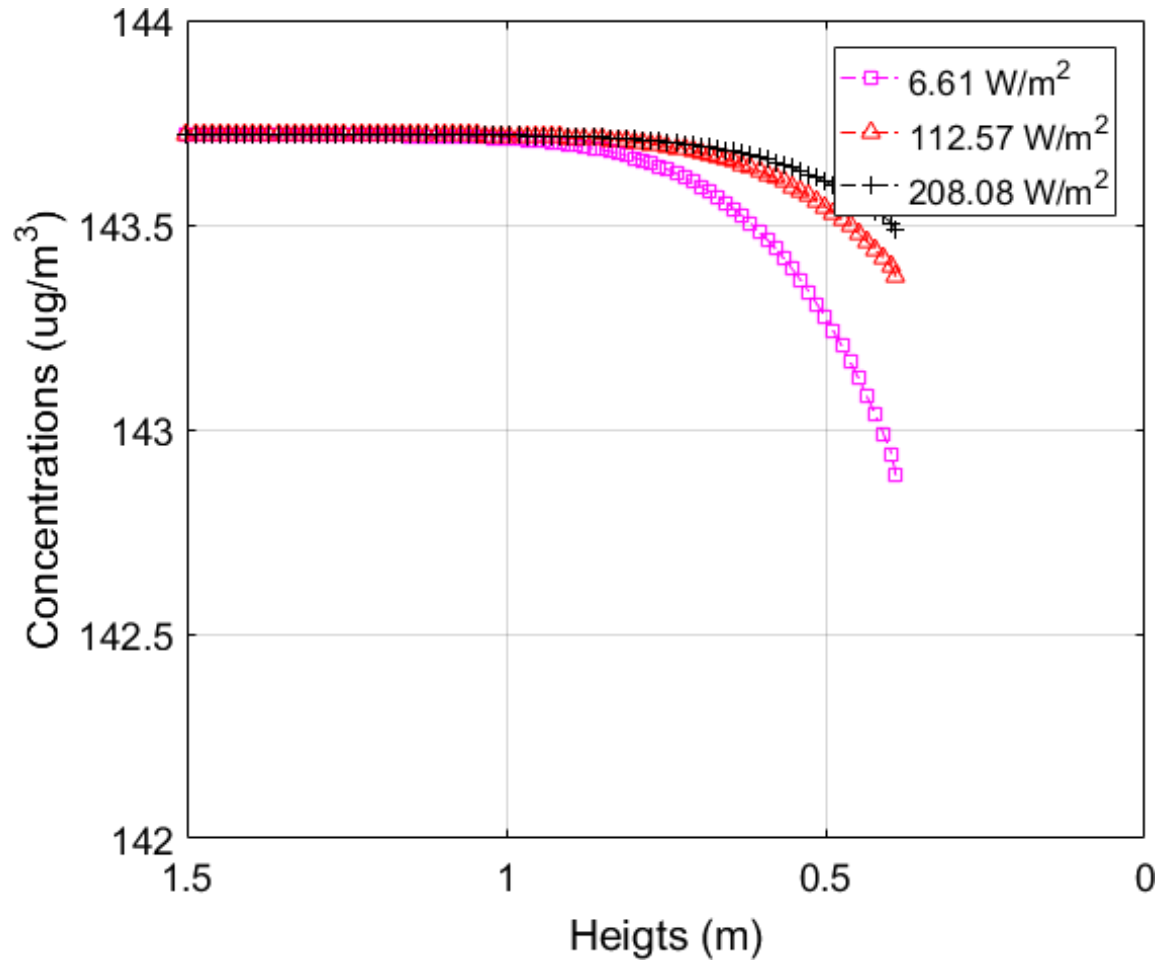

Figure 28: The case in which the heat flux was changed between the 10th, 50th and 90th percentile. The gradients represent the column of air assumed to enter the RTU 


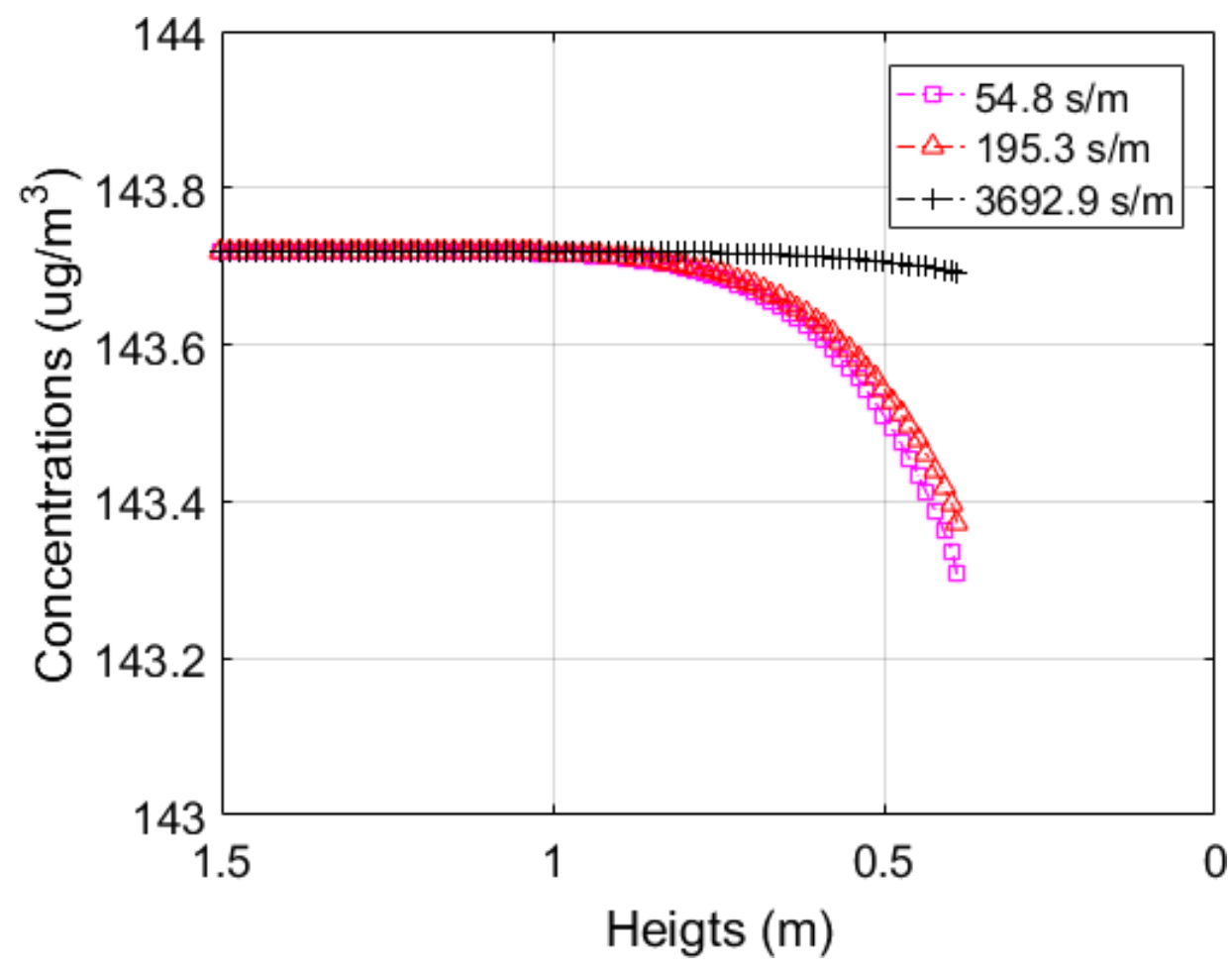

Figure 29: The case in which the surface resistance was changed between the 10th, 50th and 90th percentile. The gradients represent the column of air assumed to enter the RTU

Finally, the surface resistance has the least impact in concentration at a height where the RTU inlet is placed. This needs to be taken with a grain of salt. The surface resistance is varied between the $10^{\text {th }}, 50^{\text {th }}$ and $90^{\text {th }}$ percentile, with the $50^{\text {th }}$ percentile taken as the base case. The respective resistances were $54.8 \mathrm{~s} / \mathrm{m}, 195.3 \mathrm{~s} / \mathrm{m}$, and $3692.9 \mathrm{~s} / \mathrm{m}$. This may be a point of error as the difference between the $10^{\text {th }}$ and $50^{\text {th }}$ percentile is much smaller than the difference between the $50^{\text {th }}$ and $90^{\text {th }}$ percentile. The $90^{\text {th }}$ percentile is a case in which there is no uptake to the surface, but the $10^{\text {th }}$ percentile case is not necessarily a case where there is almost full uptake to the surface. In the $10^{\text {th }}$ and $50^{\text {th }}$ percentiles cases, the $50^{\text {th }}$ percentile friction velocity is used which means the aerodynamic resistance $(236.50 \mathrm{~s} / \mathrm{m})$ dominates. From the field measurements, we know that this cannot be the case as the surface resistance dominated the total resistance, and the highest deposition is 
seen when the surface resistance is on the same scale as the aerodynamic resistance, not lower. This is most likely the reason why the meteorological conditions seem to play a bigger impact on the concentration than surface resistance. Future work with the model will involve a closer examination of surface resistance as a function of the total resistance, not just values determined from the field.



Figure 30: - Sensitivity analysis of the different parameters at the inlet RTU height of 0.75 meters. The $\mathrm{x}$-axis represents the elasticity, a measure of how impactful the parameter is

Based on this sensitivity analysis, an ideal case is chosen, shown in Figure 31, where the parameters were pushed to their ideal values to reduce the concentration at the inlet height. The longest fetch length, the tallest elements in combination with high friction 
velocity and low buoyancy to drive transport to the surface and low surface resistance to uptake only reduced the inlet concentration by approximately $2 \mu \mathrm{g} / \mathrm{m}^{\wedge} 3$ as compared to the base case. The deposition velocity for this case is $1.7 \mathrm{~cm} / \mathrm{s}$, much higher than what would be commonly seen in the field. Even with ideal, most likely non-feasible conditions, the deposition is minimal.

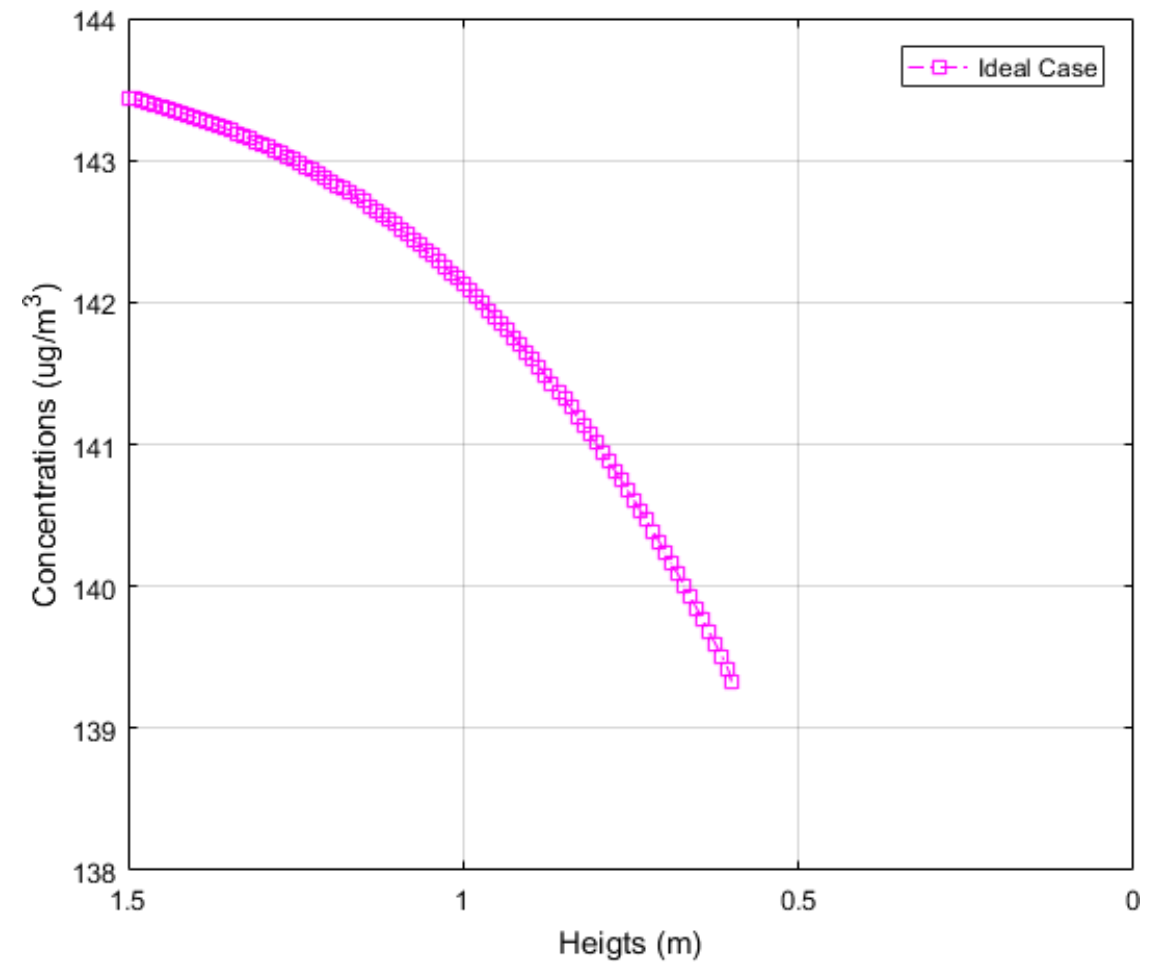

Figure 31: The ideal case in which the parameters were set to produce the lowest concentration at the RTU inlet height ( 0.75 meters) in the column of air assumed to enter the RTU 


\section{Conclusion}

Urban deposition of ozone and the impacts of green roofs is a complex subject that merits our consideration as green infrastructure is increasingly implemented as a mitigation strategy for urbanization. Ozone deposition has been measured by many different methods for urban areas, and the atmospheric gradient method is chosen due to the instrumentation available. This method involves the determination of ozone concentration at two heights as well as the measurement of meteorological conditions at the upper height. From this method we determined the flux and by assuming a dry deposition process, we determined the deposition velocity. The deposition velocity is a proportionality constant that describes the flux based on a concentration at a height, and it is a coupling of transport processes and surface uptake. The treatment of the transport processes and surface uptake is similar to electrical resistances, where the transport resistances are the aerodynamic resistance, the resistance of transport due shear and thermal stratification, the quasi-laminar boundary layer resistance, which is the resistance to transport due to the molecular diffusion process, and finally the surface resistance, which describes the surfaces' ability to uptake ozone. The aerodynamic and boundary layer resistance can be calculated from meteorological measurements, and with the measurement of the deposition velocity using the atmospheric gradient method, we can calculate the surface resistance. The calculated surface resistance is derived by selecting periods in which the air flow is over vegetated surfaces, therefore the surface resistance is attributed to the vegetated surfaces. The $10^{\text {th }} 50^{\text {th }}$ and $90^{\text {th }}$ percentiles for resistances were $54.8 \mathrm{~s} / \mathrm{m}, 195.3 \mathrm{~s} / \mathrm{m}$, and $3692.9 \mathrm{~s} / \mathrm{m}$ respectively. This is also compared with prior work published and found that it conformed well with prior 
published values for vegetation surface resistances. To our knowledge there are no other field measurements of ozone fluxes to urban greenery available in the literature.

A two-dimensional advection diffusion model is developed to describe the transport of ozone across the green roof prior to entering the RTU. The model is discretized, and a parametric study is performed. The parameters varied are the green roof length, vegetation height, friction velocity, heat flux and finally the surface resistance. A sensitivity analysis is performed at a point, taken from the height of the RTU inlet, in a column of the control volume that is assumed to enter the RTU unit. The sensitivity analysis demonstrated that the fetch length and the vegetation height had the biggest impact, followed by the meteorological parameters; the friction velocity and heat flux. The surface resistance had the least impact on deposition which is telling. This means that the type of surface plays much less of a role in impacting deposition and controlling physiological parameters and meteorological conditions has a bigger influence on ozone concentration prior to entering the RTU. 


\section{Limitations and Future Work}

\section{a. Limitations}

There are a few limitations that need to be considered in this work. First the method of flux measurements has some innate issues. A flux-gradient method requires that the flux is constant with height but in the roughness sublayer that assumption is not met. In the roughness sublayer, the elements themselves effect the flux, which means that any fluxgradient measurement method tends to overestimate the flux to the surface.

The model also has some limitations. The parameters that were varied for the sensitivity analysis were taken from the field and they were varied between the $10^{\text {th }}, 50^{\text {th }}$ and $90^{\text {th }}$ percentile with the $50^{\text {th }}$ being the base case. This may not necessarily hold as it assumed that these parameters are independent of each other. The assumption that the $10^{\text {th }}$ percentile occurs in one variable independently of changes in another variable does not hold as the measured conditions are interconnected. Periods in which high friction velocity occurred in periods of high heat flux, meaning that they are somewhat interconnected and would not change independent to each other. Another thing to note in the parametric study is that in some cases, the surface resistance did not dominate the overall resistance, a behavior that is recognized in field measurements. This is again most likely due to the assumption of independence of surface resistance from the meteorological conditions, which most likely doesn't hold. The vegetation will interact to the meteorological conditions and increase or reduce their uptake of ozone because of it, therefore it most likely cannot be decoupled. 


\section{b. Future Work}

Work on this project will move forward to apply better methods to not only better characterize deposition, but also to understand different components of deposition. A 2018 summer campaign is being planned to better characterize the deposition velocity of ozone to specifically the rooftop using either the eddy-covariance method, modified bowen-ratio method or a modified gradient method. Chamber experiments can be conducted to characterize the different processes that might affect the surface resistances of the vegetation on the rooftop. Also, these chamber experiments will be attached to a PTRTOF-MS, a instrument that allows for real-time measurement of organic compounds, to better understand the interaction of ozone with vegetated surfaces. The model will also be advanced to better incorporate the area of leaf surfaces available for interaction. This will give further understanding of the impacts of plant geometry in the deposition of pollutants. Also, the model will be coupled with a mass balance of organic compounds so that the homogeneous interactions can be studied. 


\section{References}

1. Abbass, Omed A., David J. Sailor, and Elliott T. Gall. "Effectiveness of Indoor Plants for Passive Removal of Indoor Ozone.” Building and Environment 119 (July 2017): 62-70. https://doi.org/10.1016/j.buildenv.2017.04.007.

2. Abbass, Omed A., David J. Sailor, and Elliott T. Gall. "Ozone Removal Efficiency and Surface Analysis of Green and White Roof HVAC Filters." Building and Environment 136 (May 2018): 118-27. https://doi.org/10.1016/j.buildenv.2018.03.042.

3. Aubinet, M., A. Grelle, A. Ibrom, ü. Rannik, J. Moncrieff, T. Foken, A.S. Kowalski, et al. "Estimates of the Annual Net Carbon and Water Exchange of Forests: The EUROFLUX Methodology." In Advances in Ecological Research, 30:113-75. Elsevier, 1999. https://doi.org/10.1016/S0065-2504(08)60018-5.

4. Baik, Jong-Jin, and Jae-Jin Kim. "A Numerical Study of Flow and Pollutant Dispersion Characteristics in Urban Street Canyons." Journal of Applied Meteorology 38, no. 11 (November 1999): 1576-89. https://doi.org/10.1175/15200450(1999)038<1576:ANSOFA>2.0.CO;2.

5. Baldocchi, Dennis. "A Multi-Layer Model for Estimating Sulfur Dioxide Deposition to a Deciduous Oak Forest Canopy." Atmospheric Environment (1967) 22, no. 5 (January 1988): 869-84. https://doi.org/10.1016/0004-6981(88)90264-8.

6. Baldocchi, Dennis D., Bruce B. Hicks, and Pamela Camara. "A Canopy Stomatal Resistance Model for Gaseous Deposition to Vegetated Surfaces." Atmospheric Environment (1967) 21, no. 1 (January 1987): 91-101. https://doi.org/10.1016/0004$\underline{6981(87) 90274-5}$.

7. Berndtsson, Justyna Czemiel, Lars Bengtsson, and Kenji Jinno. "Runoff Water Quality from Intensive and Extensive Vegetated Roofs." Ecological Engineering 35, no. 3 (March 2009): 369-80. https://doi.org/10.1016/j.ecoleng.2008.09.020.

8. Chang, J. S., R. A. Brost, I. S. A. Isaksen, S. Madronich, P. Middleton, W. R. Stockwell, and C. J. Walcek. "A Three-Dimensional Eulerian Acid Deposition Model: Physical Concepts and Formulation.” Journal of Geophysical Research 92, no. D12 (1987): 14681. https://doi.org/10.1029/JD092iD12p14681.

9. Clarke, J.F., E.S. Edgerton, and B.E. Martin. "Dry Deposition Calculations for the Clean Air Status and Trends Network." Atmospheric Environment 31, no. 21 (November 1997): 3667-78. https://doi.org/10.1016/S1352-2310(97)00141-6. 
10. Cole, Matthew A., and Eric Neumayer. "Examining the Impact of Demographic Factors on Air Pollution." Population and Environment 26, no. 1 (September 2004): 5-21. https://doi.org/10.1023/B:POEN.0000039950.85422.eb.

11. Coleman, Beverly K., Hugo Destaillats, Alfred T. Hodgson, and William W Nazaroff. "Ozone Consumption and Volatile Byproduct Formation from Surface Reactions with Aircraft Cabin Materials and Clothing Fabrics." Atmospheric Environment 42, no. 4 (February 2008): 642-54. https://doi.org/10.1016/j.atmosenv.2007.10.001.

12. Currie, Beth Anne, and Brad Bass. "Estimates of Air Pollution Mitigation with Green Plants and Green Roofs Using the UFORE Model." Urban Ecosystems 11, no. 4 (December 2008): 409-22. https://doi.org/10.1007/s11252-008-0054-y.

13. Edwards, G. C. "Development and Evaluation of a Sampling System to Determine Gaseous Mercury Fluxes Using an Aerodynamic Micrometeorological Gradient Method." Journal of Geophysical Research 110, no. D10 (2005). https://doi.org/10.1029/2004JD005187.

14. Gryning E, Sven. The Height of the Atmospheric Boundary Layer during Unstable Conditions. Risø-R 1536. Roskilde: Ris $\varnothing$ National Laboratory, 2005.

15. Escobedo, Francisco J., Timm Kroeger, and John E. Wagner. "Urban Forests and Pollution Mitigation: Analyzing Ecosystem Services and Disservices." Environmental Pollution 159, no. 8-9 (August 2011): 2078-87. https://doi.org/10.1016/j.envpol.2011.01.010.

16. Foken, Th., and B. Wichura. "Tools for Quality Assessment of Surface-Based Flux Measurements." Agricultural and Forest Meteorology 78, no. 1-2 (January 1996): 83-105. https://doi.org/10.1016/0168-1923(95)02248-1.

17. Garbero, Valeria. "Pollutant Dispersion in Urban Canopy,” n.d., 154.

18. Graefe, Jan. "Roughness Layer Corrections with Emphasis on SVAT Model Applications." Agricultural and Forest Meteorology 124, no. 3-4 (August 2004): 237-51. https://doi.org/10.1016/j.agrformet.2004.01.003.

19. Grimmond, C.S.B, T.S King, F.D Cropley, D.J Nowak, and C Souch. "Local-Scale Fluxes of Carbon Dioxide in Urban Environments: Methodological Challenges and Results from Chicago." Environmental Pollution 116 (March 2002): S243-54. https://doi.org/10.1016/S0269-7491(01)00256-1.

20. Hanst, Phillip L., Edgar R. Stephens, and William E. Scott. "Reactions Involving Ozone, Nitrogen Dioxide, and Organic Compounds at Low Concentrations in Air." Journal of the Air Pollution Control Association 5, no. 4 (February 1956): 219-44. https://doi.org/10.1080/00966665.1956.10467714. 
21. Henderson, Vernon. "The Urbanization Process and Economic Growth: The So-What Question," n.d., 25.

22. Hicks, B. B., D. D. Baldocchi, T. P. Meyers, R. P. Hosker, and D. R. Matt. “A Preliminary Multiple Resistance Routine for Deriving Dry Deposition Velocities from Measured Quantities." Water, Air, and Soil Pollution 36, no. 3-4 (1987): 311-30. https://doi.org/10.1007/BF00229675.

23. Jain, S.K. and Singh, V.P. (2003) Water Resources Systems Planning and Management. Elsevier Science B.V.

24. Janhäll, Sara. "Review on Urban Vegetation and Particle Air Pollution - Deposition and Dispersion." Atmospheric Environment 105 (March 2015): 130-37. https://doi.org/10.1016/j.atmosenv.2015.01.052.

25. Jenkins, Peggy L, Thomas J Phillips, Elliot J Mulberg, and Steve P Hui. “Activity Patterns of Californians: Use of and Proximity to Indoor Pollutant Sources." Atmospheric Environment. Part A. General Topics 26, no. 12 (August 1992): 2141-48. https://doi.org/10.1016/0960-1686(92)90402-7.

26. Karl, T, E Apel, A Hodzic, D D Riemer, D R Blake, and C Wiedinmyer. "Emissions of Volatile Organic Compounds Inferred from Airborne flux Measurements over a Megacity." Atmos. Chem. Phys., 2009, 15.

27. Karner, Alex A., Douglas S. Eisinger, and Deb A. Niemeier. "Near-Roadway Air Quality: Synthesizing the Findings from Real-World Data." Environmental Science \& Technology 44, no. 14 (July 15, 2010): 5334-44. https://doi.org/10.1021/es100008x.

28. Keronen, Petri, Anni Reissell, Üllar Rannik, Toivo Pohja, Erkki Siivola, Veijo Hiltunen, Pertti Hari, Markku Kulmala, and Timo Vesala. "Ozone flux Measurements over a Scots Pine Forest Using Eddy Covariance Method: Performance Evaluation and Comparison with flux-Profile Method" 8 (n.d.): 19.

29. Kljun, N., P. Calanca, M. W. Rotach, and H. P. Schmid. "A Simple Parameterisation for Flux Footprint Predictions." Boundary-Layer Meteorology 112, no. 3 (September 2004): 503-23. https://doi.org/10.1023/B:BOUN.0000030653.71031.96.

30. Kormann, Robert, and Franz X. Meixner. “An Analytical Footprint Model For Non-Neutral Stratification.” Boundary-Layer Meteorology 99, no. 2 (May 2001): 207-24. https://doi.org/10.1023/A:1018991015119.

31. Langford, B, B Davison, E Nemitz, and C N Hewitt. "Mixing Ratios and Eddy Covariance flux Measurements of Volatile Organic Compounds from an Urban Canopy (Manchester, UK)." Atmos. Chem. Phys., 2009, 17. 
32. Lin, Jin-Sheng, and Lynn M. Hildemann. "A Generalized Mathematical Scheme to Analytically Solve the Atmospheric Diffusion Equation with Dry Deposition." Atmospheric Environment 31, no. 1 (January 1997): 59-71. https://doi.org/10.1016/S13522310(96)00148-3.

33. Loubet, Benjamin, Pierre Cellier, Christophe Fléchard, Olivier Zurfluh, Mark Irvine, Eric Lamaud, Patrick Stella, et al. "Investigating Discrepancies in Heat, CO2 Fluxes and O3 Deposition Velocity over Maize as Measured by the Eddy-Covariance and the Aerodynamic Gradient Methods." Agricultural and Forest Meteorology 169 (February 2013): 35-50. https://doi.org/10.1016/j.agrformet.2012.09.010.

34. MA, JIANMIN, and S M DAGGUPATY. "Effective Dry Deposition Velocities for Gases and Particles over Heterogeneous Terrain." JOURNAL OF APPLIED METEOROLOGY 39 (2000): 12.

35. McRae, Gregory J., William R. Goodin, and John H. Seinfeld. "Development of a SecondGeneration Mathematical Model for Urban Air Pollution-I. Model Formulation." Atmospheric Environment (1967) 16, no. 4 (January 1982): 679-96. https://doi.org/10.1016/0004-6981(82)90386-9.

36. Meyers, Tilden P., and Dennis D. Baldocchi. "A Comparison of Models for Deriving Dry Deposition Fluxes of $\mathrm{O}_{3}$ and $\mathrm{SO}_{2}$ to a Forest Canopy." Tellus B 40B, no. 4 (September 1988): 270-84. https://doi.org/10.1111/j.1600-0889.1988.tb00297.x.

37. MoÈlder, Meelis, Achim Grelle, Anders Lindroth, and Sven Halldin. "Flux-Pro®le Relationships over a Boreal Forest Đ Roughness Sublayer Corrections." Agricultural and Forest Meteorology, 1999, 14.

38. Monin, A S, and A M Obukhov. "Basic Laws of Turbulent Mixing in the Surface Layer of the Atmosphere," n.d., 30.

39. Nieuwstadt, F. T. M. "Some Aspects of the Turbulent Stable Boundary Layer." BoundaryLayer Meteorology 30, no. 1 (September 1, 1984): 31-55. https://doi.org/10.1007/BF00121948.

40. Nieuwstadt, F. \& Dop, H. (1984). Atmospheric turbulence and air pollution modelling : a course held in The Hague, 21-25 September, 1981. Dordrecht, Holland Boston: D. Reidel.

41. Nowak, David J.; Crane, Daniel E. 2000. The Urban Forest Effects (UFORE) model: quantifying urban forest structure and functions. In: Hansen, Mark; Burk, Tom, eds. Integrated tools for natural resources inventories in the 21 st century. Gen. Tech. Rep. NC212. St. Paul, MN: U.S. Dept. of Agriculture, Forest Service, North Central Forest Experiment Station. 714-720. 
42. Nowak, David J, Kevin L Civerolo, S Trivikrama Rao, Gopal Sistla, Christopher J Luley, and Daniel E. Crane. "A Modeling Study of the Impact of Urban Trees on Ozone." Atmospheric Environment 34, no. 10 (January 2000): 1601-13. https://doi.org/10.1016/S1352-2310(99)00394-5.

43. Nowak, David J., Daniel E. Crane, and Jack C. Stevens. "Air Pollution Removal by Urban Trees and Shrubs in the United States." Urban Forestry \& Urban Greening 4, no. 3-4 (April 2006): 115-23. https://doi.org/10.1016/j.ufug.2006.01.007.

44. Padro, J., and G.C. Edwards. "Sensitivity of ADOM Dry Deposition Velocities to Input Parameters: A Comparison with Measurements for $\mathrm{SO}_{2}$ and $\mathrm{NO}_{2}$ over Three Land Use Types." Atmosphere-Ocean 29, no. 4 (December 1991): 667-85. https://doi.org/10.1080/07055900.1991.9649424.

45. Padro, Jacob. "Summary Of Ozone Dry Deposition Velocity Measurements And Model Estimates Over Vineyard, Cotton, Grass And Deciduous Forest In SummER,” n.d., 7.

46. Pratt, Gregory C., Evelyn J. Orr, Donald C. Bock, Rick L. Strassman, Dean W. Fundine, Clifford J. Twaroski, J. David Thornton, and Tilden P. Meyers. "Estimation of Dry Deposition of Inorganics Using Filter Pack Data and Inferred Deposition Velocity." Environmental Science \& Technology 30, no. 7 (January 1996): 2168-77. https://doi.org/10.1021/es9505558.

47. Rotach, Mathias W. "On the In\#uence of the Urban Roughness Sublayer on Turbulence and Dispersion." Atmospheric Environment, 1999, 8.

48. Salthammer, Tunga, Sibel Mentese, and Rainer Marutzky. "Formaldehyde in the Indoor Environment." Chemical Reviews 110, no. 4 (April 14, 2010): 2536-72. https://doi.org/10.1021/cr800399g.

49. Seibert, P. "Review and Intercomparison of Operational Methods for the Determination of the Mixing Height." Atmospheric Environment 34, no. 7 (2000): 1001-27. https://doi.org/10.1016/S1352-2310(99)00349-0.

50. Seinfeld, John H, and Spyros N Pandis. "From Air Pollution to Climate Change," n.d., 1248.

51. Sheppard, P. A. "The Aerodynamic Drag of the Earth's Surface and the Value of von Karman's Constant in the Lower Atmosphere." Proceedings of the Royal Society A: Mathematical, Physical and Engineering Sciences 188, no. 1013 (January 30, 1947): 20822. https://doi.org/10.1098/rspa.1947.0005.

52. Soukoulis, Christos, Luca Cappellin, Eugenio Aprea, Fabrizio Costa, Roberto Viola, Tilmann D. Märk, Flavia Gasperi, and Franco Biasioli. "PTR-ToF-MS, A Novel, Rapid, 
High Sensitivity and Non-Invasive Tool to Monitor Volatile Compound Release During Fruit Post-Harvest Storage: The Case Study of Apple Ripening." Food and Bioprocess Technology 6, no. 10 (October 2013): 2831-43. https://doi.org/10.1007/s11947-012-0930$\underline{6}$.

53. Speak, A.F., J.J. Rothwell, S.J. Lindley, and C.L. Smith. "Urban Particulate Pollution Reduction by Four Species of Green Roof Vegetation in a UK City." Atmospheric $\begin{array}{llll}\text { Environment } & 61 & \text { (December 283-93. }\end{array}$ https://doi.org/10.1016/j.atmosenv.2012.07.043.

54. Stone, Brian. "Urban Sprawl and Air Quality in Large US Cities." Journal of Environmental Management 86, no. 4 (March 2008): 688-98. https://doi.org/10.1016/j.jenvman.2006.12.034.

55. Stutz, Bruce. “Green Roofs Are Starting To Sprout in American Cities,” n.d., 6.

56. Stutz, Jochen. "Nitrous Acid Formation in the Urban Atmosphere: Gradient Measurements of $\mathrm{NO}_{2}$ and HONO over Grass in Milan, Italy." Journal of Geophysical Research 107, no. D22 (2002). https://doi.org/10.1029/2001JD000390.

57. Tagesson, Torbern. “Turbulent Transport in the Atmospheric Surface Layer,” n.d., 27.

58. Taha, Haider. "Modeling Impacts of Increased Urban Vegetation on Ozone Air Quality in the South Coast Air Basin." Atmospheric Environment 30, no. 20 (October 1996): 342330. https://doi.org/10.1016/1352-2310(96)00035-0.

59. Tirabassi, Tiziano, Daniela Buske, Davidson M. Moreira, and Marco T. Vilhena. "A TwoDimensional Solution of the Advection-Diffusion Equation with Dry Deposition to the Ground." Journal of Applied Meteorology and Climatology 47, no. 8 (August 2008): 20962104. https://doi.org/10.1175/2008JAMC1674.1.

60. Velasco, E, S Pressley, E Allwine, H Westberg, and B Lamb. "Measurements of CO Fluxes from the Mexico City Urban Landscape." Atmospheric Environment 39, no. 38 (December 2005): 7433-46. https://doi.org/10.1016/j.atmosenv.2005.08.038.

61. Velasco, E, S Pressley, R Grivicke, E Allwine, T Coons, W Foster, B T Jobson, et al. "Eddy Covariance flux Measurements of Pollutant Gases in Urban Mexico City." Atmos. Chem. Phys., 2009, 18.

62. Walcek, C J, R A Brosr, And J S Chang. "SO2, Sulfate And HNOA Deposition Velocities Computed Using Regional Landuse And Meteorological Data," n.d., 16. 
63. Weschler, Charles J. "Ozone in Indoor Environments: Concentration and Chemistry." Indoor Air 10, no. 4 (December 2000): 269-88. https://doi.org/10.1034/j.16000668.2000.010004269.x.

64. Wesely, M.L., and B.B. Hicks. "Some Factors That Affect the Deposition Rates of Sulfur Dioxide and Similar Gases on Vegetation." Journal of the Air Pollution Control Association 27, no. 11 (November 1977): 1110-16. https://doi.org/10.1080/00022470.1977.10470534.

65. Yang, Jun, Joe McBride, Jinxing Zhou, and Zhenyuan Sun. "The Urban Forest in Beijing and Its Role in Air Pollution Reduction." Urban Forestry \& Urban Greening 3, no. 2 (January 2005): 65-78. https://doi.org/10.1016/j.ufug.2004.09.001.

66. Yang, Jun, Qian Yu, and Peng Gong. "Quantifying Air Pollution Removal by Green Roofs in Chicago." Atmospheric Environment 42, no. 31 (October 2008): 7266-73. https://doi.org/10.1016/j.atmosenv.2008.07.003.

67. Zhang, L, J R Brook, and R Vet. "A Revised Parameterization for Gaseous Dry Deposition in Air-Quality Models." Atmos. Chem. Phys., 2003, 16. 


\section{Appendix A: Supporting Figures for Field Measurements}

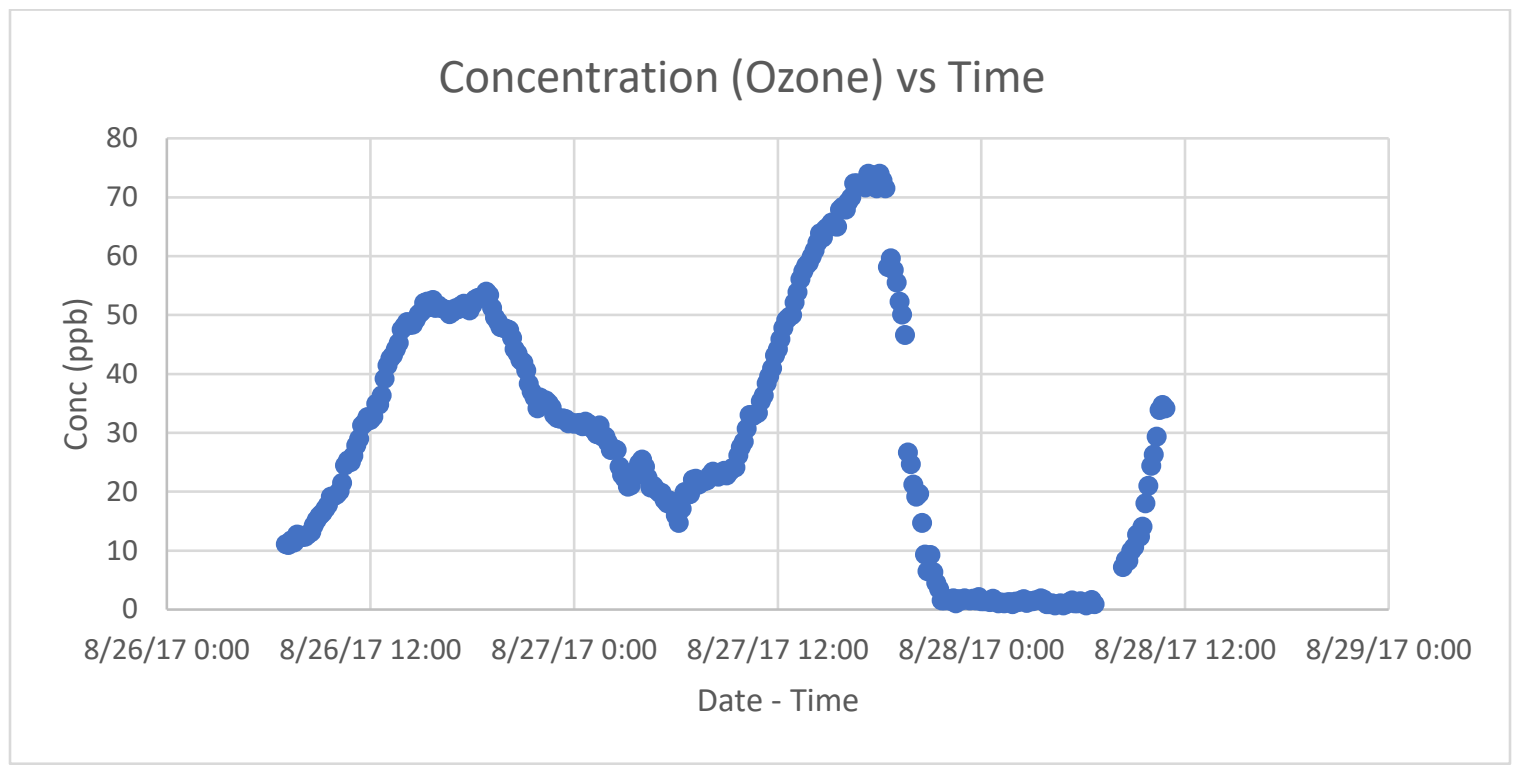

Appendix Figure 1: Ozone concentration (ppb) vs Time retrieved from the Department of Environmental Quality, Oregon at the South East Lafayette Location in Portland Oregon

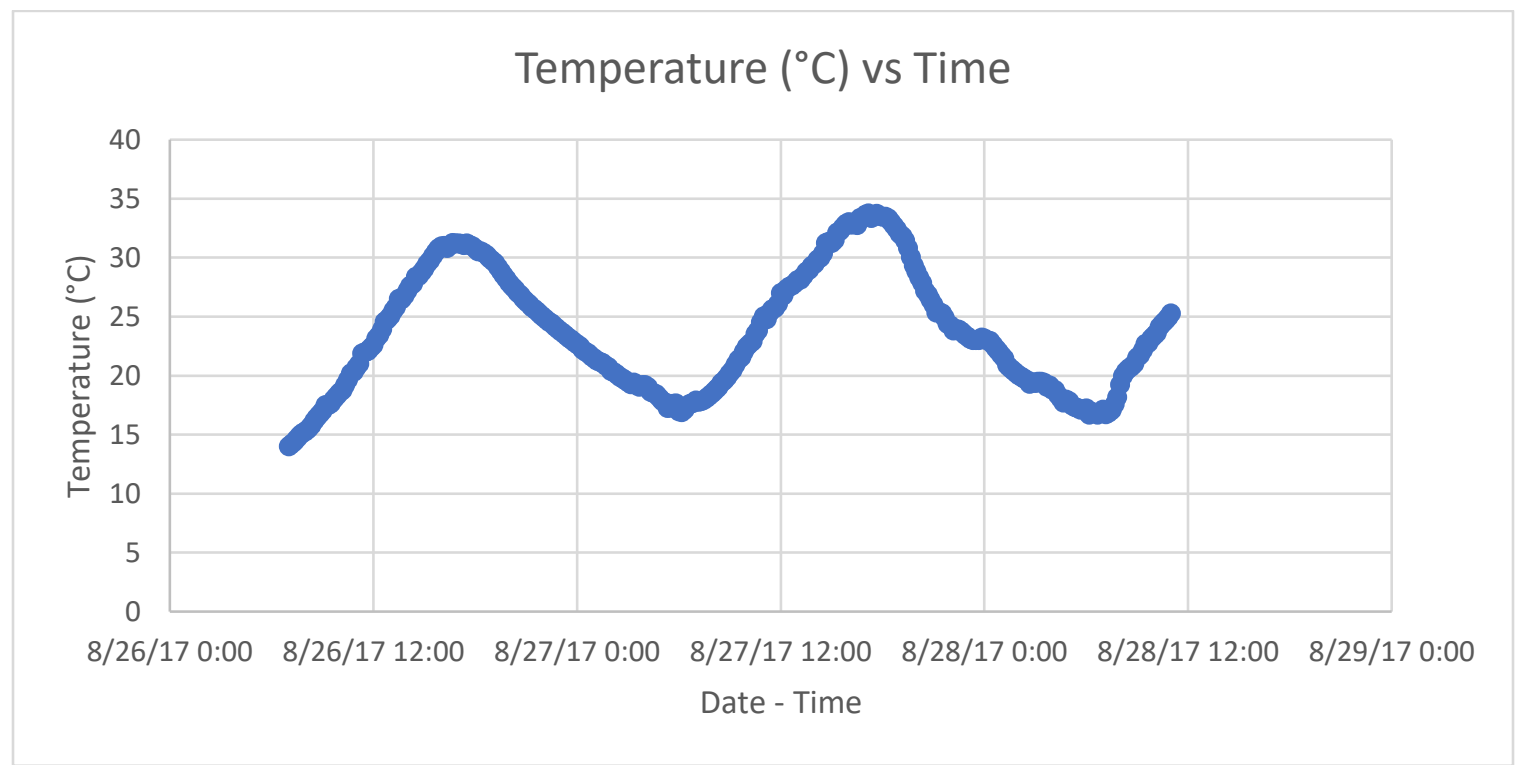

Appendix Figure 1: Temperature $\left({ }^{\circ} \mathrm{C}\right)$ vs Time retrieved from the Department of Environmental Quality, Oregon at the South East Lafayette Location in Portland Oregon 


\section{Appendix B: Model Results of Various Cases}

Case 1:
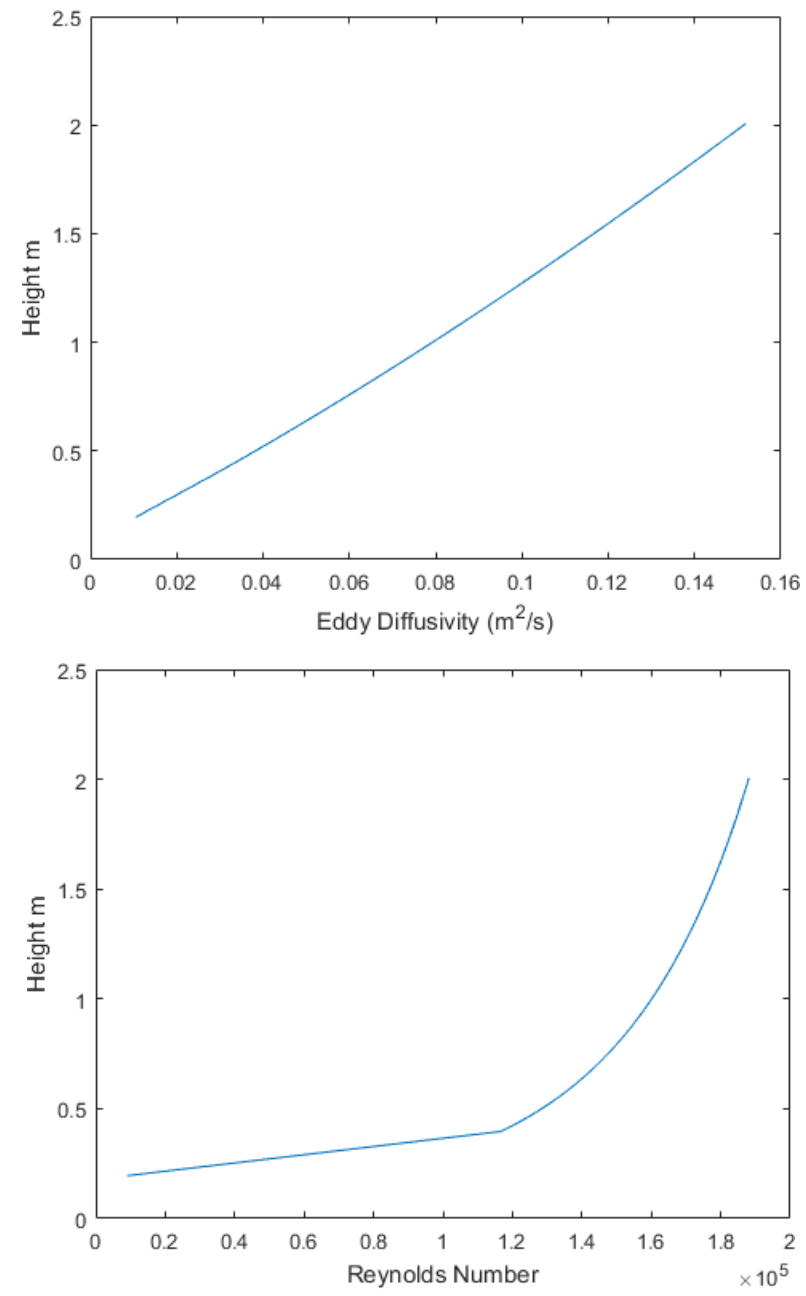


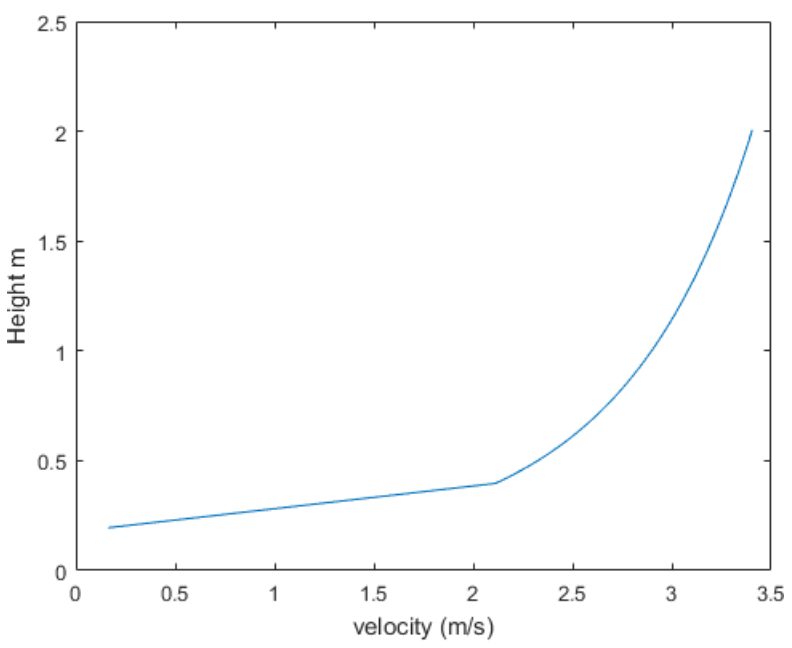




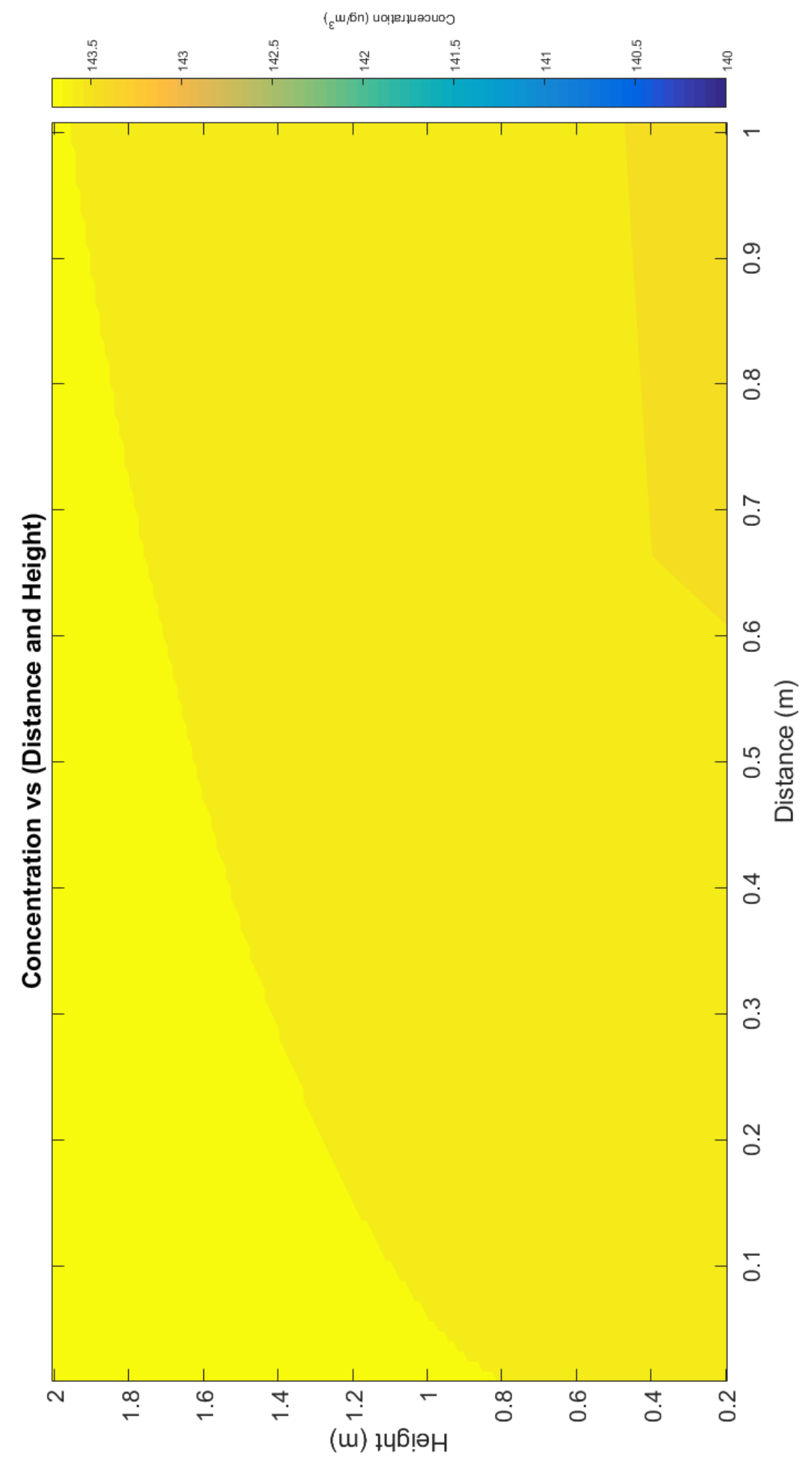


Case 2:
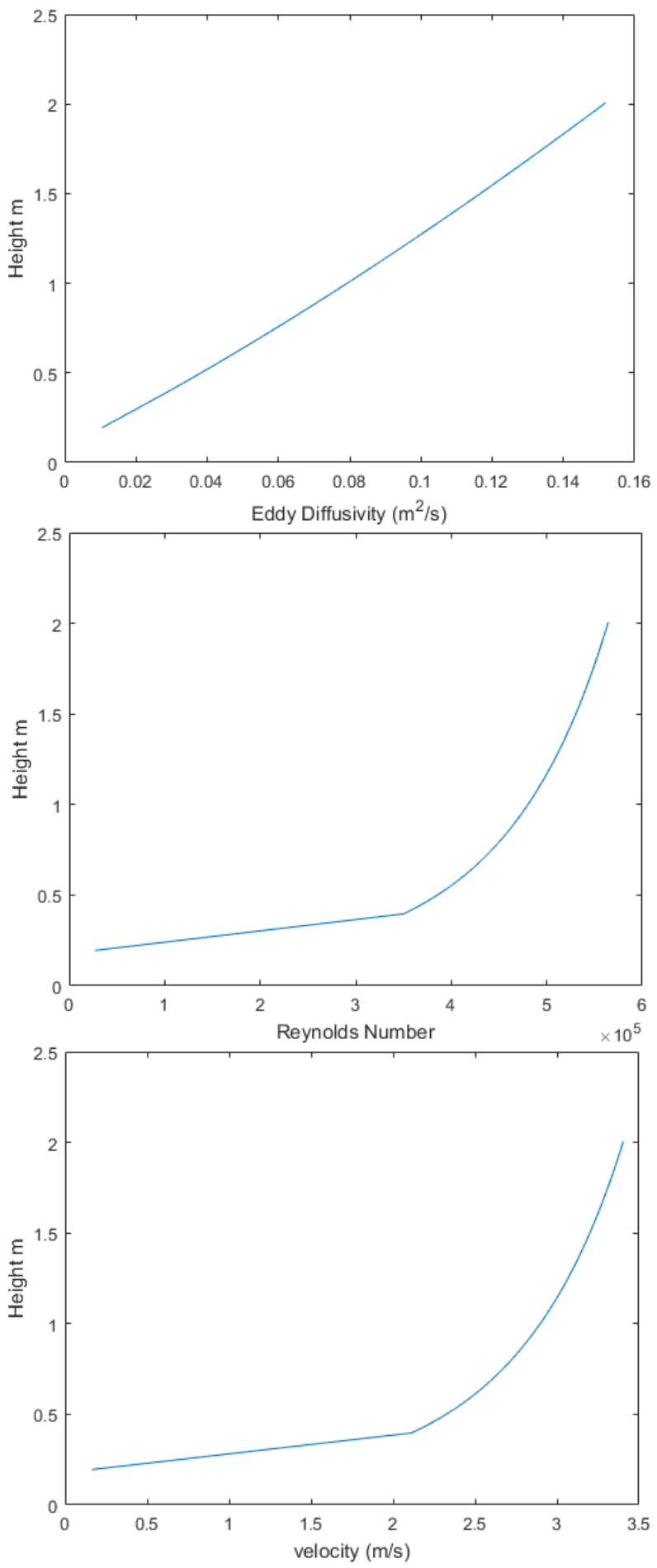


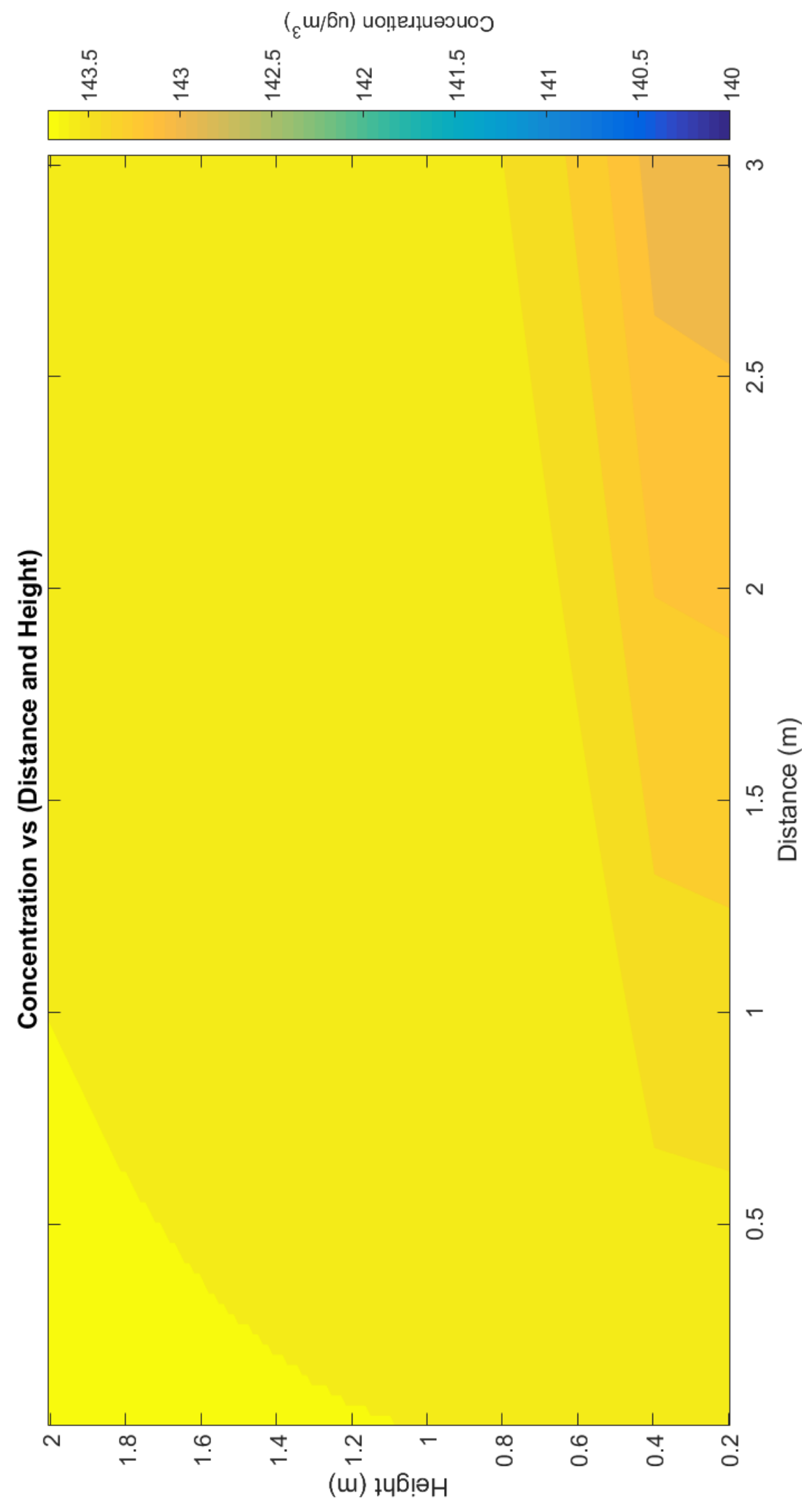


Case 3:
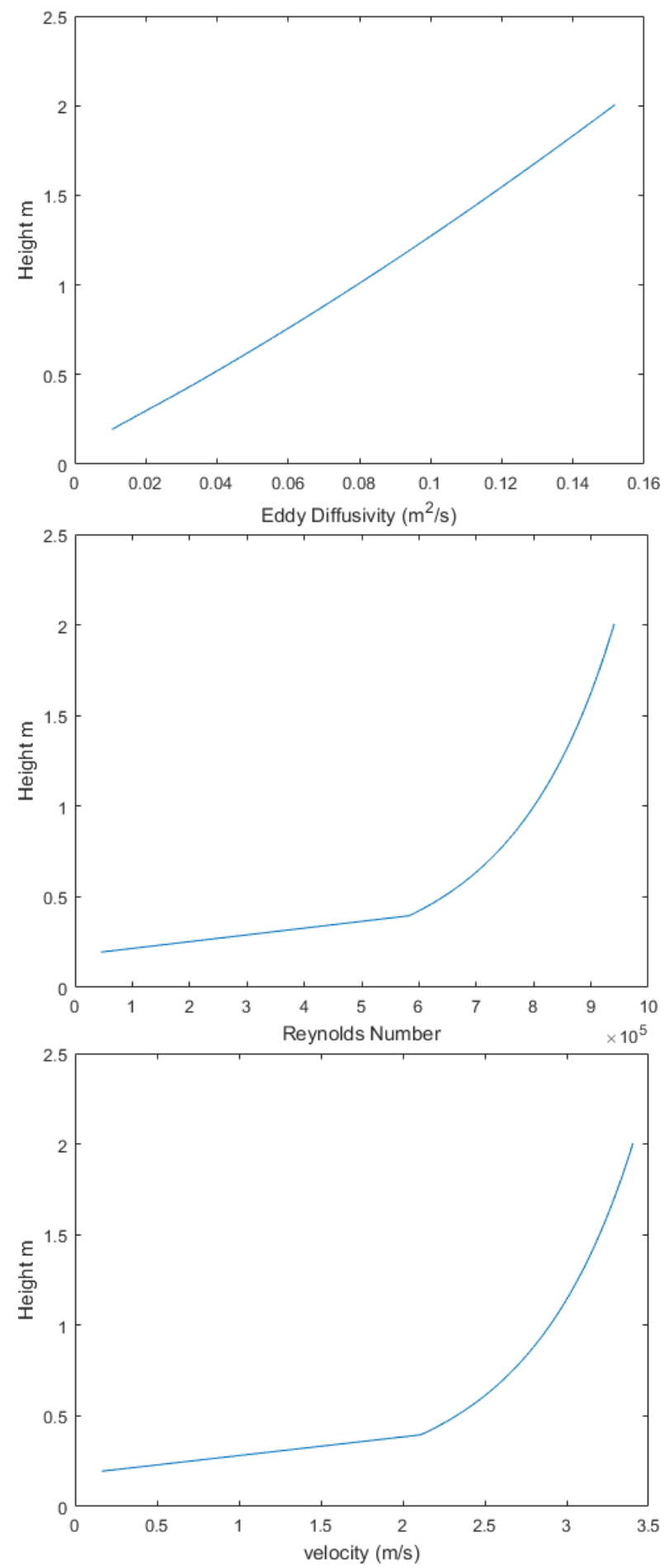





Case 4:
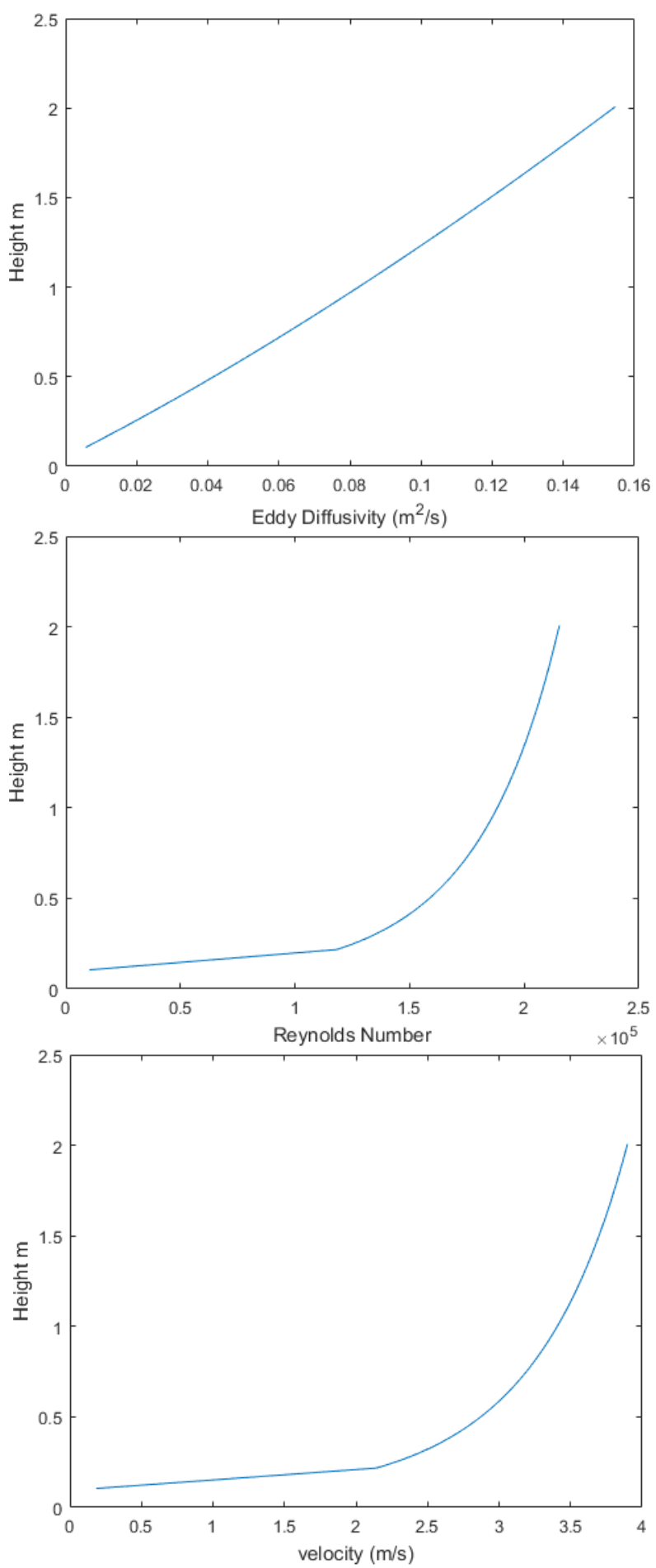





Case 5:
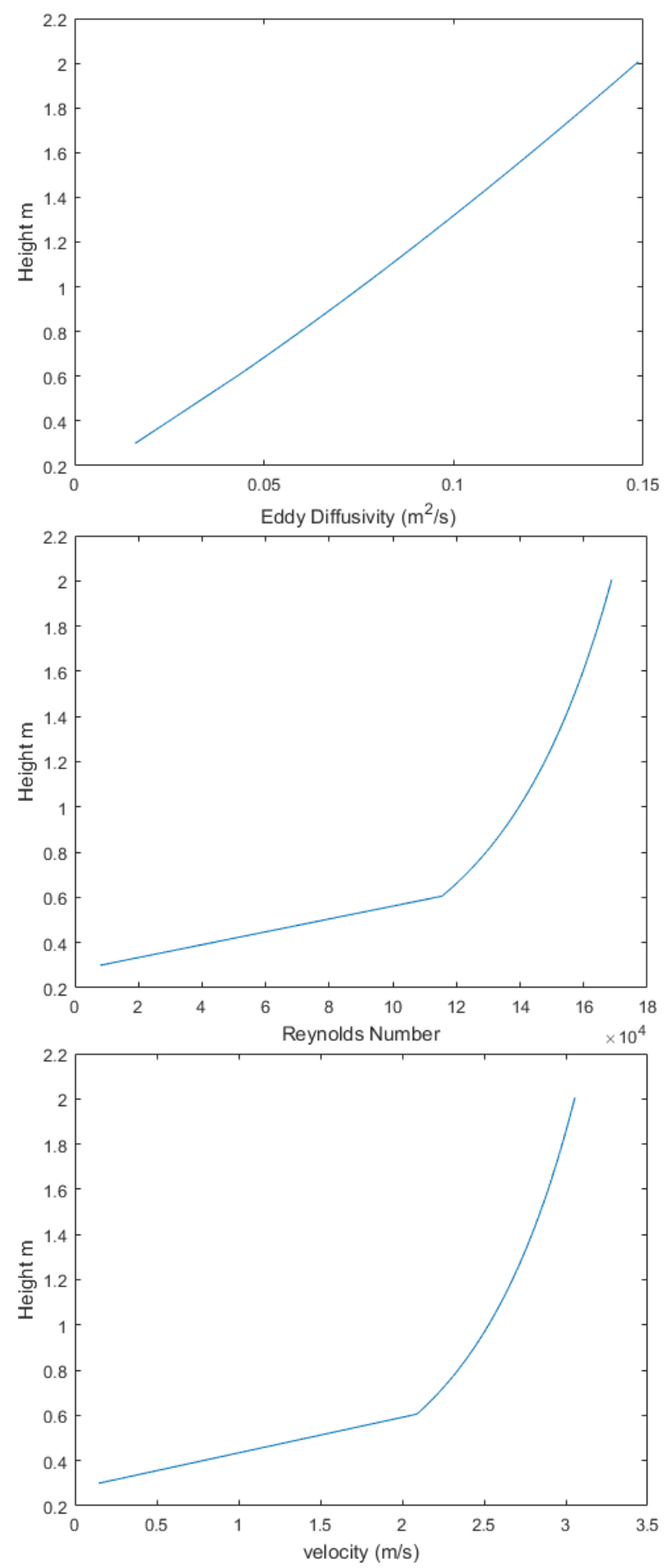


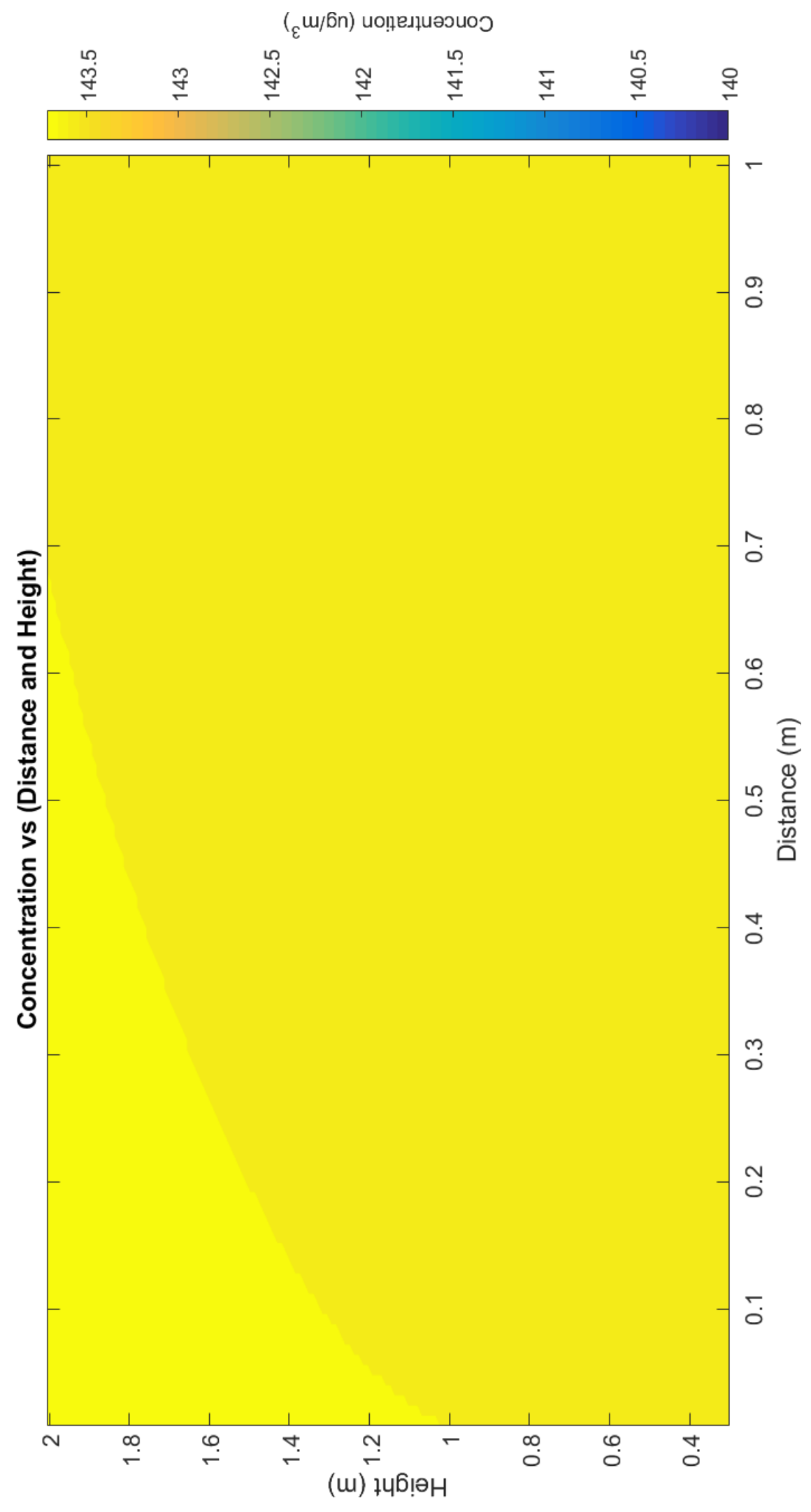


Case 6:
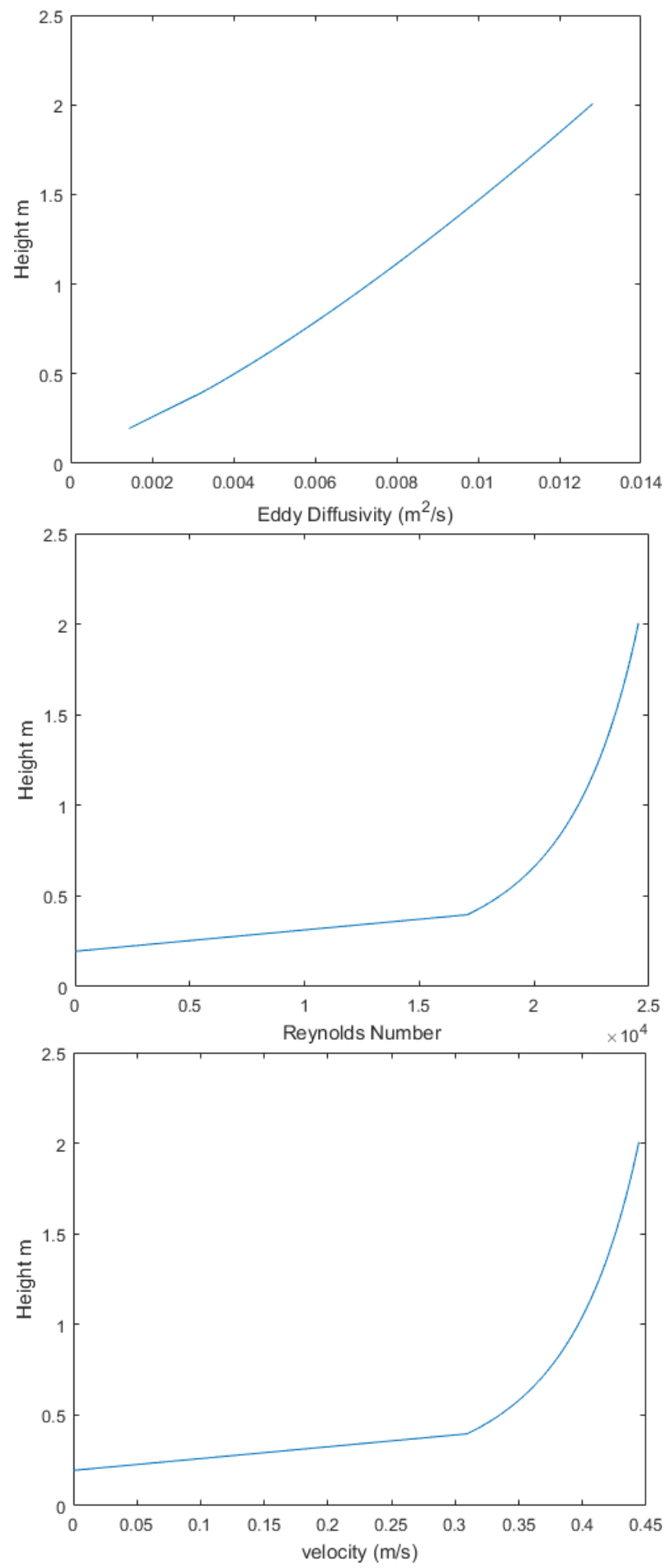


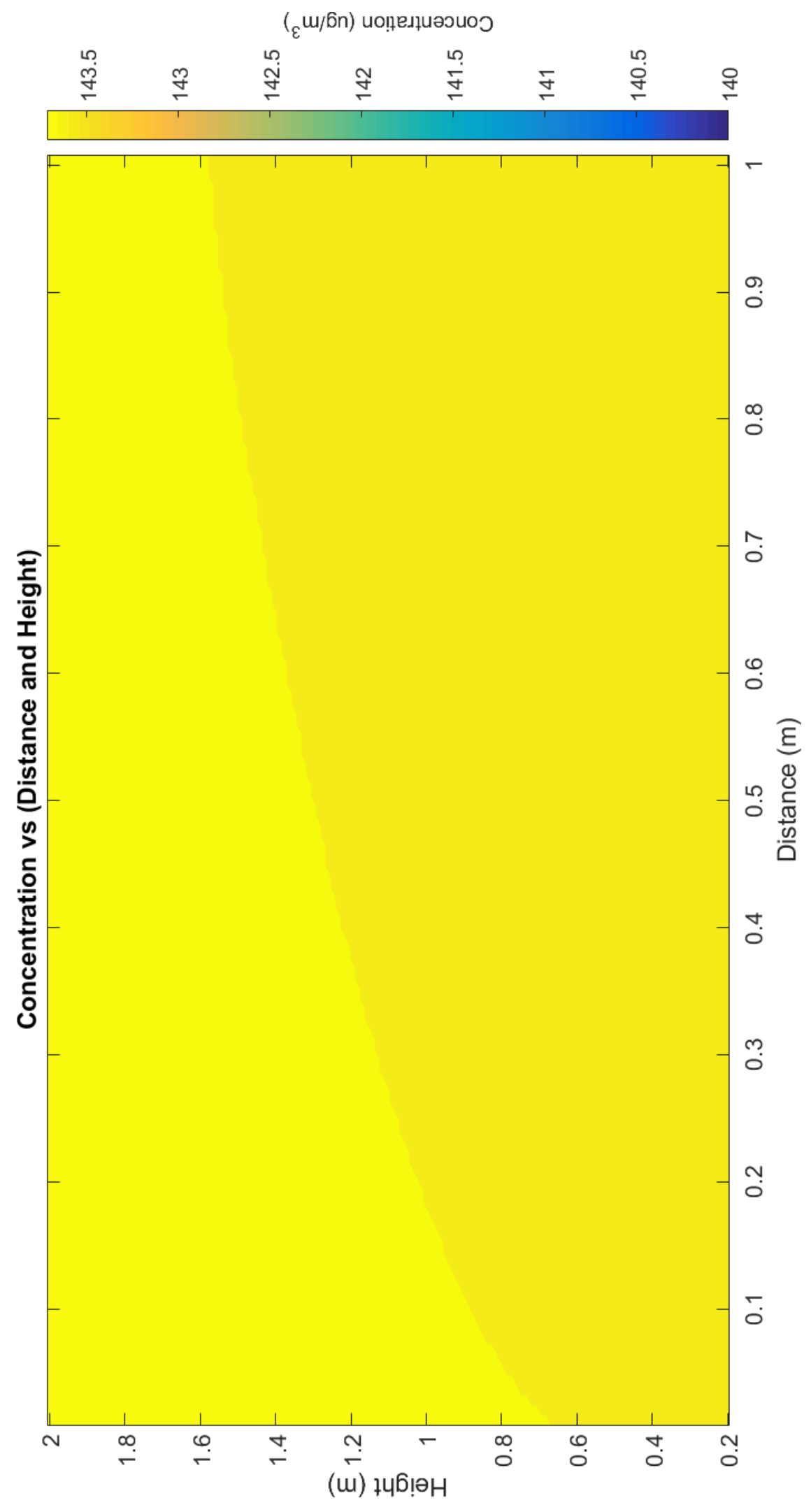


Case 7:



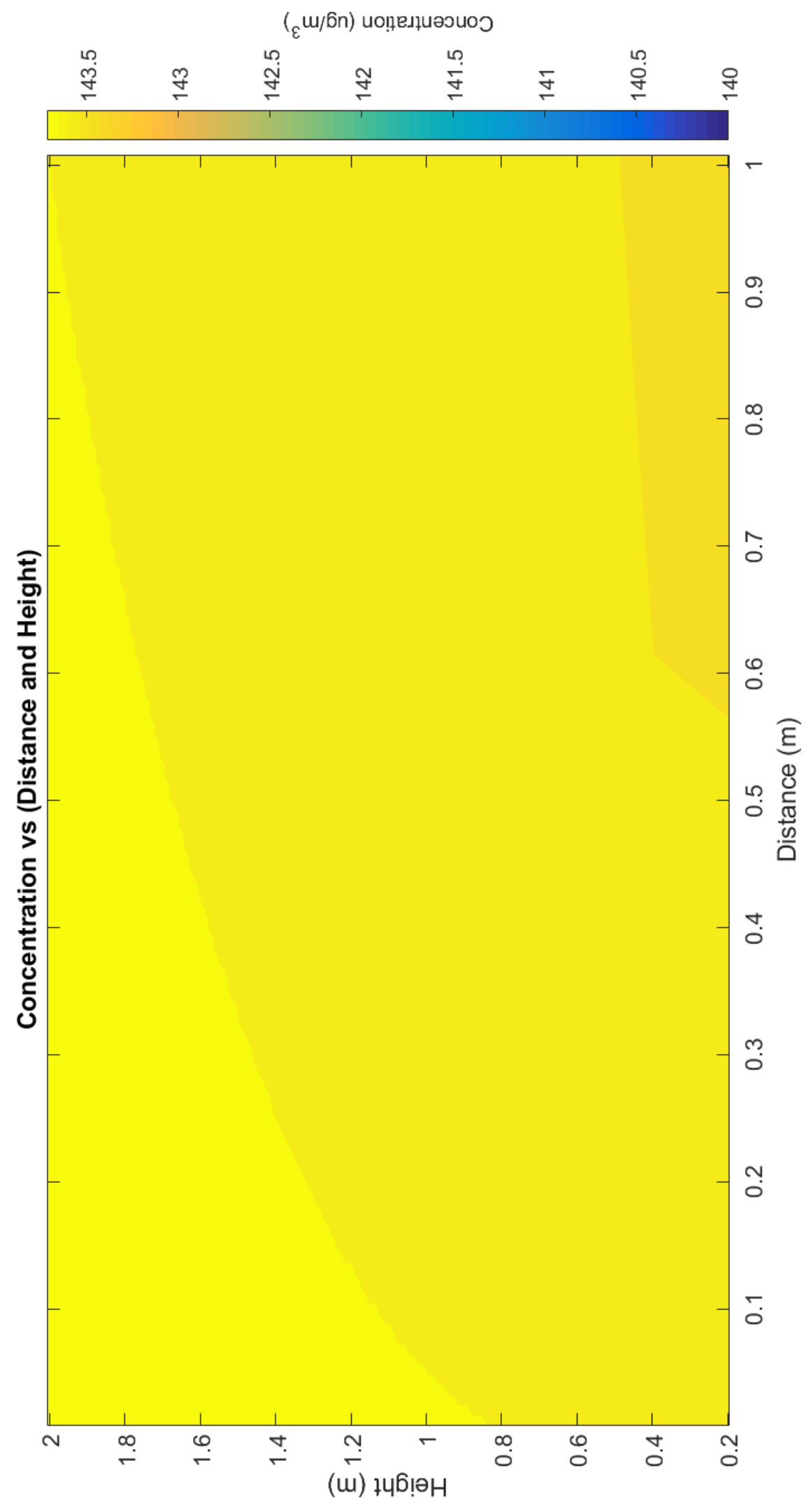


Case 8:
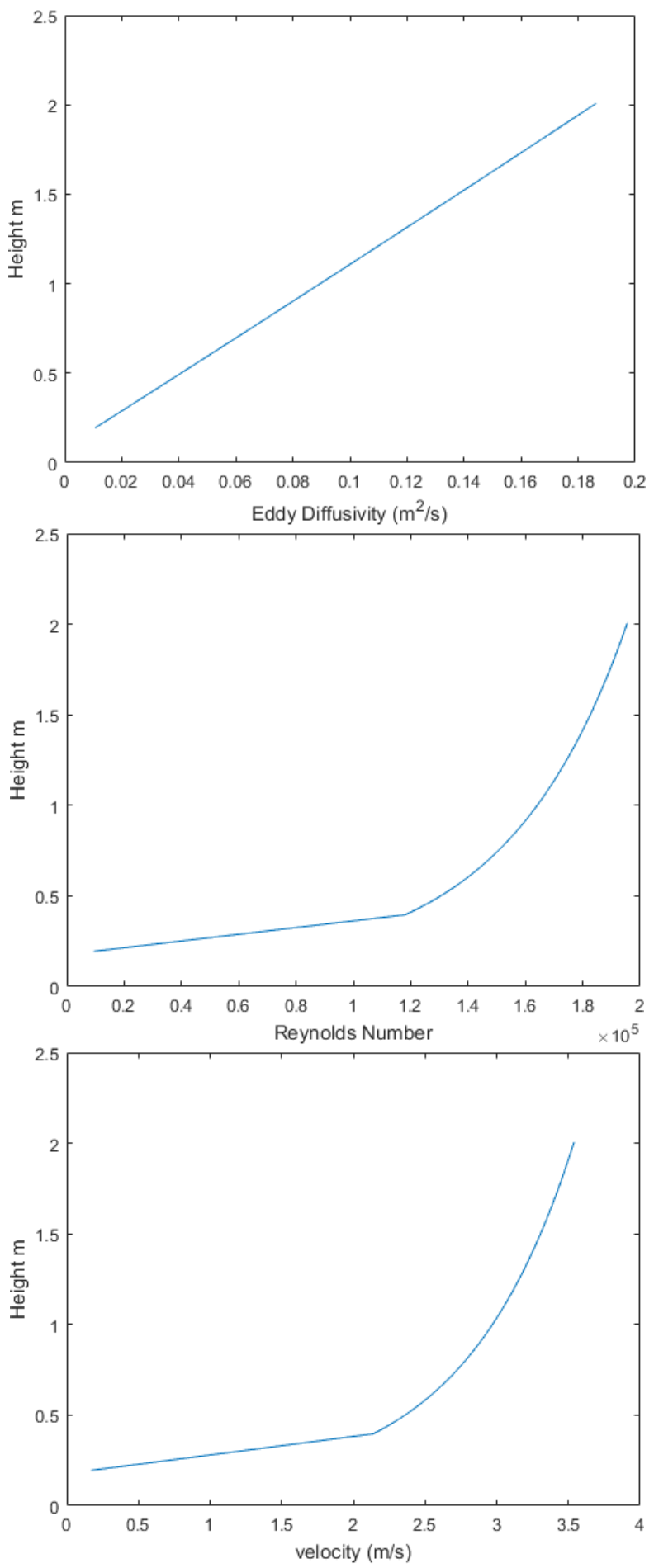


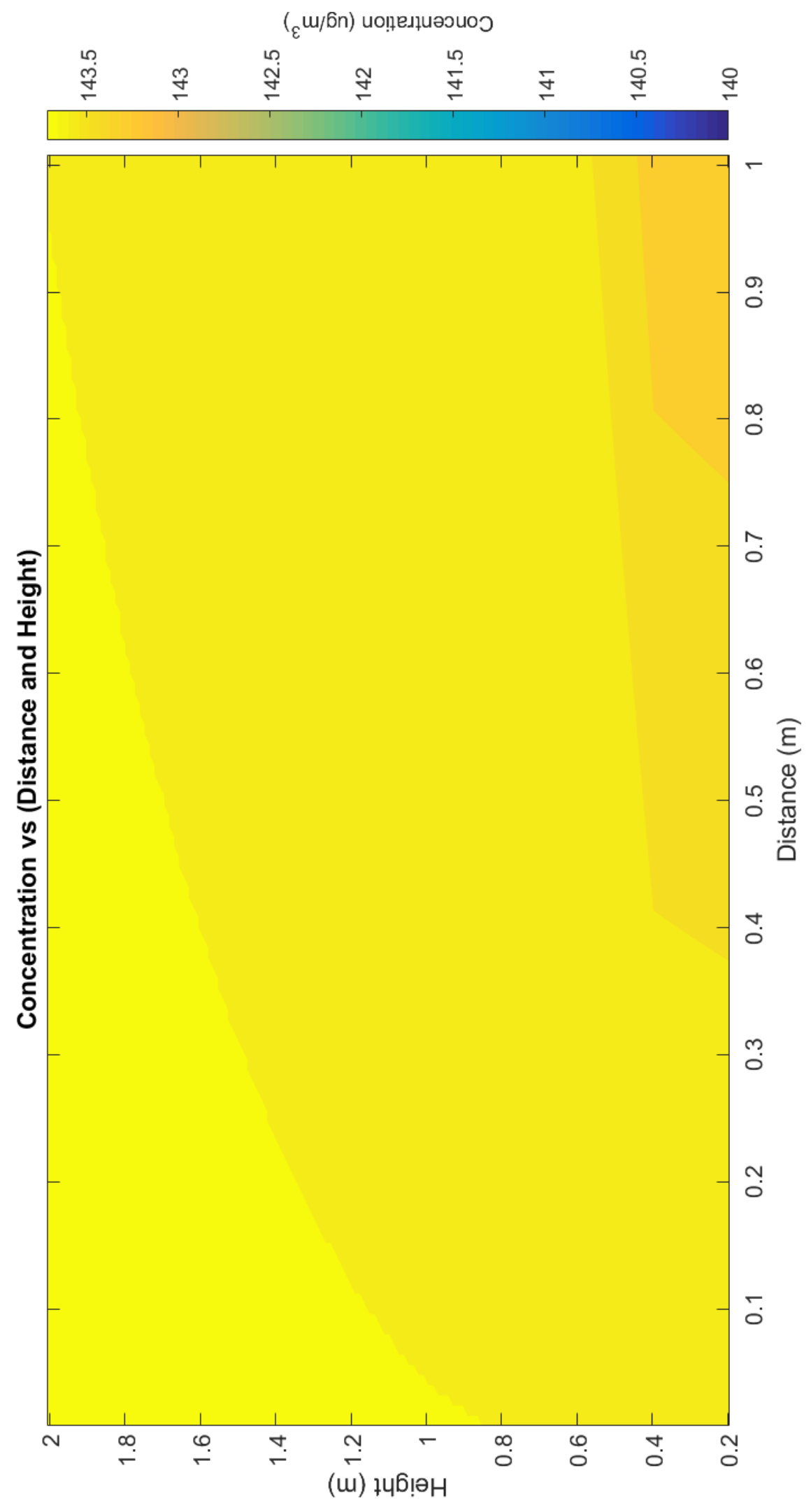


Case 9:
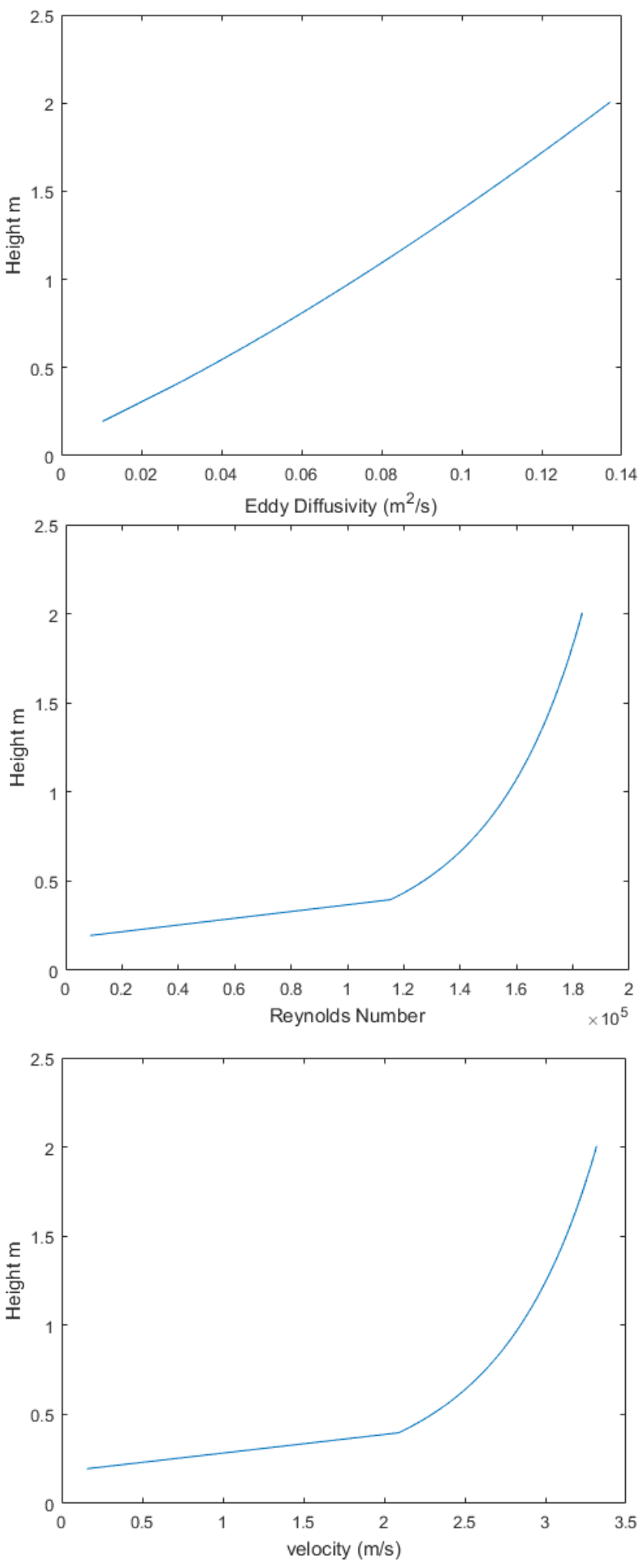





Case 10:
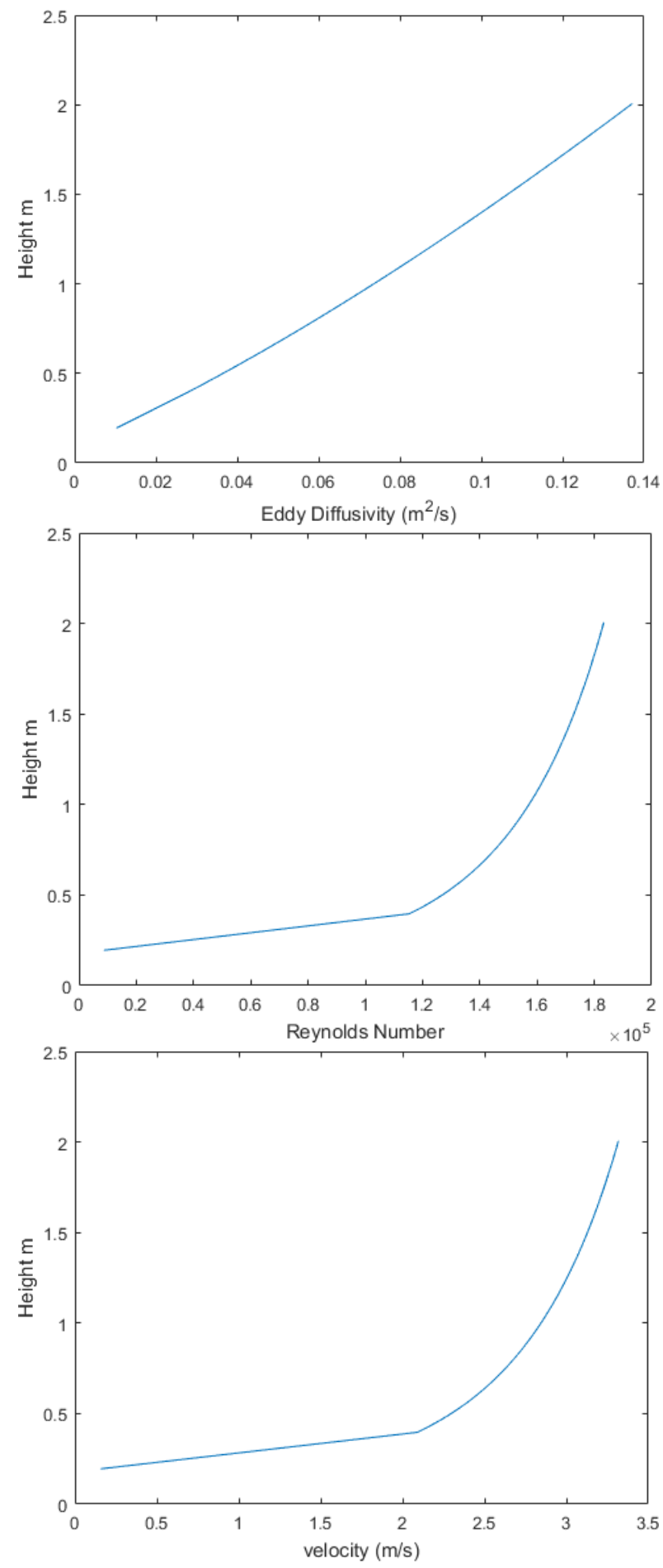







\section{Case 11:}
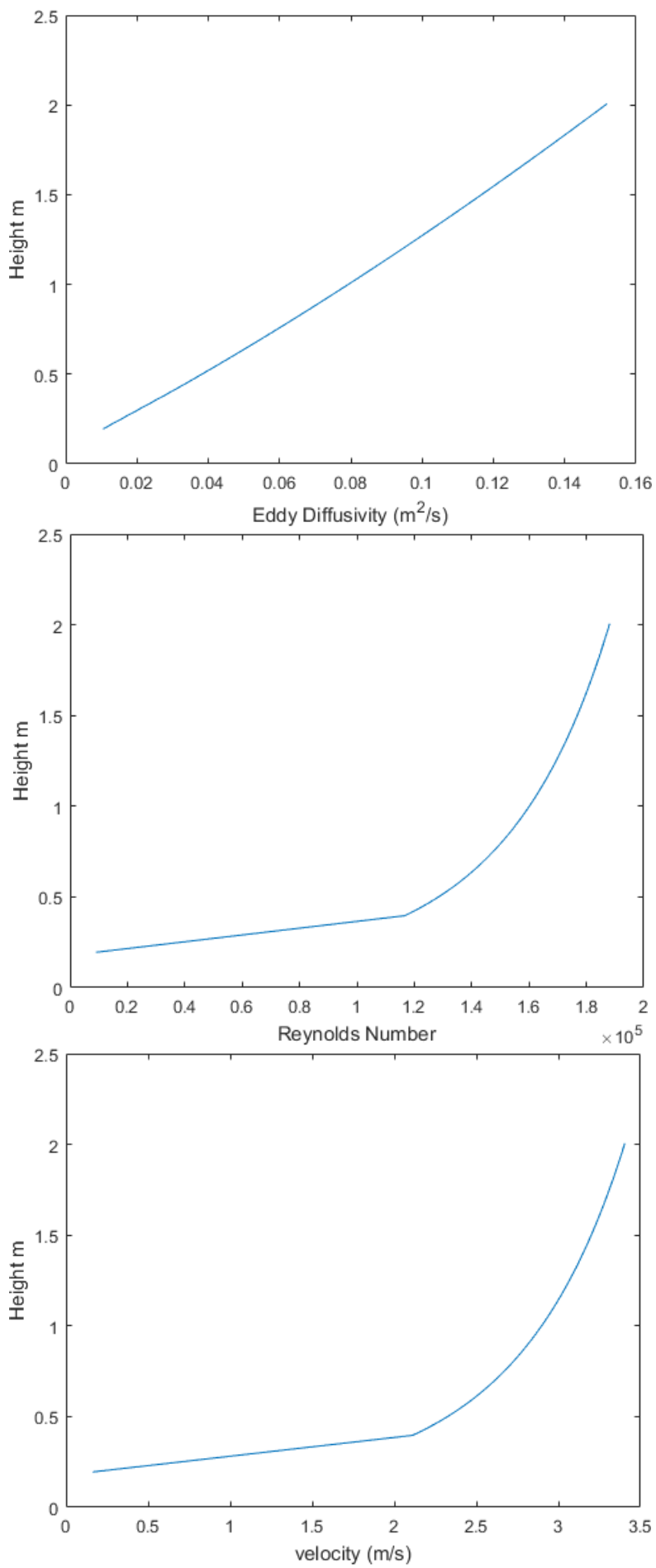


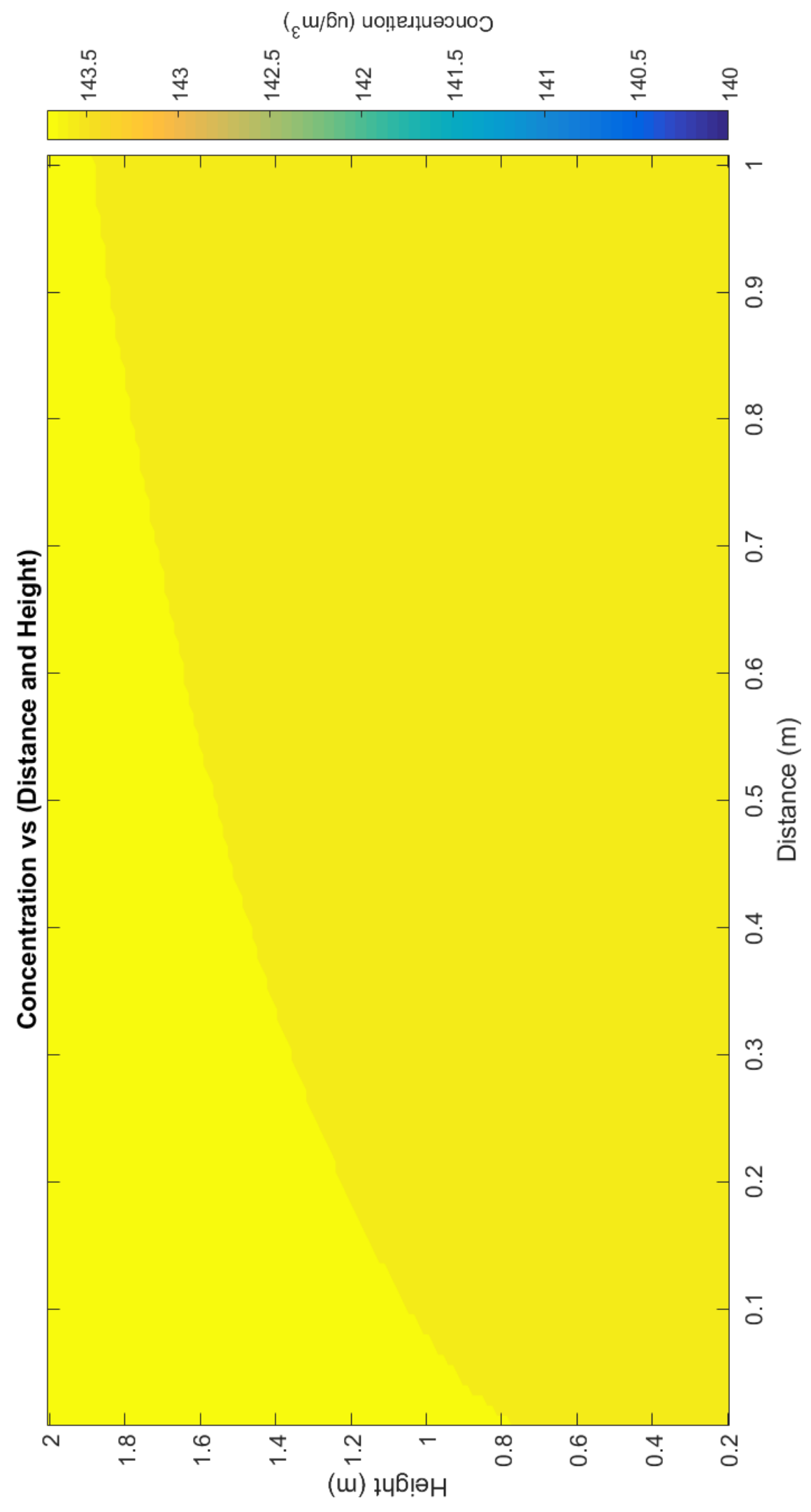


Ideal Case:
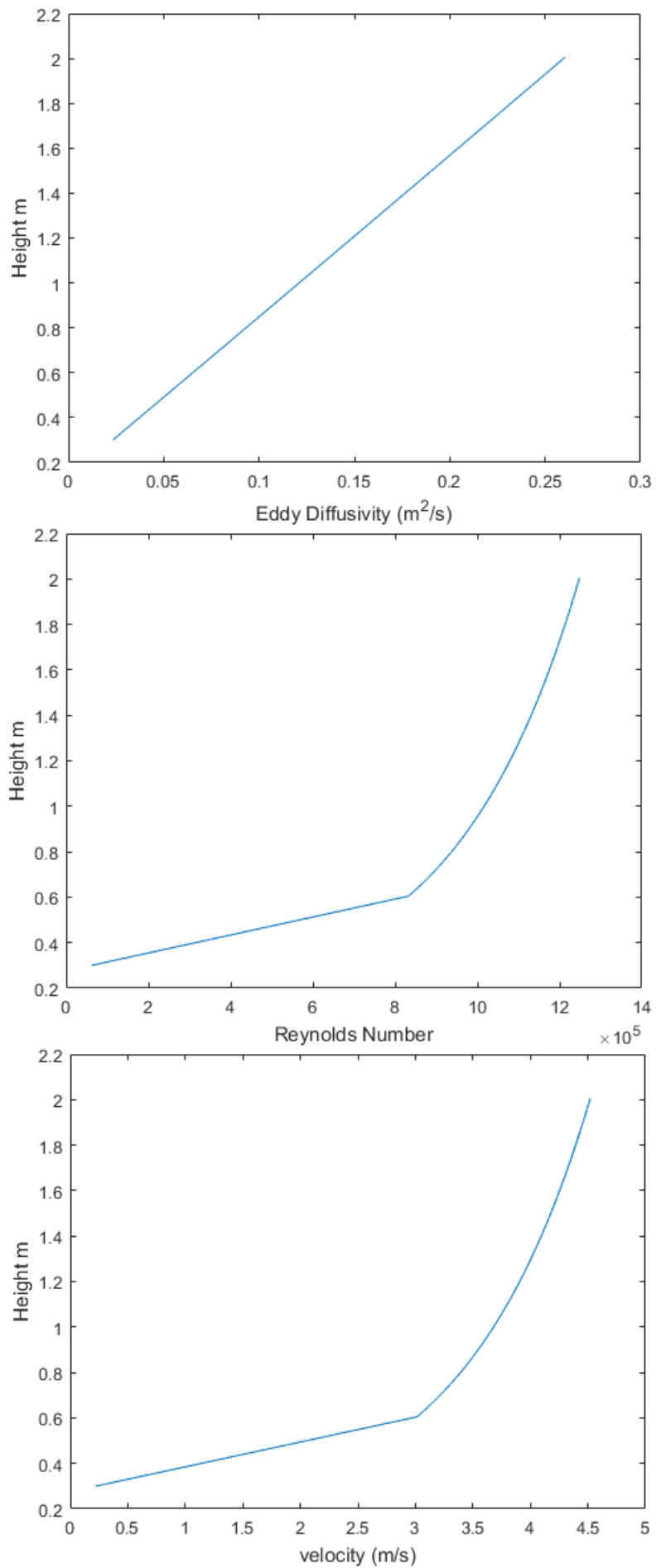


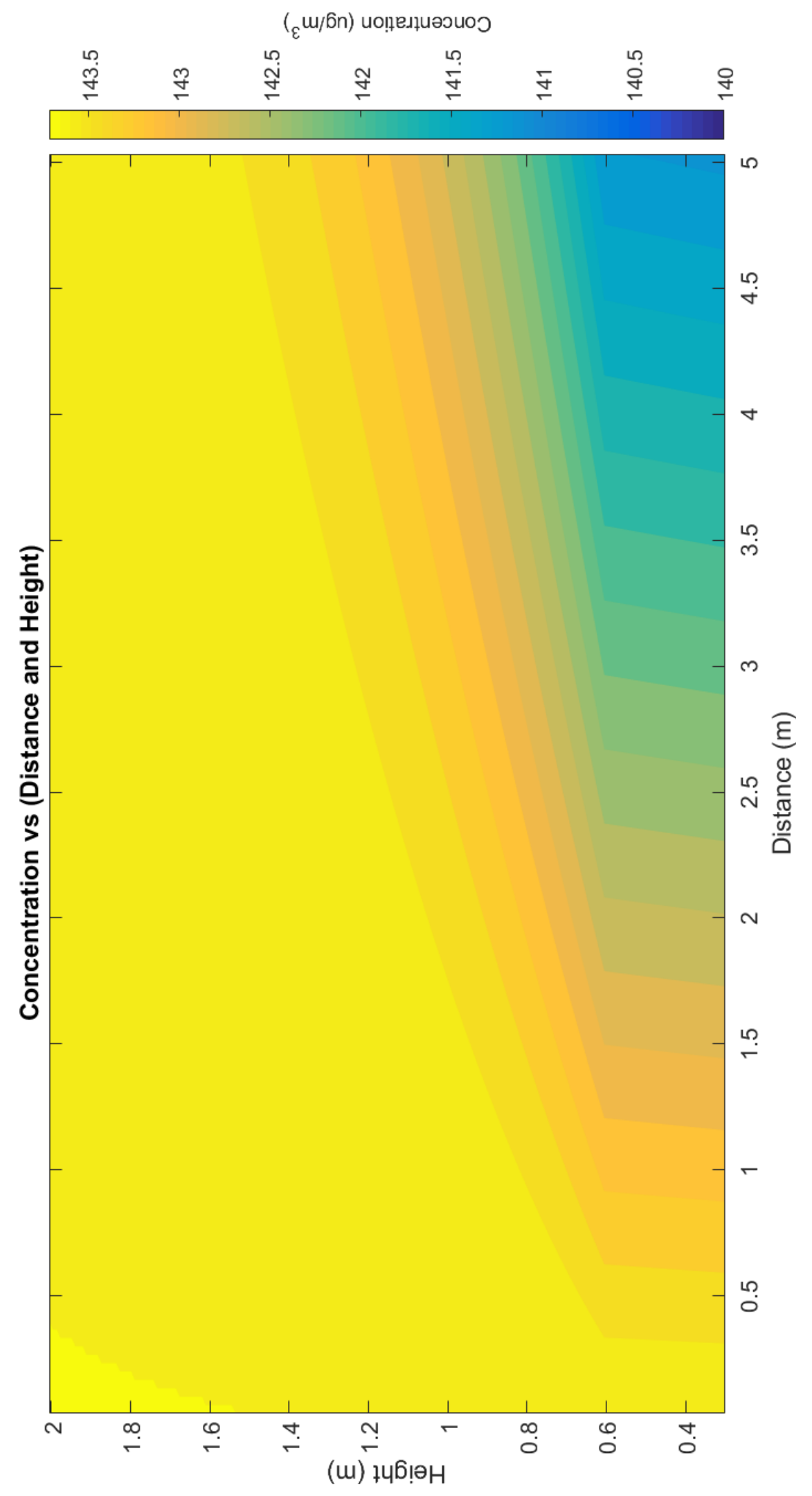


